\title{
Methionine Metabolism in Yucatan Miniature Swine
}

\author{
Laura E. McBreairty \\ Department of Biochemistry \\ Faculty of Science \\ Memorial University of Newfoundland \\ St. John's \\ Newfoundland and Labrador
}

\begin{abstract}
A thesis submitted to the School of Graduate Studies in partial fulfilment of the requirements for the degree of Doctor of Philosophy
\end{abstract}

February 2014 


\section{Abstract \\ Methionine Metabolism in Yucatan Miniature Swine}

Methionine is an essential amino acid which when not incorporated into protein, can be converted to $S$-adenosylmethionine, the universal methyl donor in over 200 transmethylation reactions, that include creatine and phosphatidylcholine (PC) synthesis, as well as deoxyribonucleic acid (DNA) methylation. Following transmethylation, homocysteine is formed which can be converted to cysteine via transsulfuration or remethylated to methionine by receiving a methyl group from folate or betaine. Changes to methyl group availability in utero can lead to permanent changes in epigenetic patterns of DNA methylation which has been implicated in "fetal programming," a phenomenon associated with poor nutrition during fetal development that results in low birth weight and disease in later life. It has been shown that programming can also occur in the neonate. So our global objective was to understand how the variability of nutrients involved in methionine metabolism can affect methionine and methyl group availability. We hypothesize that nutrients that converge on methionine metabolism can affect methionine availability for its various functions. In this thesis, we used intrauterine growth restricted (IUGR) piglets to investigate whether a global nutritional insult in utero can lead to a perturbed methionine metabolism. Our results demonstrate that IUGR piglets have a lower capacity to dispose of homocysteine via both transsulfuration and remethylation pathways, as well as a lower incorporation of methyl groups into PC. The second objective of this thesis was to determine whether variation in methionine supply and demand can affect methionine availability. We demonstrated that stimulating either 
acute or chronic creatine synthesis leads to lower methyl incorporation into protein and $\mathrm{PC}$ in pigs. Furthermore, when methionine is limiting, supplementation with either folate or betaine leads to higher methionine availability for protein synthesis. Lastly, because creatine is increasingly being utilized as an ergogenic and neuroprotective supplement, we wanted to determine whether provision of the creatine precursor, guanidinoacetate (GAA), could effectively increase tissue creatine stores. We showed that 2.5 weeks of supplementation with GAA is more effective than creatine at increasing hepatic and muscle creatine stores. The results of this thesis demonstrate that the presence of IUGR, an increased demand for creatine synthesis or the supplementation with remethylation nutrients can each affect methionine availability; all are important when considering neonatal nutrient requirements. Furthermore, although GAA is effective at increasing levels of tissue creatine, higher GAA methylation can limit methionine availability for growth and synthesis of PC. 


\section{Acknowledgements}

This project was funded by Canadian Institutes of Health Research, International Life Sciences Institute North America (ILSI N.A.) and Janeway Research Foundation.

I would like to thank my supervisors Dr. Robert Bertolo and Dr. Janet Brunton as well as my supervisory committee Dr. John Brosnan and Dr. Sukhinder Cheema.

I would also like to thank all of the members of the Dr. Bertolo/Dr. Brunton lab group, with a special thanks to Matt Nosworthy and Dr. Elaine Dodge for showing me the ropes, as well as Kayla Furlong and Jason Robinson for adding a few laughs to Saturday mornings at the vivarium.

Last and certainly not least, I would like to thank my family for their endless support. 


\section{Table of Contents}

Methionine Metabolism in Yucatan Miniature Swine .......................................................i

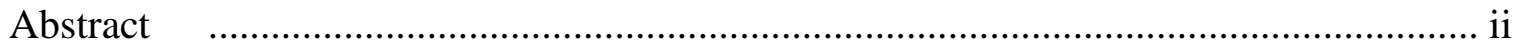

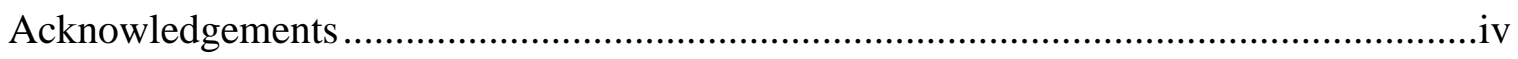

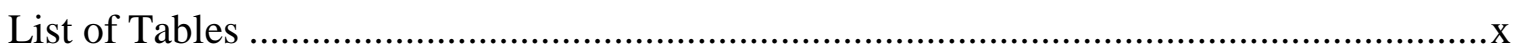

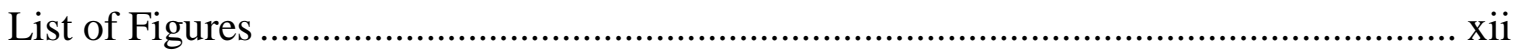

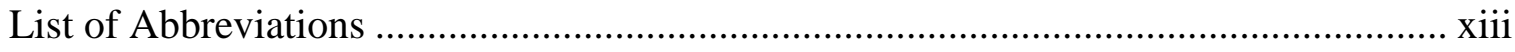

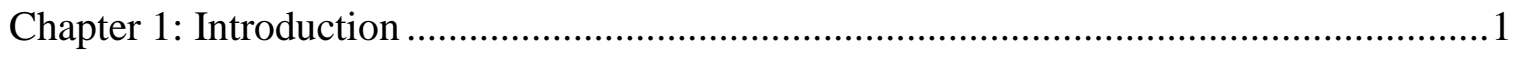

1.1 Introduction ......................................................................................

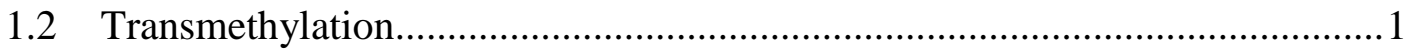

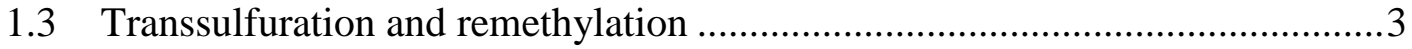

1.3.1 Remethylation: Betaine-Homocysteine methyltransferase and methionine

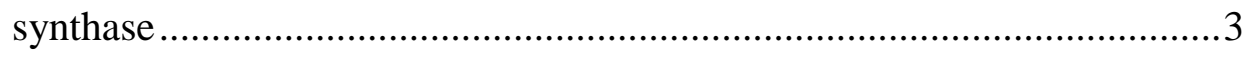

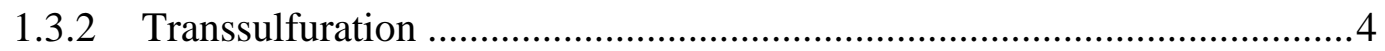

1.3.3 Regulation of homocysteine metabolism .........................................5

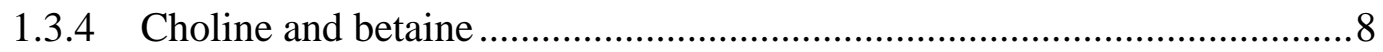

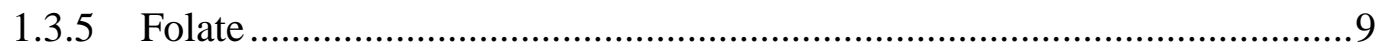

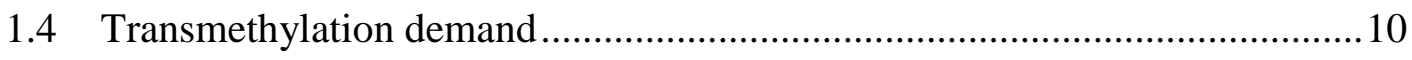

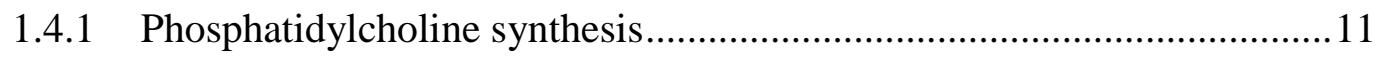




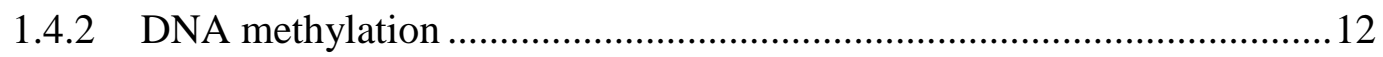

1.4.3 Epigenetics and fetal programming in IUGR ..................................... 13

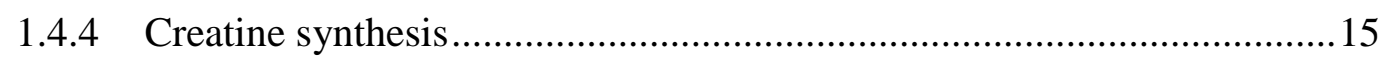

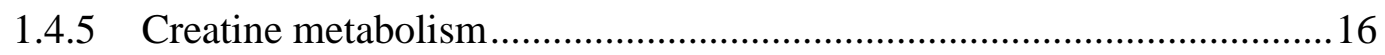

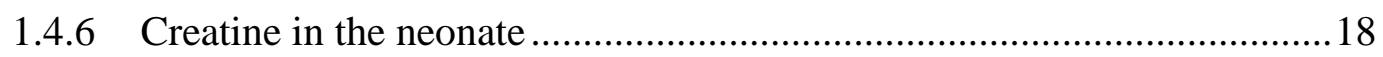

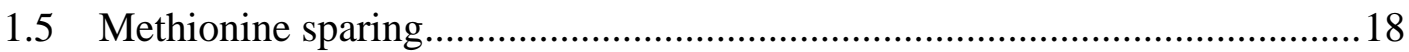

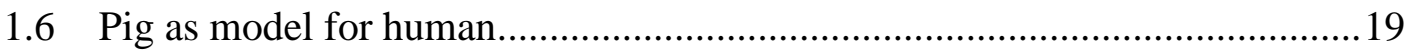

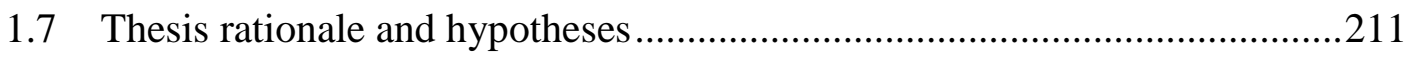

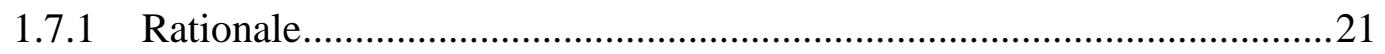

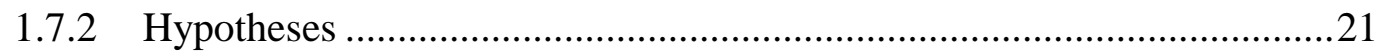

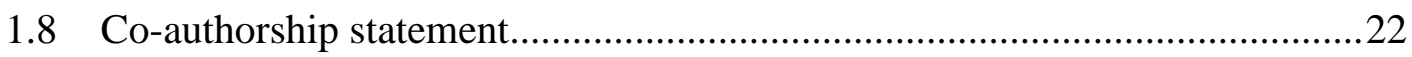

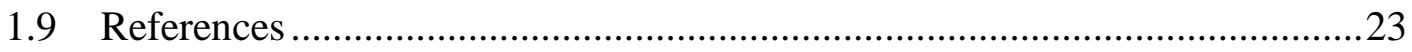

CHAPTER 2 - Intrauterine growth restriction leads to changes in sulfur amino acid metabolism, but not global DNA methylation, in Yucatan miniature piglets.38

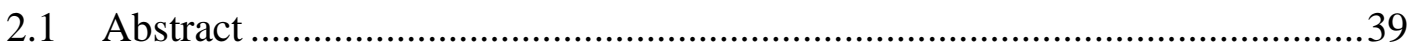

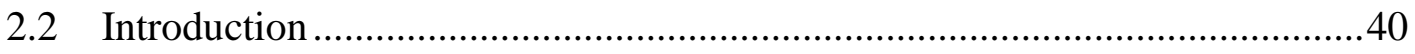

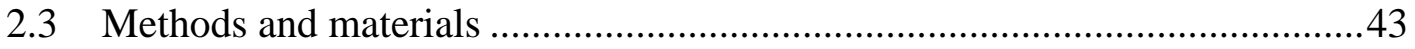

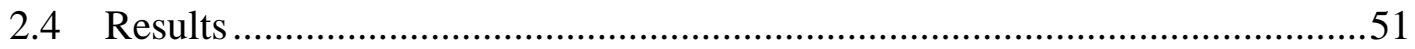

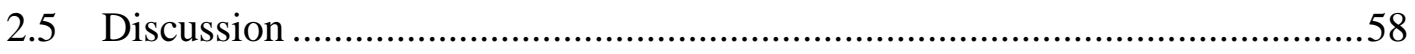

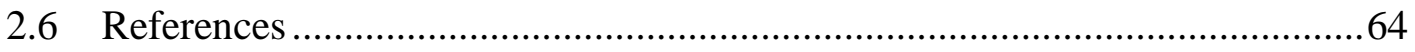


CHAPTER 3: Partitioning of [methyl- $\left.{ }^{3} \mathrm{H}\right]$ methionine to methylated products and protein is altered during high methyl demand conditions in young Yucatan miniature

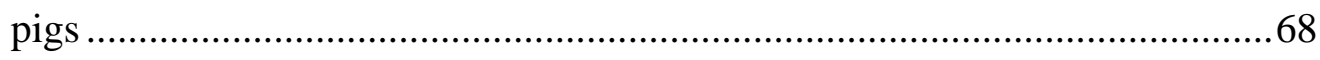

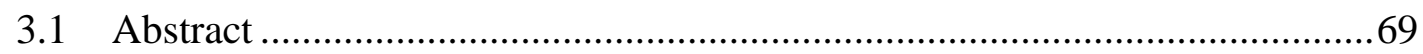

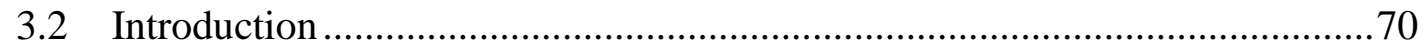

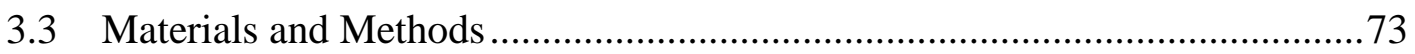

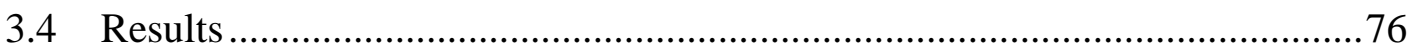

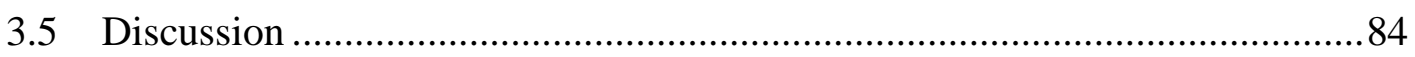

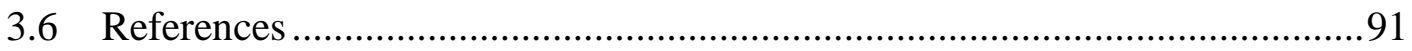

Chapter 4: Betaine is as effective as folate at re-synthesizing methionine for protein synthesis during moderate methionine deficiency in piglets ..........................95

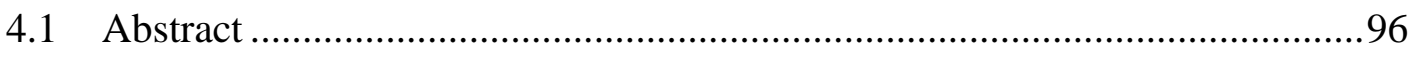

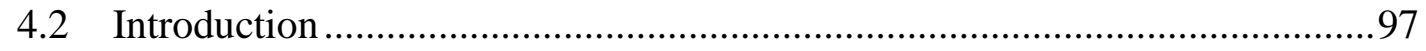

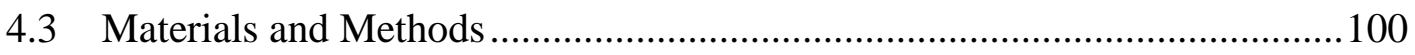

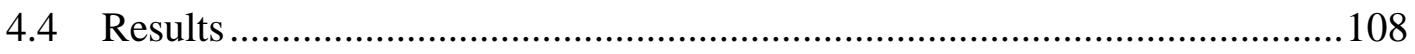

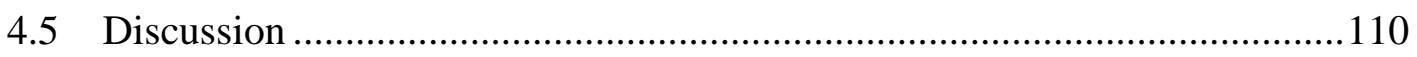

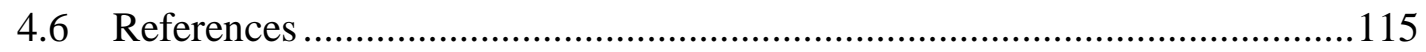

CHAPTER 5: Guanidinoacetate is not more effective than creatine at increasing muscle creatine stores and limits methionine availability in Yucutan miniature pigs 
5.1 Abstract

5.2 Introduction

5.3 Materials and Methods

5.4 Results

5.5 Discussion

Chapter 6. General Discussion......

6.1 IUGR and methionine metabolism

6.1.1 IUGR and methionine partitioning.

6.2 Methionine supply and demand

6.3 Chronic high methyl demand and creatine supplementation

6.4 Creatine Accretion

6.5 General Conclusions

6.6 References......

Appendix A: Methods

A.1. Determination of phosphatidylcholine concentration and DPM

A.2 Determination of creatine concentration and DPM

A.3 Determination of DNA concentration and DPM

A.4 Determination of SAM/SAH concentration and SAM DPM 164 
A.5 Determination of Tissue and Plasma amino acid concentrations and

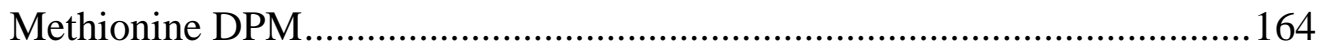

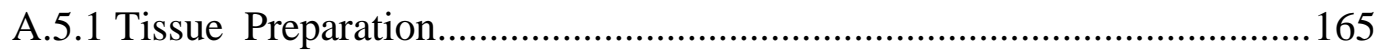

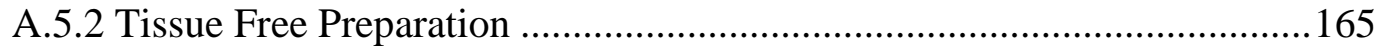

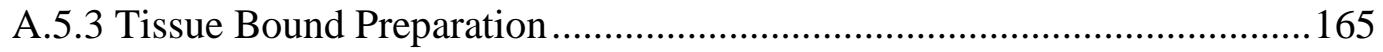

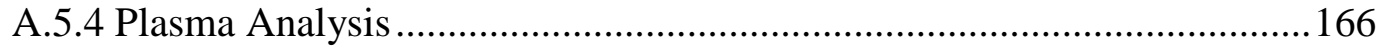

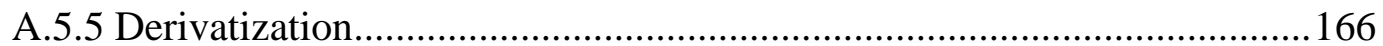

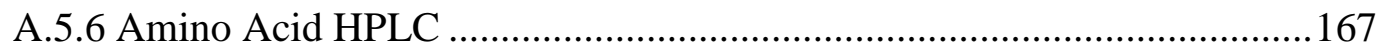

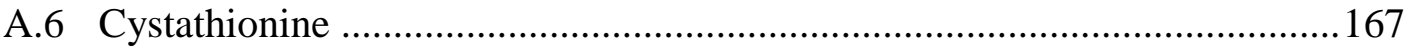

A.7 Tissue and Plasma Creatine and Guanidinoacetate (GAA) ........................ 168

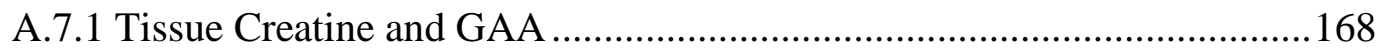

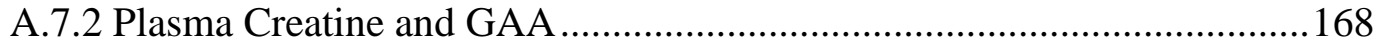

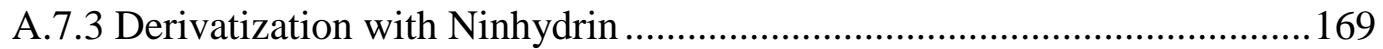

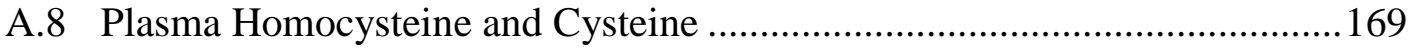

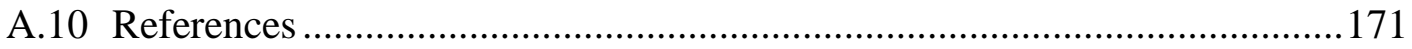




\section{List of Tables}

Table 2.1 Body weight (BWT) and organ measurements in large and runt littermate piglets

Table 2.2 Plasma concentrations of amino acids and urea in large and runt littermate piglets

Table 2.3 Liver concentrations of free amino acids in large and runt littermate piglets.55

Table 2.4 Specific activities (nmol product $/ \mathrm{min} / \mathrm{mg}$ protein) of hepatic enzymes of methionine and homocysteine metabolism in large and runt littermate piglets

Table 2.5 Hepatic capacities ( $\mathrm{nmol}$ of product $/ \mathrm{min} / \mathrm{kg}$ body weight) of enzymes of large and runt littermate piglets, corrected for body weight

Table 3.1 Plasma concentrations of metabolites in intrauterine growth-restricted (IUGR) and normal weight (NW) piglets under control or high methyl demand (HMD) conditions

Table 3.2 Hepatic concentrations of metabolites in intrauterine growth-restricted (IUGR) and normal weight (NW) piglets under control or high methyl demand (HMD) conditions

Table 3.3 Rate of ${ }^{3} \mathrm{H}$-methyl incorporation into transmethylation products and protein (corrected for precursor and time) and metabolite SRA data in intrauterine growth-restricted (IUGR) and normal weight (NW) piglets under control or high methyl demand (HMD) conditions 81

Table 3.4 Tissue creatine concentration and specific radioactivity (SRA) (corrected for time) in intrauterine growth-restricted (IUGR) and normal weight (NW) piglets under control or high methyl demand (HMD) conditions.

Table 3.5 Percent of ${ }^{3} \mathrm{H}$-methyl-labelled product remaining in the liver $60 \mathrm{~min}$ after infusion with of $\mathrm{L}-\left[\right.$ methyl- $\left.{ }^{3} \mathrm{H}\right]$ methionine in intrauterine growth-restricted (IUGR) and normal weight (NW) piglets under control or high methyl demand (HMD) conditions .85

Table 4.1 Amino acid composition of elemental diet 103 
Table 4.2 Phenylalanine kinetics following a primed, constant infusion of L-[13C]phenylalanine in piglets both after 6 days of receiving a methyl group deficient diet moderately deficient in methionine and following supplementation with either folate, betaine or a combination of both..........111

Table 5.1 Tissue distribution of creatine and GAA in pigs fed a control, creatine supplemented or GAA supplemented diet for 18 days .................................127

Table 5.2 Plasma concentrations of metabolites in pigs fed a control, creatine supplemented or GAA supplemented diet for 18 days .................................129

Table 5.3 Rate of ${ }^{3} \mathrm{H}$-methyl incorporation into transmethylation products and protein after 30 minutes (corrected for precursor) in pigs fed a control, creatine supplemented or GAA supplemented diet for 18 days

Table 5.4 Hepatic concentrations of metabolites in pigs fed a control, creatine supplemented or GAA supplemented diet for 18 days 


\section{List of Figures}

Figure 2.1 Schematic of pathways in sulfur amino acid metabolism ......................... 42

Figure 3.1 Typical mono-exponential decay curve for methionine SRA over time in a pig infused with a $11.1 \mathrm{MBq}(300 \mu \mathrm{Ci})$ per $\mathrm{kg}$ body weight bolus of L-[methyl$\left.{ }^{3} \mathrm{H}\right]$ methionine directly into the portal vein.......................................... 77

Figure 4.1 Diet and infusion protocol. Abbreviations: Met, methionine; Phe, phenylalanine ......................................................................... 102

Figure 4.2 Weight of piglets receiving a methyl group deficient diet moderately deficient in methionine (Day 7) as well as following supplementation with folate, betaine or a combination of both (Day 10).

Figure 5.1 Hepatic GAA concentration in pigs fed a control, creatine supplemented or GAA supplemented diet for 18 days. Abbreviations: GAA; guanidinoacetate 


\section{List of Abbreviations}

$\%$ Phe $_{\mathrm{ox}} \quad$ Percentage of L- $\left[{ }^{13} \mathrm{C}\right]$-phenylalanine dose oxidized

5-methyl-THF 5-Methyltetrahydrofolate

5,10-THF 5,10-Methelenetetrahydrofolate

AGAT Arginine:glycine amidinotransferase

ANTS Amino-naphthalene-1,3,6-trisulfonic acid disodium salt

ANOVA Analysis of variance

APE Atom percent excess

AU Arbitrary units

BHMT Betaine-homocysteine methyltransferase

BW Birth weight

BWT Body weight

CBS Cystathionine $\beta$-synthase

CGL Cystathionine $\gamma$-lyase

CTP Cytidine-5'-triphosphate

DMG Dimethylglycine

DNA Deoxyribonucleic acid

DNMT Deoxyribonucleic acid methyltransferase

DTT Dithiothreitol

DPM Disintegrations per minute

${ }^{13} \mathrm{CO}_{2}$ enrichment

EDTA Ethylenediaminetetraacetic acid

Ei L- $\left[{ }^{13} \mathrm{C}\right]$-phenylalanine enrichment infused 


\begin{tabular}{ll} 
Ep & L- $\left[{ }^{13} \mathrm{C}\right]-$ phenylalanine enrichment above base \\
FAD & Flavin adenine dinucleotide \\
$\mathrm{FCO}_{2}$ & $\mathrm{CO}_{2}$ production rate \\
GAA & Guanidinoacetate \\
GAMT & Guanidinoacetate methyltransferase \\
GNMT & Glycine $N$-methyltransferase \\
HMD & High methyl demand \\
HPLC & High-performance liquid chromatography \\
i & Rate of L- $\left[{ }^{13}\right.$ C]-phenylalanine infused \\
IAAO & Indicator amino acid oxidation \\
IG & Intragastric \\
IGF-1 & Insulin-like growth factor-1 \\
IRMS & Isotope ratio mass spectrometry \\
IUGR & Intrauterine growth restricted \\
MAT & Methionine adenosyltransferase \\
MPE & Mole percent excess \\
MS & Methionine synthase \\
MTHFR & Methylenetetrahydrofolate reductase \\
NADH & Nicotinamide adenine dinucleotide \\
NOD & Non-oxidative disposal \\
NW & Normal weight \\
PE & Release from protein breakdown \\
PFBBr & Phosphatidylethanolamine \\
\hline
\end{tabular}




$\begin{array}{ll}\text { Phe }_{\text {ox }} & \text { Rate of phenylalanine oxidation } \\ \text { PC } & \text { Phosphatidylcholine } \\ \text { PEMT } & \text { Phosphatidylethanolamine } N \text {-methyltransferase } \\ \text { PLP } & \text { Pyridoxal-5-phosphate } \\ \text { Q } & \text { Flux } \\ \text { SAH } & \text { S-adenosylhomocysteine } \\ \text { SAHH } & \text { S-adenosylhomocysteine hydrolase } \\ \text { SAM } & \text { S-adenosylmethionine } \\ \text { SBD-F } & \text { 7-Fluorobenzo-2,1,3-oxadiazole-sulfonic acid ammonium salt } \\ \text { SD } & \text { Standard deviation } \\ \text { SRA } & \text { Specific radioactivity } \\ \text { TCEP } & \text { Tris(2-carboxyethyl)phosphine } \\ \text { THF } & \text { Thetrahydrofolate } \\ \text { TLC } & \text { Thin-layer chromatography } \\ \text { VPDB } & \text { Treatment } \\ \text { Trenna Pee Dee Belemnite }\end{array}$




\section{Chapter 1: Introduction}

\subsection{Introduction}

Methionine is an essential amino acid which, in addition to protein synthesis, serves several other important functions in the body including provision of a methyl group in transmethylation reactions to produce products such as creatine and phosphatidylcholine (PC). Although essential in the diet, methionine can be remethylated following the donation of its methyl group by receiving a methyl group from folate or betaine, allowing methionine to "cycle" through transmethylation and remethylation. Alternatively, following donation of its methyl group methionine can be used to form the amino acids cysteine and taurine by entering the transsulfuration pathway. Methionine metabolism in the neonate is of particular importance due to growth and expansion of transmethylation products as well as the methylation of deoxyribonucleic acid (DNA). Nutritional deficits during critical stages of early development can lead to permanent changes in DNA methylation which are associated with disease in later life. This chapter will give a detailed description of methionine metabolism while highlighting the function of the nutrients involved in these pathways (Figure 2.1).

\subsection{Transmethylation}

Methionine is an essential amino acid containing a stable terminal methyl group bonded covalently to a sulfur atom. When not incorporated into protein, methionine can be activated via conjugation of sulfur with adenosine via methionine adenosyltransferase (MAT) to form the "activated" $S$-adenosylmethionine (SAM) (Cantoni, 1951). Although 
this reaction is ubiquitous, MAT activity is $20-400$ fold higher in the liver than in other organs such as kidney and pancreas (Eloranta, 1977). Due to the addition of adenosine, the methyl group of SAM is labile and is transferred in over 50 transmethylation reactions (Schubert et al., 2003). The most quantitatively important of these methylation pathways involves the synthesis of PC, creatine and sarcosine via phosphatidylethanolamine $\mathrm{N}$ methyltransferase (PEMT), guanidinoacetate methyltransferase (GAMT), and glycine $\mathrm{N}$ methyltransferase (GNMT), respectively (Mudd et al., 2007). SAM also serves to methylate DNA via DNA methyltransferase (DNMT), although the quantitative significance of this reaction is unknown.

After donating its methyl group, SAM is converted to $S$-adenosylhomocysteine (SAH) which is further hydrolyzed to homocysteine and adenosine via SAH hydrolase. Because the hydrolysis of $\mathrm{SAH}$ is a reversible reaction favoring homocysteine and adenosine condensation, the removal of hydrolysis products is imperative to prevent an accumulation of SAH (La Haba \& Cantoni, 1959). Experiments using perfused rat livers demonstrated that addition of homocysteine and adenosine led to a lower ratio of SAM/SAH and a subsequent reduction of methyl incorporation into DNA and PC (Hoffman et al., 1979). The SAM/SAH ratio is thought to be an indicator of transmethylation potential, as SAM is required for and $\mathrm{SAH}$ is an inhibitor of transmethylation reactions, although each methyltransferase enzyme responds differently (Hoffman et al., 1980). 


\subsection{Transsulfuration and remethylation}

Following transmethylation and hydrolysis of $\mathrm{SAH}$, there are three primary fates for homocysteine: 1) remethylation to form methionine; 2) catabolism to form cysteine via the transsulfuration pathway; and 3) release from the cell into the plasma.

\subsubsection{Remethylation: Betaine-Homocysteine methyltransferase and methionine synthase}

Homocysteine can be methylated to reform methionine by accepting a methyl group from either betaine via betaine-homocysteine methyltransferase (BHMT) or from folate via methionine synthase (MS). Betaine can either be consumed in the diet or endogenously synthesized via oxidation of choline following transport into the mitochondria (Kaplan et al., 1993). Choline dehydrogenase and betaine aldehyde dehydrogenase are co-localized in the mitochondria and carry out the 2 step conversion of choline to betaine (Chern \& Pietruszko, 1999), which subsequently diffuses into the cytoplasm (Porter et al., 1993). Betaine functions in the cytosol as both an osmolyte (Häussinger, 1996) and as a methyl donor to reform methionine via BHMT (Finkelstein et al., 1972). BHMT is a cytosolic zinc metalloenzyme (Millian and Garrow, 1998) that is primarily active in the liver of most species with low levels of activity also found in the kidney of humans and pigs (Finkelstein, 1990; Garrow, 1996; McKeever et al., 1991).

Alternatively, folate, in the form of 5-methyltetrahydrofolate (5-methyl-THF), can function to provide a methyl group to reform methionine via MS which is found in all tissues. Folate is consumed in the diet primairly as a polyglutamate derivative and is enzymatically converted via conjugase to an absorbable monoglutamate form, which is 
further converted to 5-methyl-THF in the intestinal mucosa (Olinger et al., 1973). Using vitamin $\mathrm{B}_{12}$ as a cofactor, 5-methyl-THF provides the methyl group for MS to reform methionine from homocysteine, also yielding tetrahydrofolate (THF) (Fujii et al., 1977). Using serine as a methyl source, THF is converted via serine hydroxymethyltransferase to 5,10-methylenetetrahydrofolate (5,10-THF) (Davis et al., 2004; Motokawa and Kikuchi, 1971), which can be converted back to 5-methyl-THF via methylenetetrahydrofolate reductase (Kutzbach \& Stokstad, 1971), completing the folate cycle. Folate is also required for purine synthesis which is important in the synthesis of DNA. Moreover, maternal folate status is also important in the prevention of neural tube defects (Scott, 1999). Although the activity of MS is highest in the liver, the enzyme is ubiquitous with high levels of activity also found in the kidney, brain and pancreas (Brosnan et al., 2009; Finkelstein et al., 1971).

\subsubsection{Transsulfuration}

The transsulfuration pathway initiates with the irreversible condensation of serine and homocysteine to form cystathionine via cystathionine $\beta$-synthase (CBS) which uses vitamin $\mathrm{B}_{6}$ as a cofactor (Finkelstein \& Chalmers, 1970). Cystathionine is then converted to cysteine via cystathionine $\gamma$-lyase (CGL), which has low activity in the neonate (Zlotkin and Anderson, 1982). In addition to use in protein synthesis, cysteine can be further metabolized to taurine by a two enzyme system (Nakamura et al., 2006; Stipanuk et al., 2002). The transsulfuration enzymes show high activity levels in the liver but are also found in the kidney, pancreas, intestine and brain (Mudd et al., 1965). 


\subsubsection{Regulation of homocysteine metabolism}

There has been considerable research examining the regulation of homocysteine remethylation via folate and betaine. In rats, remethylation is favoured over transsulfuration based on the $\mathrm{K}_{\mathrm{m}}$ values for homocysteine in rat liver for BHMT and MS, which are 0.012-0.06 $\mathrm{mM}$ and $0.06 \mathrm{mM}$, respectively, while the $\mathrm{K}_{\mathrm{m}}$ for the transsulfuration enzyme CBS is $1-25 \mathrm{mM}$ (Finkelstein and Martin, 1984). In vitro studies using rat livers demonstrated that under standard dietary conditions, both remethylation pathways contribute equally to the reformation of methionine (Finkelstein \& Martin, 1984). Interestingly, the percentage of total methionine flux contributed by remethylation and transsulfuration are roughly equal in 1-week old piglets, while 3 -week old piglets have a 4 fold higher proportion of methionine flux via transsulfuration compared to remethylation, as well as lower total flux through both pathways (Bauchart-Thevret et al., 2009). Because the absolute rates of protein synthesis are the same at both 1 and 3 weeks old, it appears that neonates have a higher methionine demand for transmethylation reactions which is sustained via an increased rate of remethylation (Bauchart-Thevret et al., 2009). Furthermore, human studies have demonstrated that neonates have a higher methionine cycle activity compared to adults (Thomas et al., 2008). The activity of BHMT is high in the neonatal rat until 3 weeks of age and it declines to a plateau by week

4 (Clow et al., 2008). Due to the maturity of the pig at birth compared to the rat, this result is in keeping with the high rates of remethylation found in the neonatal pig (Bauchart-Thevret et al., 2009). Alternatively, developmental changes in MS activity are 
organ-specific, making it difficult to draw conclusions on the contribution of MS to higher neonatal rates of remethylation (Thompson et al., 2001).

It has been suggested that under normal dietary conditions, MS is the primary remethylation pathway and BHMT functions in a secondary capacity during times of methionine deficiency (Kim et al., 2005; Park and Garrow, 1999) or excess (Finkelstein et al, 1971). Methionine deficient rats receiving adequate betaine have BHMT activity and BHMT mRNA levels $\sim 4$ fold higher than rats receiving adequate methionine and $\sim 8$ fold higher than betaine and methionine deficient rats (Park and Garrow, 1999). Activity is unaffected (Park \& Garrow, 1999) or less affected (Finkelstein et al., 1983) by moderate choline supplementation of a methionine adequate diet. Because the degree of methionine deficiency is proportional to the increase in BHMT activity when combined with provision of methyl donors, remethylation via BHMT appears to function to conserve methionine when it is limiting (Park and Garrow 1999); however, it is possible that these effects are species specific, as experiments in pigs demonstrate a modest $30 \%$ increase in BHMT activity following of betaine to a methionine deficient diet (Emmert et al., 1998). Furthermore, neither methionine deficiency nor betaine supplementation to a methionine adequate diet had an effect on hepatic BHMT activity in pigs (Emmert et al., 1998).

MS activity is also higher during situations with an increased need for methionine synthesis, such as with low dietary protein (Finkelstein et al., 1971). Similar to the benign effect of choline supplementation on BHMT activity, folate supplementation in rats, leading to $\sim 4$ fold higher plasma folate, showed no effect on hepatic MS activity 
(Achón et al., 2007). Both SAM and SAH are regulators of homocysteine metabolism, with SAM exhibiting an inhibitory effect on BHMT and MS activity, and SAH positively affecting activity of these enzymes (Finkelstein \& Martin, 1984; Finkelstein \& Martin, 1986; Kutzbach \& Stokstad, 1971). Although both enzymes are also regulated by methionine excess, methionine supplementation in rats leads to higher activity levels of both BHMT and CBS, while MS activity is lower (Finkelstein \& Martin, 1986). Similarly, a high protein diet also results in higher BHMT activity while MS is repressed (Finkelstein et al., 1971).

Although these experiments provide valuable insight into methionine metabolism, the regulation of remethylation and transsulfuration is organ specific (Finkelstein, 2007), and the quantification of hepatic enzyme activities and metabolite concentrations do not necessarily represent whole body remethylation metabolism. Although the liver is the primary site for methionine utilization, other organs also contribute significantly to methionine metabolism, such as the pancreas which exports more endogenously synthesized methionine than the liver as well as a comparable amount of homocysteine (Wilson et al., 2009). In the piglet, the gastrointestinal tract metabolizes $\sim 20 \%$ of dietary methionine, one third of which is utilized for cysteine synthesis (Riedijk et al., 2007), suggesting an intact transsulfuration pathway. Because methionine metabolism is highly variable among tissues, it is important to consider whole body methionine metabolism when determining the relative contribution of folate and betaine to remethylation. 
Supplementation of either folate or betaine have the capacity to lower plasma homocysteine (Keser et al., 2013; McRae, 2013) and fasting plasma homocysteine shows a strong inverse relationship with plasma folate. Moreover, post methionine load levels of homocysteine have a strong inverse relationship with plasma betaine (Holm, 2004), which is in keeping with the theory that BHMT functions to dispose of excess methionine. BHMT knockout mice fed a standard chow diet have higher levels of plasma homocysteine (Teng et al., 2012). Folate deficient rats also demonstrate elevated levels of homocysteine, highlighting the importance of both BHMT and MS for remethylation (Miller et al., 1994). Experiments involving in vivo comparisons of whole body remethylation via these two nutrients are currently lacking in the literature.

\subsubsection{Choline and betaine}

Choline and betaine can both be synthesized endogenously or consumed in the diet. Some dietary sources of choline are eggs, beef and wheat germ, while foods high in betaine include wheat bran, wheat germ and spinach. The recommended adequate intake of choline by the Institute of Medicine is $550 \mathrm{mg} /$ day and $425 \mathrm{mg} / \mathrm{d}$ for men and women respectively, with an adequate intake of $550 \mathrm{mg} /$ day during pregnancy (1998). An ad libitum intake study in the US reported choline intakes averaging 6.7 and $8.4 \mathrm{mg} / \mathrm{kg}$ per day for women and men, respectively (Fischer et al., 2005). Although there is no recommended daily intake for betaine, intake was reported to be 4.7 and $5.3 \mathrm{mg} / \mathrm{kg}$ per day for women and men, respectively (Fischer et al., 2005). 
The total choline concentration in mature breast milk is $\sim 1500 \mu \mathrm{M}$ consisting of $\sim 35 \%$ from each of glycerophosphocholine and phosphocholine and $\sim 15 \%$ from each of free choline and PC. Free choline in serum is higher in breast fed compared to formula fed infants and the choline concentration of breast milk is influenced by maternal choline status (Ilcol et al., 2005). Infant formula ranges from $700 \mu \mathrm{M}$ in soy-derived formula to $1800 \mu \mathrm{M}$ in bovine milk-derived formula and consists mostly of glycerophosphocholine (Holmes-McNary et al., 1996). Because the betaine concentration in breast milk is only 7 $\mu \mathrm{M}$ (Fischer et al., 2010), the primary source of betaine in the infant is most likely derived from choline which is $\sim 200$ fold higher in breast milk than betaine. In rats, $\sim 85 \%$ of labelled dietary choline and phosphocholine is recovered as betaine in the liver within 24 hours, while only $\sim 50 \%$ and $\sim 15 \%$ of PC and glycerophosphocholine, respectively, are converted to betaine after 24 hours (Cheng et al., 1996), demonstrating the variability of these choline derivatives as sources of betaine. Choline is highly important during early development and studies have demonstrated the positive association of choline intake with cognitive development (Caudill, 2010; McCann et al., 2006; Meck \& Williams, 2003).

\subsubsection{Folate}

Folate, found in supplements and used to fortify food, is primarily in the monoglutamate form while naturally occurring folate in foods, such as leafy green vegetables as well as some fruits and beans, is in the reduced polyglutamate form. In 1998, the USA and Canada implemented folic acid fortification in a variety of foods including breads and cereals in an attempt to reduce neural tube defects. Although the incidence of neural tube 
defects has lowered, it has been suggested that fortification could be leading to an excess of folate in the diet (Lucock \& Yates, 2009; Osterhues et al., 2013).

Approximately 28\% of Canadian females between 6 and 79 years of age take a folate containing supplement; however, supplementation is lowest among teenagers and young adults (Colapinto et al., 2012). The average total folate concentration in breast milk is $\sim 80 \mathrm{ng} / \mathrm{mL}$ (Smith et al., 1985) and the current global recommendation for the minimum level of folic acid in infant formula is $60 \mathrm{ng} / \mathrm{mL}$ (Koletzko et al., 2005). Unlike choline, breast milk folate levels are independent of maternal folate status with no correlation between milk folate concentration and maternal blood folate indexes in women supplemented with folate (Smith et al., 1985). In the piglet, it has been shown that folate can be synthesized by the intestinal microflora at a rate between $93-176 \mathrm{nmol} / \mathrm{day}$ which is roughly $34-65 \%$ of the daily requirement (Kim et al., 2004). It is thought that $\sim 15 \%$ of folate synthesized in the colon of the piglet is absorbed (Asrar and O'Connor, 2005), suggesting bacterial folate synthesis provides $\sim 5-10 \%$ of the piglet requirement.

\section{$1.4 \quad$ Transmethylation demand}

In addition to GAMT and PEMT, the enzyme GNMT is also known to be a quantitatively significant consumer of methyl groups by methylating glycine to form sarcosine. Dietary methionine supplementation leads to a dose dependent increase in GNMT activity (Rowling et al., 2002), and it is thought that GNMT functions in an overflow pathway to regulate the SAM/SAH ratio and transmethylation reactions (Ogawa and Fujioka, 1982). GNMT knockout mice have elevated levels of both plasma SAM and methionine 
(Martínez-Chantar, 2008) and develop hepatic steatosis via an increased flux through PEMT and a resulting increase in triglyceride synthesis (Martínez-Uña, 2013). Early investigations of the quantitative significance of transmethylation reactions led to the suggestion that creatine is the primary methyl group consumer (Mudd and Poole, 1975); however, this notion was refuted by Jacobs et al. (2005) who calculated a 2-3 fold higher SAM utilization by PEMT versus GAMT. Experiments in PEMT knockout mice demonstrate $\sim 50 \%$ lower levels of homocysteine after 3 weeks, highlighting the significant demand of PEMT for SAM (Noga and Vance, 2003). Although these transmethylation reactions have been assessed independently, there appear to be no in vivo studies directly comparing SAM utilization among transmethylation reactions (Mudd et al., 2007).

\subsubsection{Phosphatidylcholine synthesis}

The synthesis of PC via PEMT involves the sequential transfer of 3 methyl groups to phosphatidylethanolamine (PE) to produce PC (Ridgway and Vance, 1987). PC is important for bile and lipoprotein synthesis and quantitatively, the entire hepatic pool of PC is secreted in bile each day (Walkey et al., 1998). PC synthesis is also required for the hepatic secretion of VLDL (Yao and Vance, 1988). There appears to be a higher demand for PC for lipoprotein synthesis than for bile, as 5 hours after injection of [methyl-

$\left.{ }^{3} \mathrm{H}\right]$ methionine into the tail vein of mice, 2-3\% of radioactivity is found in bile, while 57\% is found in plasma (Noga and Vance, 2003). 
The PEMT pathway is responsible for approximately $30 \%$ of hepatic PC biosynthesis, with the remainder synthesized by the Kennedy pathway via the enzyme CDPcholine:1,2-diacylglycerol cholinephosphotransferase, which transfers phosphocholine to 1,2-diacylglycerol (Li and Vance, 2008). While the Kennedy pathway is ubiquitous, PEMT activity is primarily localized to the liver (Cui et al., 1993). PC can be metabolized to choline and during choline deprivation, choline recycling can occur by increasing PEMT activity via an increase in PE concentration during short term deficiency (Ridgway et al., 1989) or via an upregulation of PEMT expression during prolonged deficiency (Cui \& Vance, 1996). The synthesis of PC via the Kennedy pathway is 3 fold higher when PEMT is inhibited demonstrating the coordinated regulation of PC synthesis (Pritchard \& Vance, 1981).

\subsubsection{DNA methylation}

Another important methyltransferase is DNMT which transfers a methyl group to cytosine residues in $\mathrm{CpG}$ dinucleotides of DNA. DNA methylation is an example of an epigenetic alteration, which is a heritable modification of gene expression that does not involve alterations to the DNA sequence (Hanley et al., 2010). These modifications can occur in large regions of DNA such as repetitive DNA, or can be localized to promoter regions of DNA. Patterns of DNA methylation are established during early development and epigenetic changes near promoter regions of DNA can lead to changes in gene expression via direct effects on transcription factors or indirectly via repressor protein bindng (Reamon-Buettner et al., 2014; Tate and Bird, 1993). 


\subsubsection{Epigenetics and fetal programming in IUGR}

Epigenetic changes to DNA methylation have been implicated in the fetal origins hypothesis, which was first proposed by David Barker to describe how an insult to the fetus can result in permanent negative health effects in later life (McMillen and Robinson, 2005). This hypothesis was originally based on epidemiological studies which demonstrated an association between low birth weight and disease in later life (Barker and Osmond, 1986; Barker et al., 1989; Gluckman et al., 2008; Godfrey and Barker, 2000). Intrauterine growth restriction (IUGR) is a term used to describe a fetus with a body weight that is lower than the $10^{\text {th }}$ percentile for gestational age, which is defined as less than $2.5 \mathrm{~kg}$ for a term infant (Ferenc et al., 2014; WHO, 1995); after correction for factors such as low maternal weight, the incidence of IUGR is 4-7\% (Vandenbosche and Kirchner, 1998). The etiology of IUGR encompasses a variety of factors, including smoking and preeclampsia (Campbell et al., 2012) and it is thought that placental insufficiency is central to most cases of IUGR (Figueras and Gardosi, 2011). It has been well established in both human and animal models that IUGR can lead to an increased risk for hypertension, cardiovascular disease, diabetes and obesity in later life (McMillen \& Robinson, 2005). Recent work using Yucatan miniature pigs has demonstrated that IUGR pigs experience catch-up growth, and develop early markers for hypertension (Myrie et al., 2011), dyslipidemia and obesity (Myrie et al., 2008). It has also been demonstrated that a diet high in salt, sugar and fat exacerbates metabolic syndrome outcomes (Myrie et al., 2012). 
Recently, this 'programming' appears to be mediated by epigenetic modifications, in particular, the altered pattern of gene expression resulting from altered DNA methylation (McMillen \& Robinson, 2005). It has further been demonstrated that the dietary methyl supply can play a role in the programming process (Lillycrop et al., 2005). In a study by Sinclair et al. (2007), sheep fed a methyl deficient diet for 8 weeks preconception and 6 days post conception gave birth to male offspring that were insulin resistant with elevated blood pressure. Analysis of genome methylation suggested that this was due to decreased methylation. Alternatively, maternal folate supplementation during gestation can also lead to site specific changes in DNA methylation, as well as changes in gene expression in mice (Barua et al., 2014).

Reprogramming has also been demonstrated to extend to the neonatal phase as well. Neonatal overfeeding of rats can lead to promoter specific changes in methylation of the promoter region of the anorexigenic neurohormone proopiomelanocortin, the expression of which impacts food intake and body weight (Plagemann et al., 2009). Furthermore, rats fed a folate deficient diet from weaning until 8 weeks of age, followed by a control diet, had an increase in genomic DNA methylation compared to control or folate supplemented rats, demonstrating the importance of folate intake during early development (Kotsopoulos et al., 2008).

It has been hypothesized that an imbalance of dietary methionine in relation to other amino acids may also play a role in the programming of disease (Langley-Evans, 2000; Rees et al., 2006). Although many of the experiments examining the effect of altered methyl supply on fetal programming have focused on the provision of folate, as discussed 
in previous sections, the metabolic pathways that converge on methionine metabolism are closely linked. Because of the variable levels of nutrients in neonatal diets, more research is needed to determine the effect of these different levels of nutrients on methionine metabolism and availability.

\subsubsection{Creatine synthesis}

Creatine synthesis involves 2 steps, commencing in the kidney with the production of guanidinoacetate (GAA) and ornithine via the transfer of the amidino group from arginine to glycine by arginine:glycine amidinotransferase (AGAT) (Bloch and Schoenheimer, 1941). This reaction is followed by the SAM dependent methylation of GAA in the liver via GAMT to produce creatine and SAH (Cantoni \& Vignos, 1954). Creatine supplementation leads to lower AGAT activity (Walker, 1960) as well as lower levels of AGAT mRNA and protein (McGuire et al., 1984), thus demonstrating that creatine synthesis is regulated via GAA production. Furthermore, creatine supplementation has been shown to lower plasma homocysteine in rats (Deminice et al., 2011; Stead et al., 2001) which suggests a lower production of GAA; however, several studies in humans have demonstrated no effect of creatine supplementation on levels of plasma homocysteine (Steenge \& Verhoef, 2001; Taes et al., 2004). These differences may be attributed to the lower renal production of GAA by humans compared to rats (Edison et al., 2007).

In contrast, creatine supplementation has no effect on GAMT activity, and creatine synthesis has been shown in rats to be proportional to GAA availability (Da Silva et al., 
2009). Human studies have also demonstrated a dose response effect of GAA supplementation on the plasma levels of both GAA and creatine, as well as a higher concentration of plasma homocysteine with GAA supplementation (Ostojic et al., 2013). Furthermore, GAA has also been used as a means to increase methylation demand (Kharb et al., 2014).

\subsubsection{Creatine metabolism}

In addition to endogenous synthesis, creatine can be consumed in the diet and is primarily found in animal products such as red meat and fish. Approximately $1.7 \%$ of total creatine is excreted as creatinine each day (Wyss \& Kaddurah-Daouk, 2000) and the typical 20-39 year old adult consumes $7.9 \mathrm{mmol}$ and $5.0 \mathrm{mmol}$ of creatine for men and women respectively, which accounts for replenishing approximately half of daily creatine loss (Stead et al., 2006). In the body, the enzyme creatine kinase utilizes ATP to phosphorylate creatine to form creatine phosphate. The reversibility of this reaction allows creatine phosphate to function as an energy buffer by synthesizing ATP during times of high energy demand (Wallimann et al., 1992). Tissue stores of creatine and creatine phosphate are highest in skeletal muscle, heart and brain, due to the high energy requirement and utilization of ATP in these tissues (Horn et al., 1998; Ipsiroglu et al., 2001).

Following hepatic synthesis, creatine is released from the liver into the blood and transported into tissues against a concentration gradient via the sodium and chloride dependent creatine transporter (SLC6A8), which is specific for the amidine group and is a 
saturable process (Fitch and Shields, 1966; Loike et al., 1986). Because creatine is arguably the most effective ergogenic nutritional supplement (Buford et al., 2007), several studies have focused on methods to increase creatine accretion, such as high carbohydrate consumption during supplementation (Green et al., 1996; Steenge and Verhoef, 2001). Creatine is typically consumed at doses up to $20 \mathrm{~g} /$ day by individuals who wish to improve exercise or sports performance (Bemben and Lamont, 2005; Terjung et al., 2000). Furthermore, creatine has recently been proposed as a therapeutic agent for a variety of neurodegenerative conditions including Parkinson's disease (Bender et al., 2008) and Huntington's disease (Hersch et al., 2006) as well as a potential neuroprotectant (Peña-Altamira et al., 2005). The agriculture industry has also investigated creatine as a potential food additive due to its demonstrated capacity to increase tissue stores of phosphocreatine (Lindahl et al., 2006) and increase weight gain (Young et al., 2005). Interestingly, creatine supplementation can lead to downregulation of the creatine transporter as a negative feedback mechanism to control intracellular creatine levels (Guerrero-Ontiveros \& Wallimann, 1998).

GAA has also recently gained attention as a potential supplement to increase creatine stores in humans and livestock (Baker, 2009); however, research in this area is currently limited. A recent clinical trial investigating the effect of a 6 week supplementation period with $24 \mathrm{~g} /$ day of GAA demonstrated an increase in plasma creatine and a low incidence of biochemical abnormalities (Ostojic et al., 2013). Higher levels of creatine as well as improvements in breast meat yield and gain:feed ratio have been reported in broiler chickens fed a vegetable based diet supplemented with GAA (Michiels et al., 2012). 


\subsubsection{Creatine in the neonate}

Total body creatine in the neonatal piglet increases by $\sim 70 \%$ during the period from 4 to 11 days of age demonstrating the high demand for creatine during early development (Brosnan et al. 2009). The neonatal pig receives $25 \%$ of its creatine requirement from the sow's milk and consequently must synthesize the majority of its creatine needs (Brosnan et al., 2009). A recent analysis of breast milk and infant formula determined a wide variability in the creatine concentration with values of $330 \mu \mathrm{M}$ in standard infant formula and $10 \mu \mathrm{M}$ in soy-based formula (Edison et al., 2013). The contribution between dietary and endogenously synthesized creatine in the infant is variable with breast-fed infants receiving $\sim 10 \%$ of their creatine from diet while infants receiving cow milk-based formulas consume $\sim 35 \%$ of their total creatine via diet (Edison et al., 2013). Furthermore, infants fed soy-based formula consume negligible amounts of dietary creatine, thus requiring synthesis of the entire creatine requirement. This inconsistency in infant dietary creatine intake translates into variability in the demand for creatine synthesis, which consequently creates a variable demand for methyl groups. This is important during early development, as the neonate appears to have a high demand for transmethylation reactions (Bauchart-Thevret et al., 2009).

\section{$1.5 \quad$ Methionine sparing}

Several studies have demonstrated that the provision of excess cysteine can spare the methionine requirement by up to $40 \%$ (Fukagawa, 2006; Shoveller et al., 2003a), and the 
concept of folate, betaine and creatine functioning to spare methionine has been previously proposed (Fukagawa, 2006). Betaine has been shown to spare methionine in chickens (Dilger et al., 2007); however, experiments in pigs concluded that supplemental betaine cannot replace dietary methionine (Matthews et al., 2001). Creatine and GAA have also been considered as having potential in agriculture to spare both methionine and arginine; when added to an arginine-deficient diet, both GAA and creatine supplementation in chicks resulted in a higher gain:feed ratio (Dilger et al., 2013). More research is needed using more precise techniques to determine whether these nutrients can indeed spare methionine for growth, especially in mammalian species.

\subsection{Pig as model for human}

There are several factors that make the pig an excellent model to examine amino acid metabolism and IUGR. The nutrient requirements of the piglet resemble those of the human more so than any other non-primate mammalian species, especially with respect to amino acids (Miller and Ullrey, 1987). Similar to the human, pigs have a long gestation time and organ systems are similarly developed at birth (Guilloteau et al., 2010). Furthermore, fetal pigs have an amino acid composition similar to humans which demonstrates the pig is an ideal model to study amino acid metabolism during early development (Wu et al., 1999).

Research methodologies for investigating amino acid metabolism have also been well established in the pig. Specifically, the methionine requirement of the piglet has been determined both parenterally and enterally with either excess or deficient levels of dietary 
cysteine (Shoveller at al., 2003b). The indicator amino acid oxidation technique used to determine amino acid requirements has been used extensively in pigs. It is based on the principle that if the amount of a limiting amino acid is increased incrementally while determining the rate of phenylalanine oxidation at each test level, phenylalanine oxidation will eventually plateau, indicating the maximum amount of phenylalanine that has been incorporated into protein and the test amino acid is no longer limiting (Bertolo et al., 2005; Elango et al., 2002; House et al., 1998). The runt pig, defined as less than $65 \%$ of the average weight of the littermates (Hegarty \& Allen, 1978), is assumed to have suffered a global nutritional insult in utero as compared to its littermates; this spontaneous IUGR piglet model has been successfully used to study fetal programming (Ferenc et al., 2014; Guilloteau et al., 2010; Myrie, 2011). The Yucatan miniature pig has been used in our lab to study intestinal dipeptide uptake (Nosworthy et al., 2013), short bowel syndrome (Dodge et al., 2012) and parenteral nutrition (Alemmari et al., 2012). Furthermore, this model has been used by our lab to demonstrate compensatory growth in IUGR pigs (McKnight, 2012) as well as fewer nephrons and higher diastolic blood pressure in adult IUGR pigs compared to normal weight pigs fed the same diet (Myrie, 2011). 


\subsection{Thesis rationale and hypotheses}

\subsubsection{Rationale}

Although the methionine requirement has been determined in the human infant and piglet, it has been shown that variability in the nutrients involved in methionine metabolism can affect the methionine requirement. Furthemore, it has been proposed that an imbalance of sulfur amino acids during early development may play a role in fetal programming. Because IUGR piglets have been used as a model for fetal programming, this research was conducted to determine whether IUGR piglets have altered methionine metabolism. We also wanted to determine whether changes in the availability or demand of nutrients involved in methionine metabolism can impact methionine availability during early development. The primary objectives of this thesis are 1) to determine whether IUGR piglets have perturbed methionine metabolism; 2) to determine whether an increased methylation demand for one product can limit methionine availability for protein synthesis and other transmethylation reactions; and 3) to determine whether the nutrients folate, betaine and creatine can affect the availability of methionine for protein synthesis.

\subsubsection{Hypotheses}

We hypothesize that 1) IUGR piglets will have perturbed methionine metabolism compared to normal weight littermates; 2) increasing the demand for creatine synthesis in

the neonatal piglet will limit methionine availability for protein synthesis and other transmethylation reactions; and 3) provision of folate, betaine or creatine will increase availability of methionine for protein synthesis. 


\section{$1.8 \quad$ Co-authorship statement}

Laura McBreairty, B.Sc., B.A., is the first author of Chapters 3, 4 and 5 and is $3^{\text {rd }}$ author of Chapter 2. Further information is provided at the beginning of respective chapters. 


\subsection{References}

Achón, M., Alonso-Aperte, E., Úbeda, N. and Varela-Moreiras, G. (2007). "Supranormal dietary folic acid supplementation: effects on methionine metabolism in weanling rats." Br J Nutr 98(3): 490-6.

Alemmari, A., Miller, G.G., Bertolo, R.F., Dinesh, C., Brunton, J.A., Arnold, C.J., Zello, G.A. (2012). "Reduced aluminum contamination decreases parenteral nutrition associated liver injury.” J Pediatr Surg 47(5): 889-94.

Asrar, F.M. and O'Connor, D.L. (2005). "Bacterially synthesized folate and supplemental folic acid are absorbed across the large intestine of piglets." J Nutr Biochem 16(10): 58793.

Baker, D.H. (2009). “Advances in protein-amino acid nutrition of poultry.” Amino Acids 37(1): 29-41.

Barker, D.J. and Osmond, C. (1986). "Infant mortality, childhood nutrition, and ischaemic heart disease in England and Wales.” Lancet 1(8489): 1077-81.

Barker, D.J. Osmond, C. and Law, C.M. (1989). "The intrauterine and early postnatal origins of cardiovascular disease and chronic bronchitis." J Epidemiol Community Health 43(3): 237-40.

Barua, S., Chadman, K.K., Kuizon, S., Buenaventura, D., Stapley, N.W., Ruocco, F. Begum, U., Guariglia, S.R., Brown, W.T. and Junaid, M.A. (2014). "Increasing maternal or post-weaning folic acid alters gene expression and moderately changes behavior in the offspring." PLoS One 9(7): e101674.

Bauchart-Thevret, C., Stoll, B., Chacko, S. and Burrin, D.G. (2009). "Sulfur amino acid deficiency upregulates intestinal methionine cycle activity and suppresses epithelial growth in neonatal pigs.” Am J Physiol Endocrinol Metab 296(6): 1239-50.

Bemben, M.G. and Lamont, H.S. (2005). "Creatine supplementation and exercise performance: recent findings." Sports Med 35(2): 107-25.

Bender, A., Samtleben, W., Elstner, M. and Klopstock, T. (2008). "Long-term creatine supplementation is safe in aged patients with Parkinson disease.” Nutr Res 28(3): 172-8. 
Bertolo, R.F., Moehn, S., Pencharz, P.B. and Ball, R.O. (2005). "Estimate of the variability of the lysine requirement of growing pigs using the indicator amino acid oxidation technique." J Anim Sci 83(11): 2535-42.

Bloch, K. and Schoenheimer, R. (1941). "The biological precursors of creatine.” J Biol Chem 138: 167-94.

Brosnan, J.T., Wijekoon, E.P., Warford-Woolgar, L., Trottier, N.L., Brosnan, M.E., Brunton, J.A. and Bertolo, R.F. (2009). "Creatine synthesis is a major metabolic process in neonatal piglets and has important implications for amino acid metabolism and methyl balance." J Nutr 139(7): 1292-7.

Buford, T.W., Kreider, R.B., Stout, J.R., Greenwood, M., Campbell, B., Spano, M., Ziegenfuss, T., Lopez, H., Landis, J. and Antonio, J. (2007). "International Society of Sports Nutrition position stand: creatine supplementation and exercise." J Int Soc Sports Nutr 4(6): 1-8.

Campbell, M.K., Cartier, S., Xie, B., Kouniakis, G., Huang, W. and Han, V. (2012). "Determinants of small for gestational age birth at term." Paediatr Perinat Epidemiol 26(6): 525-33.

Cantoni, G.L. (1951). "Activation of methionine for transmethylation.” J Biol Chem 189(2): 745-54.

Cantoni, G.L. and Vignos, P.J. (1954). “Enzymatic mechanism of creatine synthesis.” J Biol Chem 209(2): 647-59.

Caudill, M.A. (2010). "Pre- and postnatal health: evidence of increased choline needs." J Am Diet Assoc 110(8): 1198-206.

Cheng, W.L., Holmes-McNarya, M.Q., Mara, M.H., Lien, E.L. and Zeisel, S.H. (1996). "Bioavailability of choline and choline esters from milk in rat pups." J Nutr Biochem 7(8): 457-64.

Chern, M.K. and Pietruszko, R. (1999). "Evidence for mitochondrial localization of betaine aldehyde dehydrogenase in rat liver: purification, characterization, and comparison with human cytoplasmic E3 isozyme.” Biochem Cell Biol 77(3): 179-87.

Clow, K.A., Treberg, J.R., Brosnan, M.E. and Brosnan, J.T. (2008). "Elevated tissue betaine contents in developing rats are due to dietary betaine, not to synthesis." J Nutr 138(9): 1641-6. 
Colapinto, C.K., O'Connor, D.L., Dubois, L. and Tremblay, M.S. (2012). "Prevalence and correlates of folic acid supplement use in Canada." Health Rep 23(2): 39-44.

Cui, Z. and Vance, D.E. (1996). "Expression of phosphatidylethanolamine Nmethyltransferase-2 is markedly enhanced in long term choline-deficient rats." J Biol Chem 271(5): 2839-43.

Cui, Z., Vance, J.E., Chen, M.H., Voelker, D.R. and Vance, D.E. (1993). "Cloning and expression of a novel phosphatidylethanolamine $\mathrm{N}$-methyltransferase. A specific biochemical and cytological marker for a unique membrane fraction in rat liver." J Biol Chem 268(22): 16655-63.

da Silva, R.P., Nissim, I., Brosnan, M.E. and Brosnan J.T. (2009). "Creatine synthesis: hepatic metabolism of guanidinoacetate and creatine in the rat in vitro and in vivo." Am $\mathrm{J}$ Physiol Endocrinol Metab 296(2): E256-61.

Davis, S.R., Stacpoole, P.W., Williamson, J., Kick, L.S., Quinlivan, E.P., Coats, B.S., Shane, B., Bailey, L.B. and Gregory, J.F. (2004). "Tracer-derived total and folatedependent homocysteine remethylation and synthesis rates in humans indicate that serine is the main one-carbon donor." Am J Physiol Endocrinol Metab 286(2): E272-9.

Deminice, R., Vannucchi, H., Simões-Ambrosio, L.M. and Jordao, A.A. (2011). "Creatine supplementation reduces increased homocysteine concentration induced by acute exercise in rats.” Eur J Appl Physiol 111(11): 2663-70.

Dilger, R.N., Bryant-Angeloni, K, Payne, R.L., Lemme A. and Parsons, C.M. (2013). "Dietary guanidino acetic acid is an efficacious replacement for arginine for young chicks.” Poult Sci 92(1): 171-7.

Dilger, R.N., Garrow, T.A. and Baker, D.H. (2007). "Betaine can partially spare choline in chicks but only when added to diets containing a minimal level of choline." J Nutr 137(10): 2224-8.

Dodge, M.E., Bertolo, R.F., Brunton, J.A. (2012). Enteral feeding induces early intestinal adaptation in a parenterally fed neonatal piglet model of short bowel syndrome. JPEN J Parenter Enteral Nutr 36(2): 205-12.

Edison, E.E., Brosnan, M.E., Aziz, K. and Brosnan, J.T. (2013). "Creatine and guanidinoacetate content of human milk and infant formulas: implications for creatine deficiency syndromes and amino acid metabolism.” Br J Nutr 110(6): 1075-8. 
Edison, E.E., Brosnan, M.E., Meyer, C. and Brosnan, J.T. (2007). "Creatine synthesis: production of guanidinoacetate by the rat and human kidney in vivo." Am J Physiol Renal Physiol 293(6): F1799-804.

Elango, R., Pencharz, P.B. and Ball, R.O. (2002). "The branched-chain amino acid requirement of parenterally fed neonatal piglets is less than the enteral requirement." $\mathrm{J}$ Nutr 132(10): 3123-9.

Eloranta, T.O. (1977). "Tissue distribution of S-adenosylmethionine and Sadenosylhomocysteine in the rat. Effect of age, sex and methionine administration on the metabolism of S-adenosylmethionine, S-adenosylhomocysteine and polyamines." Biochem J 166(3) 521-9.

Emmert, J.L., Webel, D.M., Biehl, R.R., Griffiths, M.A., Garrow, L.S., Garrow, T.A. and Baker, D.H. (1998). "Hepatic and renal betaine-homocysteine methyltransferase activity in pigs as affected by dietary intakes of sulfur amino acids, choline, and betaine." J Anim Sci 76(2): 606-10.

Ferenc, K., Pietrzak, P., Godlewski, M.M., Piwowarski, J., Kiliańczyk, R., Guilloteau, P. and Zabielski, R. (2014). "Intrauterine growth retarded piglet as a model for humans Studies on the perinatal development of the gut structure and function." Reprod Biol 14(1): 51-60.

Figueras, F. and Gardosi, J. (2011). "Intrauterine growth restriction: new concepts in antenatal surveillance, diagnosis, and management." Am J Obstet Gynecol 204(4): 288300 .

Finkelstein, J.D. (1990). "Methionine metabolism in mammals." J Nutr Biochem 1(5): 228-37.

Finkelstein, J.D. (2007). "Metabolic regulatory properties of S-adenosylmethionine and S-adenosylhomocysteine." Clin Chem Lab Med 45(12): 1694-9.

Finkelstein, J.D. and Chalmers, F.T. (1970). "Pyridoxine effects on cystathionine synthase in rat liver." J Nutr 100(4): 467-9.

Finkelstein, J.D. and Martin, J.J. (1984). "Methionine metabolism in mammals. Distribution of homocysteine between competing pathways." J Biol Chem 259(15): 950813.

Finkelstein, J.D. and Martin, J.J. (1986). "Methionine metabolism in mammals. Adaptation to methionine excess." J Biol Chem 261(4): 1582-7. 
Finkelstein, J.D., Harris, B.J. and Kyle, W.E. (1972). "Methionine metabolism in mammals: kinetic study of betaine-homocysteine methyltransferase." Arch Biochem Biophys 153(1): 320-4.

Finkelstein, J.D., Kyle, W. and Harris B.J. (1971). "Methionine metabolism in mammals. Regulation of homocysteine methyltransferases in rat tissue." Arch Biochem Biophys 146(1): 84-92.

Finkelstein, J.D., Martin, J.J., Harris, B.J. and Kyle, W.E. (1983). "Regulation of hepatic betaine-homocysteine methyltransferase by dietary betaine.” J Nutr 113(3): 519-21.

Fischer, L.M., Da Costa, K.A., Galanko, J., Sha, W., Stephenson, B., Vick, J. and Zeisel, S.H. (2010). "Choline intake and genetic polymorphisms influence choline metabolite concentrations in human breast milk and plasma.” Am J Clin Nutr 92(2): 336-46.

Fischer, L.M., Scearce, J.A., Mar, M., Patel, J.R., Blanchard, R.T., Macintosh, B.A., Busby, M.G. and Zeisel, S.H. (2005). "Ad libitum choline intake in healthy individuals meets or exceeds the proposed adequate intake level." J Nutr 135(4): 826-9.

Fitch, C.D. and Shields, R.P. (1966). "Creatine metabolism in skeletal muscle. I. Creatine movement across muscle membranes." J Biol Chem 241(15): 3611-4.

Fujii, K., Galivan, J.H. and Huennekens, F.M. (1977). "Activation of methionine synthase: further characterization of flavoprotein system." Arch Biochem Biophys 178(2): 662-70.

Fukagawa, N.K. (2006). "Sparing of methionine requirements: evaluation of human data takes sulfur amino acids beyond protein.” J Nutr 136(6 Suppl): 1676S-81S.

Garrow, T.A. (1996). "Purification, kinetic properties, and cDNA cloning of mammalian betaine-homocysteine methyltransferase.” J Biol Chem 271(37): 22831-8.

Gluckman, P.D., Hanson, M.A., Cooper, C. and Thornburg, K.L. (2008). "Effect of in utero and early-life conditions on adult health and disease." N Engl J Med 359(1): 1-13.

Godfrey, K.M., and Barker, D.J. (2000). "Fetal nutrition and adult disease.” Am J Clin Nutr 71(5 Suppl): 1344S-52S.

Green, A.L., Hultman, E., Macdonald, I.A., Sewell, D.A. and Greenhaff, P.L. (1996). "Carbohydrate ingestion augments skeletal muscle creatine accumulation during creatine supplementation in humans.” Am J Physiol 271(5 Pt 1): E821-6. 
Guerrero-Ontiveros, M.L. and Wallimann, T. (1998). "Creatine supplementation in health and disease. Effects of chronic creatine ingestion in vivo: down-regulation of the expression of creatine transporter isoforms in skeletal muscle." Mol Cell Biochem 184(12): 427-37.

Guilloteau, P., Zabielski, R., Hammon, H.M. and Metges, C.C. (2010). "Nutritional programming of gastrointestinal tract development. Is the pig a good model for man?" Nutr Res Rev 23(1): 1-19.

Hanley, B., Dijane, J., Fewtrell, M., Grynberg, A.S., Hummel, R., Junien, C., Koletzko, B., Lewis, S., Renz, H., Symonds, M., Gros, M., Harthoorn, L., Mace, K., Samuels, F. and van Der Beek, E.M. (2010). "Metabolic imprinting, programming and epigenetics - a review of present priorities and future opportunities." Br J Nutr 104 Suppl 1:S1-25

Häussinger, D. (1996). "The role of cellular hydration in the regulation of cell function." Biochem J 313(Pt 3): 697-710.

Hegarty, P.V. and Allen, C.E. (1978). "Effect of pre-natal runting on the post-natal development of skeletal muscles in swine and rats." J Anim Sci 46(6): 1634-40.

Hersch, S.M., Gevorkian, S., Marder, K., Moskowitz, C., Feigin, A., Cox, M., Como, P., Zimmerman, C., Lin, M., Zhang, L., Ulug, A.M., Beal, M.F., Matson, W., Bogdanov, M., Ebbel, E., Zaleta, A., Kaneko, Y., Jenkins, B., Hevelone, N., Zhang, H., Yu, H., Schoenfeld, D., Ferrante, R. and Rosas, H.D. (2006). "Creatine in Huntington disease is safe, tolerable, bioavailable in brain and reduces serum 8OH2'dG." Neurology 66(2): 250-2.

Hirata, F., Viveros, O.H., Diliberto, E.J. and Axelrod, J. (1978). "Identification and properties of two methyltransferases in conversion of phosphatidylethanolamine to phosphatidylcholine." Proc Natl Acad Sci USA 75(4): 1718-21.

Hoffman, D.R., Cornatzer, W.E. and Duerre, J.A. (1979). "Relationship between tissue levels of S-adenosylmethionine, S-adenylhomocysteine, and transmethylation reactions." Can J Biochem 57(1): 56-65

Hoffman, D.R., Marion, D.W., Cornatzer, W.E. and Duerre, J.A. (1980). "SAdenosylmethionine and S-adenosylhomocystein metabolism in isolated rat liver. Effects of L-methionine, L-homocystein, and adenosine." J Biol Chem 255(22): 10822-7.

Holm, P.I. (2004). "Betaine and folate status as cooperative determinants of plasma homocysteine in humans." Arterioscler Thromb Vasc Biol 25(2): 379-85. 
Holmes-McNary, M.Q., Cheng, W.L., Mar, M.H., Fussell, S. and Zeisel, S.H. (1996). "Choline and choline esters in human and rat milk and in infant formulas." Am J Clin Nutr 64(4): 572-6.

Horn, M., Frantz, S., Remkes, H., Laser, A., Urban, B., Mettenleiter, A., Schnackerz, K. and Neubauer, S. (1998). "Effects of chronic dietary creatine feeding on cardiac energy metabolism and on creatine content in heart, skeletal muscle, brain, liver and kidney." $\mathrm{J}$ Mol Cell Cardiol 30(2): 1-8.

House, J.D., Pencharz, P.B. and Ball, R.O. (1998). "Lysine requirement of neonatal piglets receiving total parenteral nutrition as determined by oxidation of the indicator amino acid L-[1-14C]phenylalanine.” Am J Clin Nutr 67(1): 67-73.

Ilcol, Y.O., Ozbek, R., Hamurtekin, E. and Ulus, I.H. (2005). "Choline status in newborns, infants, children, breast-feeding women, breast-fed infants and human breast milk." J Nutr Biochem 16(8): 489-99.

Institute of Medicine (US) Standing Committee on the Scientific Evaluation of Dietary Reference Intakes and its Panel on Folate, Other B Vitamins, and Choline. (1998). "Dietary Reference Intakes for Thiamin, Riboflavin, Niacin, Vitamin B6, Folate, Vitamin B12, Pantothenic Acid, Biotin, and Choline." Washington, DC: National Academy Press.

Ipsiroglu, O.S., Stromberger, C., Ilas, J., Höger, H., Mühl, A. and Stöckler-Ipsiroglu, S. (2001). Changes of tissue creatine concentrations upon oral supplementation of creatinemonohydrate in various animal species." Life Sci 69(15): 1805-15.

Jacobs, R.L., Stead, L.M., Devlin, C., Tabas, I., Brosnan, M.E., Brosnan, J.T. and Vance, D.E. (2005). "Physiological regulation of phospholipid methylation alters plasma homocysteine in mice." J Biol Chem 280(31): 28299-305.

Kaplan, C.P., Porter, R.K., Br, M.D. and Brand, M.D. (1993). "The choline transporter is the major site of control of choline oxidation in isolated rat liver mitochondria." FEBS Lett 321(1): 24-6.

Keser, I., Ilich, J.Z., Vrkić, N., Giljević, Z. and Colić Barić, I. (2013). "Folic acid and vitamin $\mathrm{B}(12)$ supplementation lowers plasma homocysteine but has no effect on serum bone turnover markers in elderly women: a randomized, double-blind, placebo-controlled trial." Nutr Res 12(1): 20-5. 
Kharb, K.K., Todero, R.L., Thomes, P.G., Orlicky, D.J., Osna, N.A., French, S.W. and Tuma, D.J. (2014). "Increased methylation demand exacerbates ethanol-induced liver injury.” Exp Mol Pathol 97(1): 1-8.

Kim Y.I. (2005). "Nutritional epigenetics: impact of folate deficiency on DNA methylation and colon cancer susceptibility." J Nutr 135(11): 2703-9.

Kim, T.H., Yang, J., Darling, P.B. and O'Connor, D.L. (2004). "A large pool of available folate exists in the large intestine of human infants and piglets." J Nutr 134(6): 1389-94.

Koletzko, B., Baker, S., Cleghorn, G., Neto, U.F., Gopalan, S., Hernell, O., Hock, Q.S., Jirapinyo, P., Lonnerdal, B., Pencharz, P., Pzyrembel, H., Ramirez-Mayans, J., Shamir, R., Turck, D., Yamashiro, Y. and Zong-Yi, D. (2005). "Global standard for the composition of infant formula: recommendations of an ESPGHAN coordinated international expert group.” J Pediatr Gastroenterol Nutr 41(5): 584-99.

Kotsopoulos, J., Sohn, K.J. and Kim, Y.I. (2008). "Postweaning dietary folate deficiency provided through childhood to puberty permanently increases genomic DNA methylation in adult rat liver." J Nutr 138(4): 703-9.

Kutzbach, C. and Stokstad, E.L (1971). "Mammalian methylenetetrahydrofolate reductase. Partial purification, properties, and inhibition by S-adenosylmethionine." Biochim Biophys Acta 250(3): 459-77.

La Haba, G. and Cantoni, G. L. (1959). "The enzymatic synthesis of S-adenosyl-Lhomocysteine from adenosine and homocysteine." J Biol Chem 234(3): 603-8.

Langley-Evans, S.C. (2000). "Critical differences between two low protein diet protocols in the programming of hypertension in the rat." Int J Food Sci Nutr 51(1): 11-7.

Li, Z. and Vance, D.E. (2008). "Phosphatidylcholine and choline homeostasis." J Lipid Res 49(6):1187-94.

Lillycrop, K.A., Phillips, E.S., Jackson, A.A., Hanson, M.A. and Burdge, G.C. (2005). "Dietary protein restriction of pregnant rats induces and folic acid supplementation prevents epigenetic modification of hepatic gene expression in the offspring." J Nutr 135(6):1382-6.

Lindahl, G., Young, J.F., Oksbjerg, N. and Andersen, H.J. (2006). "Influence of dietary creatine monohydrate and carcass cooling rate on colour characteristics of pork loin from different pure breeds." Meat Sci 72(4): 624-34. 
Loike, J.D., Somes, M. and Silverstein, S.C. (1986). "Creatine uptake, metabolism, and efflux in human monocytes and macrophages." Am J Physiol 251(1 Pt 1): C128-35.

Lucock, M. and Yates, Z. (2009). "Folic acid fortification: a double-edged sword." Curr Opin Clin Nutr Metab Care 12(6): 555-64.

Martínez-Chantar, M.L., Vázquez-Chantada, M., Ariz, U., Martínez, N., Varela, M., Luka, Z., Capdevila, A., Rodríguez, J., Aransay, A.M., Matthiesen, R., Yang, H., Calvisi, D.F., Esteller, M., Fraga, M., Lu, S.C., Wagner, C., Mato, J.M. (2008). "Loss of the glycine N-methyltransferase gene leads to steatosis and hepatocellular carcinoma in mice." Hepatology 47(4): 1191-9.

Martínez-Uña, M., Varela-Rey, M., Cano, A., Fernández-Ares, L., Beraza, N., Aurrekoetxea, I., Martínez-Arranz, I., García-Rodríguez, J.L., Buqué, X., Mestre, D., Luka, Z., Wagner, C., Alonso, C., Finnell, R.H., Lu, S.C., Martínez-Chantar, M.L., Aspichueta, P., Mato, J.M. (2013) "Excess S-adenosylmethionine reroutes phosphatidylethanolamine towards phosphatidylcholine and triglyceride synthesis. Hepatology." 58(4): 1296-305.

Matthews, J.O., Southern, L.L., Higbie, A.D., Persica, M.A. and Bidner, T.D. (2001). "Effects of betaine on growth, carcass characteristics, pork quality, and plasma metabolites of finishing pigs.” J Anim Sci 79(3): 722-8.

McCann J.C., Hudes M. and Ames B.N. (2006). "An overview of evidence for a causal relationship between dietary availability of choline during development and cognitive function in offspring." Neurosci Biobehav Rev 30(5): 696-712.

McGuire, D.M., Gross, M.D., van Pilsum, J.F. and Towle, H.C. (1984). "Repression of rat kidney L-arginine:glycine amidinotransferase synthesis by creatine at a pretranslational level." J Biol Chem 259(19): 12034-8.

McKeever, M.P., Weir, D.G., Molloy, A. and Scott, J.M. (1991). "Betaine-homocysteine methyltransferase: organ distribution in man, pig and rat and subcellular distribution in the rat." Clin Sci (Lond) 81(4): 551-6.

McKnight, L.L., Myrie, S.B., Mackay, D.S., Brunton, J.A., Bertolo, R.F. (2012). "Glucose tolerance is affected by visceral adiposity and sex, but not birth weight, in Yucatan miniature pigs.” Appl Physiol Nutr Metab 37(1): 106-14.

McMillen, I.C. and Robinson, J.S. (2005). "Developmental origins of the metabolic syndrome: prediction, plasticity, and programming." Physiol Rev 85(2): 571-633. 
McRae, M.P. (2013). "Betaine supplementation decreases plasma homocysteine in healthy adult participants: a meta-analysis.” J Chiropr Med 12(1): 20-5.

Meck, W.H. and Williams, C.L. (2003). "Metabolic imprinting of choline by its availability during gestation: implications for memory and attentional processing across the lifespan." Neurosci and Biobehav Rev 27(4): 385-99.

Michiels, J., Maertens, L., Buyse, J., Lemme, A., Rademacher, M., Dierick, N.A. and De Smet, S. (2012). "Supplementation of guanidinoacetic acid to broiler diets: Effects on performance, carcass characteristics, meat quality, and energy metabolism." Poult Sci 91(2): 402-12.

Miller, E.R. and Ullrey, D.E. (1987). "The pig as a model for human nutrition." Annu Rev Nutr 7: 361-82.

Miller, J., Nadeau, M., Smith, J., Smith, D. and Selhub, J. (1994). "Folate-deficiencyinduced homocysteinaemia in rats: disruption of S-adenosylmethionine's co-ordinate regulation of homocysteine metabolism.” Biochem J. 298 (Pt 2): 415-9.

Millian, N.S. and Garrow T.A. (1998). "Human betaine-homocysteine methyltransferase is a zinc metalloenzyme 1"Arch Biochem Biophys 356(1): 93-8.

Motokawa, Y. and Kikuchi, G. (1971). "Glycine metabolism in rat liver mitochondria. V. Intramitochondrial localization of the reversible glycine cleavage system and serine hydroxymethyltransferase.” Arch Biochem Biophys 146(2): 461-4.

Mudd, S.H. and Poole, J.R. (1975). "Labile methyl balances for normal humans on various dietary regimens." Metabolism 24(6): 721-35.

Mudd, S.H., Finkelstein, J.D., Irreverre, F. and Laster, L. (1965). "Transsulfuration in mammals. Microassays and tissue distributions of three enzymes of the pathway." J Biol Chem 240(11): 4382-92.

Mudd, S.H., Brosnan, J.T., Brosnan, M.E., Jacobs, R.L., Stabler, S.P., Allen, R.H., Vance, D.E. and Wagner, C. (2007). "Methyl balance and transmethylation fluxes in humans." Am J Clin Nutr 85(1): 19-25.

Myrie, S.B., McKnight, L.L, Van Vliet, B.N. and Bertolo, R.F. (2008). "Early development of excess visceral fat is associated with the development of metabolic syndrome in small birth weight pigs." Appl Physiol Nutr Metab 33: 627. 
Myrie, S.B., McKnight, L.L., Van Vliet, B.N. and Bertolo R.F. (2011). "Low birth weight is associated with reduced nephron number and increased blood pressure in adulthood in a novel spontaneous intrauterine growth-restricted model in Yucatan miniature swine." Neonatology 100(4): 380-6.

Myrie, S.B., MacKay, D.S., van Vliet, B.N. and Bertolo, R.F. (2012). "Early programming of adult blood pressure in the low birth weight Yucatan miniature pig is exacerbated by a post-weaning high-salt-fat-sugar diet.” Br J Nutr 108(7): 1218-25.

Nakamura, H., Yatsuki, J. and Ubuka, T. (2006). "Production of hypotaurine, taurine and sulfate in rats and mice injected with L-cysteinesulfinate." Amino Acids 31(1): 27-33.

Noga, A.A. and Vance, D.E. (2003). "Insights into the requirement of phosphatidylcholine synthesis for liver function in mice.” J Lipid Res 44(10): 1998-2005.

Nosworthy, M.G., Bertolo, R.F., Brunton, J.A. (2013). "Ontogeny of dipeptide uptake and peptide transporter 1 (PepT1) expression along the gastrointestinal tract in the neonatal Yucatan miniature pig." Br J Nutr 110(2): 275-81.

Ogawa, H. and Fujioka, M. (1982). "Purification and properties of glycine Nmethyltransferase from rat liver.” J Biol Chem 257(7): 3447-52.

Olinger, E.J., Bertino, J.R. and Binder, H.J. (1973). "Intestinal Folate Absorption.” J Clin Investig 52(9): 2138-45.

Osterhues, A., Ali, N.S. and Michels, K.B. (2013). "The role of folic acid fortification in neural tube defects: a review.” Crit Rev Food Sci Nutr 53(11): 1180-90.

Ostojic, S.M., Niess, B., Stojanovic, M. and Obrenovic, M. (2013). "Creatine metabolism and safety profiles after six-week oral guanidinoacetic acid administration in healthy humans." Int J Med Sci 10(2): 141-7.

Park, E.I. and Garrow, T.A. (1999). "Interaction between dietary methionine and methyl donor intake on rat liver betaine-homocysteine methyltransferase gene expression and organization of the human gene." J Biol Chem 274(12): 7816-24.

Peña-Altamira, E., Crochemore, C., Virgili, M. and Contestabile, A. (2005). "Neurochemical correlates of differential neuroprotection by long-term dietary creatine supplementation.” Brain Res 1058(1-2): 183-8.

Plagemann, A., Harder, T., Brunn, M., Harder, A., Roepke, K., Melchior, K. and Dudenhausen, J.W. (2009). "Hypothalamic proopiomelanocortin promoter methylation 
becomes altered by early overfeeding: an epigenetic model of obesity and the metabolic syndrome." J Physiol. 587(Pt 20): 4963-76.

Porter, R.K., Scott, J.M. and Brand M.D. (1993). "Characterization of betaine efflux from rat liver mitochondria.” Biochim Biophys Acta 1141(2-3): 269-74.

Pritchard, P.H. and Vance, D.E. (1981). "Choline metabolism and phosphatidylcholine biosynthesis in cultured rat hepatocytes." Biochem J 196(1): 261-7.

Reamon-Buettner, S.M., Buschmann, J. and Lewin, G. (2014). "Identifying placental epigenetic alterations in an intrauterine growth restriction (IUGR) rat model induced by gestational protein deficiency." Reprod Toxicol 45: 117-24.

Rees, W.D., Hay, S.M. and Cruickshank, M. (2006). "An imbalance in the methionine content of the maternal diet reduces postnatal growth in the rat." Metabolism 55(6): 76370 .

Ridgway, N.D. and Vance, D.E. (1987). "Purification of phosphatidylethanolamine Nmethyltransferase from rat liver." J Biol Chem 262(35): 17231-9.

Ridgway, N.D., Yao, Z. and Vance, D.E. (1989). "Phosphatidylethanolamine levels and regulation of phosphatidylethanolamine N-methyltransferase." J Biol Chem 264(2): 12037.

Riedijk, M.A., Stoll, B., Chacko, S., Schierbeek, H., Sunehag, A.L., van Goudoever, J.B. and Burrin, D.G. (2007). "Methionine transmethylation and transsulfuration in the piglet gastrointestinal tract." Proc Natl Acad Sci USA 104(9): 3408-13.

Rowling, M.J., McMullen, M.H., Chipman, D.C. and Schalinske, K.L. (2002). "Hepatic glycine $\mathrm{N}$-methyltransferase is up-regulated by excess dietary methionine in rats." J Nutr 132(9): 2545-50.

Schubert, H.L., Blumenthal, R.M. and Cheng, X. (2003). "Many paths to methyltransfer: a chronicle of convergence.” Trends Biochem Sci 28(6): 329-35.

Scott, J.M. (1999). "Folate and vitamin B12.” Proc Nutr Soc 58(2) 441-8.

Shoveller, A.K., Brunton, J.A., House, J.D., Pencharz, P.B. and Ball, R.O. (2003a). "Dietary cysteine reduces the methionine requirement by an equal proportion in both parenterally and enterally fed piglets." J Nutr 133(12): 4215-24. 
Shoveller, A.K., Brunton, J.A., Pencharz, P.B. and Ball, R.O. (2003b). "The methionine requirement is lower in neonatal piglets fed parenterally than in those fed enterally." $\mathrm{J}$ Nutr 133(5): 1390-7.

Sinclair, K.D., Allegrucci, C., Singh, R., Gardner, D.S., Sebastian, S., Bispham, J., Thurston, A., Huntley, J.F., Rees, W.D., Maloney, C.A., Lea, R.G., Craigon, J., McEvoy, T.G. and Young, L.E. (2007). "DNA methylation, insulin resistance, and blood pressure in offspring determined by maternal periconceptional B vitamin and methionine status." Proc Natl Acad Sci USA 104(49):19351-6.

Smith, A.M., Picciano, M.F. and Deering, R. H. (1985). "Folate intake and blood concentrations of term infants." Am J Clin Nutr 41(3): 590-8.

Stead, L.M., Brosnan, J.T., Brosnan, M.E., Vance, D.E. and Jacobs, R.L. (2006). "Is it time to reevaluate methyl balance in humans?" Am J Clin Nutr 83(1):5-10.

Stead, L.M., Au, K.P., Jacobs, R.L., Brosnan, M.E. and Brosnan, J.T. (2001). "Methylation demand and homocysteine metabolism: effects of dietary provision of creatine and guanidinoacetate." Am J Physiol Endocrinol Metab 281(5): E1095-100.

Steenge, G. and Verhoef, P. (2001). "The effect of creatine and resistance training on plasma homocysteine concentration in healthy volunteers." Arch Intern Med 161(11): 1455-6.

Stipanuk, M.H., Londono, M., Lee, J., Hu, M. and Yu, A.F. (2002). "Enzymes and metabolites of cysteine metabolism in nonhepatic tissues of rats show little response to changes in dietary protein or sulfur amino acid levels." J Nutr 132(11): 3369-78.

Taes, Y., Delanghe, J. and Bacquer, D. (2004). "Creatine supplementation does not decrease total plasma homocysteine in chronic hemodialysis patients." Kidney Int 66(6): 2422-8.

Tate, P.H. and Bird, A.P. (1993). "Effects of DNA methylation on DNA-binding proteins and gene expression." Curr Opin Genet Dev 3(2): 226-31.

Teng, Y., Cerdena, I. and Zeisel, S.H. (2012). "Homocysteinemia in mice with genetic betaine homocysteine S-methyltransferase deficiency is independent of dietary folate intake." J Nutr 142(11): 1964-7.

Terjung, R.L., Clarkson, P., Eichner, E.R., Greenhaff, P.L., Hespel, P.J., Israel, R.G., Kraemer, W.J., Meyer, R.A., Spriet, L.L., Tarnopolsky, M.A., Wagenmakers, A.J. and Williams, M.H. (2000). "American College of Sports Medicine roundtable. The 
physiological and health effects of oral creatine supplementation." Med Sci Sports Exerc 32(3): 706-17.

Thomas, B., Gruca, L.L., Bennett, C., Parimi, P.S., Hanson, R.W. and Kalhan, S.C. (2008). "Metabolism of methionine in the newborn infant: response to the parenteral and enteral administration of nutrients." Pediatr Res 64(4): 381-6.

Thompson, H.R., Jones, G.M. and Narkewicz, M.R. (2001). "Ontogeny of hepatic enzymes involved in serine- and folate-dependent one-carbon metabolism in rabbits." Am J Physiol Gastrointest Liver Physiol 280(5): G873-8.

Vandenbosche, R.C. and Kirchner, J.T. (1998). "Intrauterine growth retardation." Am Fam Physician 58(6):1384-90.

Walker, J.B. (1960). "Metabolic control of creatine biosynthesis. I. Effect of dietary creatine." J Biol Chem 235: 2357-61.

Walkey, C.J., Yu, L., Agellon, L.B. and Vance, D.E. (1998). "Biochemical and evolutionary significance of phospholipid methylation." J Biol Chem 273(42): 27043-6.

Wallimann, T., Wyss, M., Brdiczka, D., Nicolay, K. and Eppenberger, H.M. (1992). "Intracellular compartmentation, structure and function of creatine kinase isoenzymes in tissues with high and fluctuating energy demands: the 'phosphocreatine circuit' for cellular energy homeostasis.” Biochem J 281 ( Pt 1): 21-40.

WHO. (1995). "Physical status: the use and interpretation of anthropometry." Report of a WHO Expert Committee World Health Organization Technical Report Series 854: 1-452.

Wilson, F.A., van den Borne, J.J., Calder, A.G., O'Kennedy, N., Holtrop, G., Rees, W.D. and Lobley, G.E. (2009). "Tissue methionine cycle activity and homocysteine metabolism in female rats: impact of dietary methionine and folate plus choline." Am J Physiol Endocrinol Metab 296(4): E702-13.

Wu, G., Ott, T.L., Knabe, D.A., Bazer, F.W. (1999). "Amino acid composition of the fetal pig." J Nutr 129(5): 1031-8.

Wyss, M. and Kaddurah-Daouk, R. (2000). "Creatine and creatinine metabolism." Physiol Rev 80(3): 1107-213.

Yao, Z.M. and Vance, D.E. (1988). "The active synthesis of phosphatidylcholine is required for very low density lipoprotein secretion from rat hepatocytes." J Biol Chem 263(6): 2998-3004. 
Yates, A.A., Schlicker, S.A. and Suitor, C.W. (1998). "Dietary reference intakes." J Am Diet Assoc 98(6): 699-706.

Young, J.F., Bertram, H.C., Rosenvold, K., Lindahl, G. and Oksbjerg, N. (2005). "Dietary creatine monohydrate affects quality attributes of Duroc but not Landrace pork." Meat Sci 70(4): 717-25.

Zlotkin, S.H. and Anderson, G.H. (1982). "The development of cystathionase activity during the first year of life." Pediatr Res 16(1): 65-8. 
CHAPTER 2 - Intrauterine growth restriction leads to changes in sulfur amino acid metabolism, but not global DNA methylation, in Yucatan miniature piglets

J Nutr Biochem. 2012 Sep;23(9):1121-7

Dylan S. MacKay, Julie D. Brophy, Laura E. McBreairty, Ross A. McGowan, Robert F. Bertolo $^{\S}$

Chapter 2 was primarily designed by R. Bertolo. L. McBreairty analyzed plasma homocysteine and cysteine, tissue free amino acids and metabolites and transglutaminase activity. The manuscript was prepared by D. Mackay and R. Bertolo. The final manuscript was read and approved by all authors. 


\subsection{Abstract}

Intrauterine growth restriction (IUGR), in both animals and humans, has been linked to metabolic syndrome later in life. There has been recent evidence that perturbations in sulfur amino acid metabolism may be involved in this early programming phenomenon. Methionine is the precursor for cellular methylation reactions and for the synthesis of cysteine. It has been suggested that the mechanism behind the "fetal origins" of adult diseases may be epigenetic, involving DNA methylation. Because we have recently demonstrated the fetal origins phenomenon in Yucatan miniature swine, we hypothesized that sulfur amino acid metabolism is altered in IUGR piglets. In this study metabolites and the activities of sulfur amino acid cycle enzymes were analyzed in liver samples of 35-d-old runt (IUGR: $0.85 \pm 0.13 \mathrm{~kg})$ and large $(1.36 \pm 0.21 \mathrm{~kg})$ Yucatan miniature pig littermates ( $n=6$ pairs). IUGR piglets had significantly lower specific and total activities of betaine-homocysteine methyl transferase (BHMT) and cystathionine $\gamma$-lyase (CGL), than larger littermates $(P<0.05)$. Expression of CGL (but not BHMT) mRNA was also lower in IUGR piglets $(P<0.05)$. This low CGL reduced cysteine and taurine concentrations in IUGR pigs and led to an accumulation of hepatic cystathionine, with lower homocysteine concentrations. Methylation index and liver global DNA methylation were unaltered. Reduced prenatal growth in Yucatan miniature piglets impairs their remethylation capacity as well as their ability to remove cystathionine and synthesize cysteine and taurine, which could have important implications on long term health outcomes of IUGR neonates. 


\subsection{Introduction}

The "fetal origins" of adult disease hypothesizes that factors in utero can affect the development of disease later in life [1]. Many studies in both animals and humans have demonstrated links between prenatal growth rate and adult diseases, including obesity, cardiovascular diseases and type 2 diabetes [2]. Because the initial hypotheses generated from epidemiological data implicated small birth weight, the most successful animal model in fetal programming has been the protein-deficient rat dam [3]. The intrauterine growth-restricted (IUGR) rat pups became adult rats that exhibited symptoms of various chronic diseases such as obesity, coronary heart disease, hypertension, glucose intolerance, appetite dysregulation and osteoporosis [3]. In addition, postnatal catch-up growth in growth retarded pups also led to reduced longevity and increased hypertension, similar to epidemiological data [4]. Recently, the protein-deficient rat dams were found to be hyperhomocysteinemic because the low protein diet was disproportionately high in methionine and low in cysteine (Figure 2.1) [5-7]. Hyperhomocysteinemia in pregnancy has been linked to intrauterine growth retardation [8] and hyperhomocysteinemia in children has been linked to development of obesity and hypertension [9]. Because the mediating mechanism of fetal programming does not seem to be protein deficiency per se, focus has been more recently directed toward imbalance of sulfur amino acid metabolism as a potential mechanism for this phenomenon. Indeed, Rees [7] concluded that changes in cell function only occur when the metabolism of sulfur amino acids is disturbed. 
Methionine is required for protein synthesis and for oxidation to synthesize cysteine; the oxidation to cysteine involves both transmethylation and transsulfuration pathways (Figure 2.1). However, the oxidative enzymes in the transsulfuration pathway are low in utero and may be limiting for cysteine synthesis [10,11]. With intrauterine growth retardation, where nutrient flow to the fetus is reduced, oxidative pathways are further reduced due to less substrate availability. In the postnatal situation, compensatory growth following IUGR involves more efficient use of nutrients which, for amino acids, usually also involves a downregulation of oxidative pathways [12]. So, IUGR neonates have an imbalanced methionine metabolism such that oxidation, or transsulfuration, is reduced leading to a potential accumulation of homocysteine.

One of the key transmethylation reactions is methylation of DNA, which is an inheritable mechanism regulating gene expression [13]. Indeed, such epigenetic changes have been proposed as the underlying mechanisms in the plasticity associated with early development which can plausibly program risk for disease in later life $[13,14]$. Methylation of DNA can be affected by dietary levels of methyl-donor components, such as methionine, choline and folate [13,15]. Moreover, in fetuses of rat dams fed methionine-imbalanced low protein diets, global methylation of DNA was increased in several tissues, including the fetal liver [6]. Thus, changes in sulfur amino acid metabolism have been suggested as a possible mechanism by which environmental influences during fetal development could permanently affect fetal nutrition [7].

More recently, we $[16,17]$ and others $[18,19]$ have validated the pig as a model for early programming by demonstrating that the naturally occurring runt IUGR pig develops 


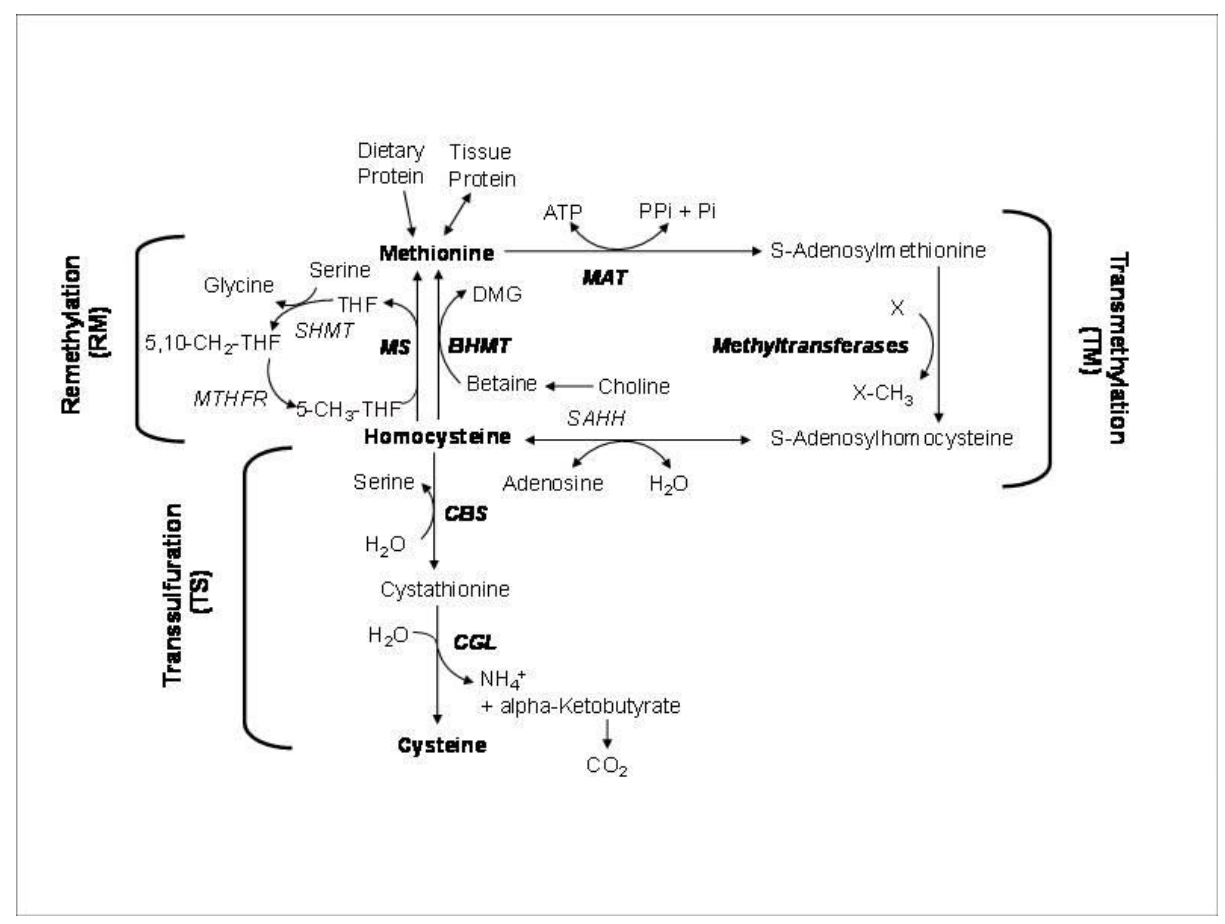

Figure 2.1 Schematic of pathways in sulfur amino acid metabolism. Abbreviations: MAT, methionine adenosyltransferase; SAHH, S-adenosylhomocysteine hydrolase; CBS, cystathionine $\beta$-synthase; CGL, cystathionine $\gamma$-lyase; MS, methionine synthase; BHMT, betaine:homocysteine methyltransferase; SHMT, serine hydroxymethyltransferase; MTHFR, methylenetetrahydrofolate reductase; THF, tetrahydrofolate; DMG, dimethylglycine. 
biomarkers for hypertension, diabetes, obesity and dyslipidemia early in adulthood, compared to larger siblings. The pig has distinct advantages over rodent models of this phenomenon in that postnatal metabolism can be studied and the nutritional requirements of the pig are more similar to those of the human, especially with respect to amino acids [20]. Therefore, using the Yucatan miniature piglet as a model, we hypothesized that the lowered fetal nutrition which caused the subsequent low birth weight of the runt would also result in a decrease in the activity of the enzymes that facilitate the removal of excess sulfur amino acids, such as methionine and homocysteine. The imbalanced metabolic pathways and accumulation of homocysteine would also modify the methylation of DNA, thereby affecting the long term regulation of gene expression and perhaps explaining the higher risk for chronic diseases later in life observed in IUGR piglets [16-19]. The main objectives of this study are: 1) to determine if IUGR limits the capacity of certain sulfur amino acid enzymes; 2) to determine if IUGR affects expression of altered sulfur amino acid enzymes; and 3) to determine if IUGR affects global methylation of DNA as a result of sulfur amino acid enzyme alterations.

\subsection{Methods and materials}

Reagents. L-[3- $\left.{ }^{14} \mathrm{C}\right]$ serine was obtained from American Radiolabeled Chemicals, Inc. (St. Louis, MO) and 5-[ $\left.{ }^{14} \mathrm{C}\right]$ methyl-tetrahydrofolic acid, barium salt was from Amersham Biosciences UK Limited (Buckinghamshire, UK). L- $\left[1-{ }^{14} \mathrm{C}\right]$ methionine and $N, N, N-$ trimethyl [methyl $-{ }^{14} \mathrm{C}$ ]glycine $\left({ }^{14} \mathrm{C}\right.$-betaine) were acquired from Moravek Biochemicals (Brea, CA). The poly-prep pre-filled chromatography columns (AG 1-X8, AG1-X4, and AG50W-X4 resins, 200-400 mesh, 0.8 x 4 cm) were obtained from Bio-Rad Laboratories, 
Inc. (Hercules, CA). All other chemicals were of analytical grade and were from Sigma (St. Louis, MO) or Fisher Scientific (Fair Lawn, NJ).

Animals. Yucatan miniature piglets $(n=12)$ were obtained from the Memorial University of Newfoundland breeding colony. Animal care and handling procedures were approved by the Institutional Animal Care Committee and in accordance with the guidelines of the Canadian Council on Animal Care. Six pairs of littermates, each consisting of a spontaneously occurring runt ( 3 male, 3 female) and its largest littermate ( 2 male, 4 female), were removed from sows at 3-5 d of age. For the purposes of this study, a runt (i.e., IUGR) was defined as the smallest piglet in a litter that was at least $25 \%$ smaller than its largest littermate at birth. In this herd of Yucatan pigs, piglets fitting these parameters occur naturally in $\sim 90 \%$ of litters. Within $1 \mathrm{~h}$ of removal from the sow, pigs were anesthetized with halothane and blood was sampled via cardiac puncture and centrifuged immediately at $1500 \times \mathrm{g}$ for $10 \mathrm{~min}$ at $4^{\circ} \mathrm{C}$ to isolate plasma; since pigs were within 1.5-2 h of last suckling, piglets were in fed state. Organs (liver, kidneys, colon, small intestine, lung, and heart) were removed quickly under anesthesia, weighed and samples were immediately frozen in liquid nitrogen and stored at $-80^{\circ} \mathrm{C}$ until further analyses.

Liver homogenate preparation. Approximately 0.5-1.5 g of frozen liver was weighed and kept on ice. A homogenate of liver and $50 \mathrm{mM}$ potassium phosphate dibasic ( $\mathrm{pH} 7.0$ ) buffer (1:5) was freshly prepared on ice using a Polytron homogenizer (Brinkmann Instruments, Mississauga, ON, Canada) for $30 \mathrm{~s}$ at $50 \%$ output. The homogenate was centrifuged at $20000 \times \mathrm{g}$ for $30 \mathrm{~min}$ at $4^{\circ} \mathrm{C}$ (Beckman L8 - M Ultracentrifuge) and the 
supernatant was removed and used immediately to measure the activities of sulfur amino acid metabolism enzymes. Homogenates were centrifuged at $13000 \times \mathrm{g}$ for $5 \mathrm{~min}$ at $4^{\circ} \mathrm{C}$. Protein concentration of homogenates was determined using the Biuret assay using porcine serum albumin as a standard.

Metabolite analyses. Total homocysteine and cysteine concentrations [21], S-adenosyl-Lmethionine (SAM) and S-adenosyl-L-homocysteine (SAH) concentrations [22] and cystathionine concentrations [23] were determined by high-performance liquid chromatography (HPLC); all samples were first reduced with tris(2carboxyethyl)phosphine. Other amino acids were determined by reverse-phase HPLC using phenylisothiocyanate derivatives [24]. Plasma urea concentrations were determined using a spectrophotometric assay kit (Sigma Chemical Co., St. Louis, MO).

Enzyme assays. We measured the activities of three enzymes involved in the remethylation of homocysteine to methionine-methionine synthase (MS), betaine:homocysteine methyltransferase (BHMT), and methylenetetrahydrofolate reductase (MTHFR) — and three enzymes involved in catabolism of methionine to cysteine - methionine adenosyltransferase (MAT), cystathionine $\beta$-synthase (CBS), and cystathionine $\gamma$-lyase (CGL). All assays were first demonstrated to be linear with respect to time (0-60 $\mathrm{min})$ and protein concentration (0-2 $\mathrm{mg})$. Specific activities were expressed as nmol of product per minute per mg protein. The hepatic enzyme capacity (nmol of product/min/kg body weight) was determined for each animal by multiplying the enzyme specific activity by the total protein content in the whole liver (ie mg protein/g wet liver $\times$ total liver weight) and correcting for body weight. Protein content of the liver was 
determined using a combustion method (Application Note-154 for FP-528, LECO Instruments, Mississauga, ON, Canada) and analyzing for total elemental nitrogen; a factor of $6.25 \mathrm{~g}$ protein/g nitrogen was used to convert nitrogen to protein. Hepatic transglutaminase activity was measured using a colorimetric microassay as per kit instructions (Covalab - UK Ltd., Cambridge, UK).

Methionine synthase. MS was measured using an assay described by Koblin et al. [25]. Briefly, liver homogenate $(100 \mu \mathrm{L}$ of $2 \mathrm{mg} / \mathrm{mL})$ was mixed with $100 \mu \mathrm{L}$ substrate mixture (20 $\mu \mathrm{M}$ cyanocobalamin, $58 \mathrm{mM}$ dithiothreitol (DTT), $0.5 \mathrm{mM}$ S-adenosylmethionine (SAM), $15 \quad \mathrm{mM} \quad$ DL-homocysteine, $14 \quad \mathrm{mM} \quad \beta$-mercaptoethanol, $1 \mathrm{mM}$ methyltetrahydrofolate with $2.5 \mu \mathrm{Ci}$ of $5-\left[{ }^{14} \mathrm{C}\right]$ methyl-tetrahydrofolic acid, and $175 \mathrm{mM}$ potassium phosphate buffer, $\mathrm{pH}$ 7.5), capped with nitrogen and incubated in the dark at $37^{\circ} \mathrm{C}$ for $30 \mathrm{~min}$. The reaction was stopped with $400 \mu \mathrm{L}$ cold deionized water and stored on ice. The product, ${ }^{14} \mathrm{C}$-methionine, was separated from the reactant, 5 - $\left[{ }^{14} \mathrm{C}\right]$ methyltetrahydrofolic acid, by ion-exchange column (AG 1-X8 resin, 200-400 mesh) and counted for radioactivity.

Betaine:homocysteine methyltransferase. BHMT activity was measured with an assay described by Garrow [26]. Briefly, liver homogenate (100 $\mu \mathrm{L}$ of $15 \mathrm{mg} / \mathrm{mL})$ was added to the assay mixture $\left(5 \mathrm{mM}\right.$ DL-homocysteine, $2 \mathrm{mM}$ betaine with $0.1 \mu \mathrm{Ci}$ of ${ }^{14} \mathrm{C}$-betaine, and $50 \mathrm{mM}$ Tris, $\mathrm{pH} \mathrm{7.5)}$ and incubated at $37^{\circ} \mathrm{C}$ for $20 \mathrm{~min}$; the reaction was stopped with $2.5 \mathrm{~mL}$ of cold deionized water and stored on ice. The samples $(2 \mathrm{~mL})$ were then applied to columns. The unreacted betaine was washed from a column (Dowex AG1-X4, 200-400 
mesh, hydroxide form) with deionized water and radiolabeled dimethylglycine and methionine were eluted with $3 \mathrm{~mL}$ of $1.5 \mathrm{M} \mathrm{HCl}$ and counted for radioactivity.

Methylenetetrahydrofolate reductase. MTHFR activity was measured using the assay described by Engbersen et al. [27]. Briefly, liver homogenate (100 $\mu \mathrm{L}$ of $5 \mathrm{mg} / \mathrm{mL})$ was added to $400 \mu \mathrm{L}$ of assay mixture $(0.27 \mathrm{M}$ potassium phosphate, $1.72 \mathrm{mM}$ Ethylenediaminetetraacetic acid (EDTA), $17.25 \mathrm{mM}$ ascorbic acid, $81 \mu \mathrm{M}$ flavin adenine dinucleotide (FAD), $21 \mathrm{mM}$ menadione, $30 \mu \mathrm{M} 5-\left[{ }^{14} \mathrm{C}\right]$ methyl-tetrahydrofolic acid, $\mathrm{pH}$ 6.8) and incubated in the dark at $37^{\circ} \mathrm{C}$ for $20 \mathrm{~min}$; the reaction was stopped with $100 \mu \mathrm{L} 3$ M potassium acetate, $(\mathrm{pH} 4.5), 200 \mu \mathrm{L}$ dimedone $(50 \mu$ mol dimedone in $200 \mu \mathrm{L} 1: 1$ ethanol:water), and $10 \mu \mathrm{L}$ of $1 \mathrm{M}$ formaldehyde and then immediately placed in $95^{\circ} \mathrm{C}$ water bath for $15 \mathrm{~min}$ and cooled on ice for $10 \mathrm{~min}$. After addition of $3 \mathrm{~mL}$ of toluene, samples were vortexed, centrifuged at low speed and the toluene phase was measured for radioactivity.

Methionine adenosyltransferase. MAT activity was assayed using the method of Duce et al. [28]. Briefly, $30 \mu \mathrm{L}$ of homogenate $(20 \mathrm{mg} / \mathrm{mL})$ was added to $200 \mu \mathrm{L}$ of assay mixture (125 mM Tris $\mathrm{HCl}, 250 \mathrm{mM} \mathrm{KCl}, 12.5 \mathrm{mM} \mathrm{MgCl} 2,1.25 \mathrm{mM}$ DTT, and $6.25 \mathrm{mM}$ ATP, $\mathrm{pH} 7.80$ ) and equilibrated at $37^{\circ} \mathrm{C}$. Reaction was started by adding $20 \mu \mathrm{L}$ of $62.5 \mathrm{mM}$ ${ }^{14} \mathrm{C}$-methionine and incubated in the dark at $37^{\circ} \mathrm{C}$ for $45 \mathrm{~min}$. Reaction was stopped with $750 \mu \mathrm{L}$ of cold water and stored on ice. Labeled product was eluted on columns (Biorad 50W-X4 resin, 200-400 mesh, $\mathrm{NH}_{4}$ form) with $3 \mathrm{M} \mathrm{NH}_{4} \mathrm{OH}$ and measured for radioactivity. 
Cystathionine $\beta$-synthase. The CBS assay was performed as described by Taoka et al. [29]. Briefly, liver homogenate $(150 \mu \mathrm{L}$ of $15 \mathrm{mg} / \mathrm{mL})$ was combined with $400 \mu \mathrm{L}$ of substrate mixture $(0.219 \mathrm{mM}$ L-cystathionine, $62.5 \mathrm{mM}$ DL-homocysteine, $3.125 \mathrm{mM}$ DL-propargglycine, $0.38 \mathrm{mM}$ SAM, and $0.625 \mathrm{mM}$ pyridoxal-5-phosphate (PLP) in 187.5 mM Tris- $\mathrm{HCl} / 3.125 \mathrm{mM}$ EDTA, $\mathrm{pH} 8.3$ ) and allowed to equilibrate at $37^{\circ} \mathrm{C}$. Fifty $\mu \mathrm{L}$ of $300 \mathrm{mM}{ }^{14} \mathrm{C}$-serine $(0.1 \mu \mathrm{Ci})$ was added to start the reaction and after $30 \mathrm{~min}$, the reaction was stopped with $300 \mu \mathrm{L}$ of cold $15 \%$ trichloroacetic acid and samples stored on ice. After centrifugation at $9000 \times \mathrm{g}$ for $10 \mathrm{~min}, 500 \mu \mathrm{l}$ of the deproteinized sample was loaded on a column (AG 50W-X4 resin, 200-400 mesh, hydrogen form) and serine was washed out with deionized water, $1 \mathrm{M}$ hydrochloric acid, followed again by deionized water. ${ }^{14} \mathrm{C}$-cystathionine, was eluted with $5 \mathrm{~mL}$ of $3 \mathrm{M} \mathrm{NaOH}$ and radioactivity was measured. This assay was light sensitive and all sample tubes were covered in aluminum foil.

Cystathionine $\gamma$-lyase. CGL was assayed as described by Stipanuk [30]. Briefly, 20\% liver homogenate was incubated with $100 \mathrm{mM}$ potassium phosphate buffer, $4.0 \mathrm{mM} \mathrm{L}$ cystathionine, $0.125 \mathrm{mM}$ pyridoxal 5'-phosphate, $0.32 \mathrm{mM}$ nicotinamide adenine dinucleotide $(\mathrm{NADH})$ and 1.5 units of lactate dehydrogenase, $\mathrm{pH}$ 7.5. The decrease in absorbance at $340 \mathrm{~nm}$ was monitored to determine activity.

Real time RT-PCR analysis of BHMT and CGL gene expression. Total RNA was obtained from liver samples by the RNeasy kit (Qiagen, Valencia, CA) and cDNA was synthesized using $1 \mu \mathrm{g}$ of total RNA using QuantiTect reverse transcription kit (Qiagen, Valencia, CA), including a genomic DNA wipeout step. PCR primers and probes for porcine 
BHMT (U53421) (forward primer, GTT CGC CAG CTT CAT C; reverse primer, CTC CAG CTT GTC CTC A; probe, CTC AGA GCC GGA TCG AAT GTC ATG C), CGL or cystathionase (DQ499449) (forward primer, CTG AGA GTT TGG GAG GAT A; reverse primer, CTT AGG CAC AGA TGA ATG A; probe, AAG TCT TGC TGA GCT TCC GGC A), and ß-actin (DQ845171) (forward primer, CCC AGC ACG ATG AAG A; reverse primer, CGA TCC ACA CGG AGT A; probe, TCA AGA TCA TCG CGC CTC CAG A) were designed using RealTimeDesign software (Biosearch technologies, Novato, CA). Expression of $ß$-actin was used as an endogenous reference to account for differences in sample loading and PCR efficiencies between reactions. Taqman probes for B-actin were labeled with reporter dye FAM on the 5' end and quencher BHQ-1 on the 3' end. Taqman probes for BHMT and CGL were labeled with reporter dye PULSAR 650 on the 3' end and quencher BHQ-2 on the 5' end. Amplification reactions were carried out using QuantiTect Multiplex PCR NoRox kit (Qiagen, Valencia, CA) for a $20 \mu \mathrm{L}$ duplex PCR reaction volume. All reactions were performed in triplicate on a LightCycler 1.2 real-time PCR system (Roche, Laval, QC, Canada). The thermal cycling conditions were $15 \mathrm{~min}$ at $95^{\circ} \mathrm{C}$ to activate HotStarTaq DNA polymerase, followed by 40 cycles of $96^{\circ} \mathrm{C}$ for $1 \mathrm{~min}$ and $55^{\circ} \mathrm{C}$ for $1 \mathrm{~min}$. A sample of reverse transcriptase reaction without reverse transcriptase enzyme, and a sample of PCR reaction mixture without cDNA were used as negative controls. Relative gene expression was calculated using a formula outlined by M. W. Pfaffl [31]; a PCR efficiency of 2.0 was used for all calculations.

Cytosine extension assay. Global methylation was estimated using the method of Pogribny et al. [32]. This method utilizes Hpa II, a methyl sensitive endonuclease which 
cuts at the sequence CCGG, if the middle CG is unmethylated, leaving an overhanging guanine nucleotide. This guanine is paired with a radiolabeled cytosine using Taq polymerase thereby estimating the amount of cleaved CCGG sequences in a DNA sample. Briefly, approximately $2 \mu \mathrm{g}$ of genomic DNA is digested overnight with a 5 -fold excess of Hpa II, according to manufacturer's protocol (NEB, Ipswich, MA). A $2 \mu \mathrm{g}$ sample of genomic DNA in digestion buffer without endonuclease serves as a background control. A single nucleotide extension reaction was performed on each digested and undigested DNA sample in $25 \mu \mathrm{L}$ reaction mixture containing $2 \mu \mathrm{g}$ digested DNA, $2.5 \mu \mathrm{L}$ $10 \mathrm{x}$ Native Taq buffer (Invitrogen, Burlington, ON, Canada), $0.75 \mu \mathrm{L} 50 \mathrm{mM} \mathrm{MgCl}, 0.2$ $\mu \mathrm{L}$ of Native Taq polymerase, $0.2 \mu \mathrm{L}\left[{ }^{3} \mathrm{H}\right]$-Cytidine-5'-triphosphate (CTP) $(57.4 \mathrm{Ci} / \mathrm{mmol})$ (Moravek Radiochemical, Brea, CA) and incubated at $55^{\circ} \mathrm{C}$ for $1 \mathrm{~h}$. Ten $\mu \mathrm{L}$ of each reaction digest was applied to two separate D-81 ion exchange filters, and each filter was washed 3 times in sodium phosphate buffer $(\mathrm{pH}$ 7.0). The filters were dried overnight and counted for radioactivity; results were expressed as relative $\left[{ }^{3} \mathrm{H}\right]-\mathrm{dCTP}$ incorporation disintegrations per minute (DPM)/0.5 $\mu$ g of digested DNA.

Statistical analyses. All data are shown as mean \pm standard deviation (SD) and differences were considered significant at $P<0.05$. Comparisons were made using general linear model (Minitab Software version 15.1; Minitab Inc. State College, PA) with each runt-large littermate representing a matching pair. Data were analyzed using a model containing runt/large, pairing, sex and sex $\times$ runt/large interaction; non-significant parameters were removed (never runt/large) and the model reduced until the adjusted Rsquared was maximized. Analyses in which sex was a significant covariate for runt/large 
differences are indicated; all other differences were in reduced models in which runt/large and pairing were maintained. Linear regressions were performed on data versus body weight (GraphPad Prism 5, GraphPad Software Inc.). To determine whether difference in pair's birth weight was related to outcome difference, linear regressions were performed on significant outcomes, but no significant associations were found.

\subsection{Results}

Animals. At birth, IUGR piglets $(0.665 \pm 0.121 \mathrm{~kg}$; range: $0.460-0.807 \mathrm{~kg})$ were $62 \pm$ $12 \%$ (range, $45-74 \%)$ of their respective large littermates $(1.091 \pm 0.158 \mathrm{~kg}$; range: $0.929-1.332 \mathrm{~kg})(P<0.001)$ and came from litters with $7.0 \pm 1.4$ piglets (range: $5-9$ per litter). At necropsy, IUGR pigs had body weights $63 \pm 11 \%$ of their siblings and had proportionately smaller $(P<0.01)$ organs than littermates (liver: $66 \pm 14 \%$; kidneys: $62 \pm$ 9\%; colon: $72 \pm 12 \%$; small intestine mass $68 \pm 15 \%$; small intestine length $80 \pm 11 \%$ ) such that when organ measurements were corrected for body weight, no differences were observed for any organs between IUGR and littermates (Table 2.1); these data suggest no sparing effect for organ development during IUGR.

Metabolite concentrations. Plasma concentrations of urea and amino acids are displayed in Table 2.2. Of the sulfur metabolism amino acids, only plasma cysteine concentrations were significantly lower in IUGR versus large piglets $(P=0.03)$. Plasma concentrations of histidine, isoleucine, alanine, glutamate and hydroxyproline were significantly higher in IUGR piglets $(P<0.05)$; sex was a significant covariate for the plasma concentrations of histidine and isoleucine. Liver concentrations of taurine $(P=0.01)$ and homocysteine 
Table 2.1 Body weight (BWT) and organ measurements in large and runt littermate piglets

\begin{tabular}{llcc}
\hline & & Large & Runt \\
\hline Body Weight & $(\mathrm{kg})$ & $1.36 \pm 0.21^{*}$ & $0.85 \pm 0.13$ \\
Liver & $(\mathrm{g})$ & $49.6 \pm 9.2^{*}$ & $32.1 \pm 4.5$ \\
& $(\mathrm{~g} / \mathrm{kg} \mathrm{BWT})$ & $36.4 \pm 2.9$ & $37.9 \pm 2.0$ \\
Kidney & $(\mathrm{g})$ & $10.7 \pm 2.4^{*}$ & $6.4 \pm 0.8$ \\
& $(\mathrm{~g} / \mathrm{kg} \mathrm{BWT})$ & $7.8 \pm 0.7$ & $7.7 \pm 1.0$ \\
Colon & $(\mathrm{g})$ & $19.7 \pm 5.5^{*}$ & $13.9 \pm 2.9$ \\
& $(\mathrm{~g} / \mathrm{kg} \mathrm{BWT})$ & $14.7 \pm 4.3$ & $16.9 \pm 5.0$ \\
Small Intestine & $(\mathrm{g})$ & $56.0 \pm 11.7^{*}$ & $37.2 \pm 7.5$ \\
& $(\mathrm{~g} / \mathrm{kg} \mathrm{BWT})$ & $40.9 \pm 2.7$ & $43.6 \pm 2.9$ \\
& $(\mathrm{~cm})$ & $455 \pm 51^{*}$ & $362 \pm 40$ \\
& $(\mathrm{~cm} / \mathrm{kg} \mathrm{BWT})$ & $336 \pm 25$ & $429 \pm 27^{*}$
\end{tabular}

Results are mean $\pm \mathrm{SD}(n=6$ per group). $* P<0.05$ 
Table 2.2 Plasma concentrations of amino acids and urea in large and runt littermate piglets

\begin{tabular}{|c|c|c|}
\hline & Large & Runt \\
\hline Urea, mM & $4.79 \pm 1.21^{*}$ & $3.42 \pm 0.93$ \\
\hline \multicolumn{3}{|c|}{ Sulfur Metabolism Amino Acids, $\mu \mathrm{M}$} \\
\hline Methionine & $16.0 \pm 3.5$ & $15.6 \pm 3.4$ \\
\hline Homocysteine & $29.6 \pm 4.7$ & $27.7 \pm 5.0$ \\
\hline Cysteine & $99.1 \pm 14.4^{*}$ & $86.6 \pm 4.2$ \\
\hline Taurine & $140 \pm 20$ & $127 \pm 24$ \\
\hline Serine & $373 \pm 142$ & $415 \pm 87$ \\
\hline Glycine & $919 \pm 182$ & $842 \pm 116$ \\
\hline \multicolumn{3}{|c|}{ Indispensable Amino Acids, $\mu \mathrm{M}$} \\
\hline Arginine & $203 \pm 44$ & $238 \pm 67$ \\
\hline Histidine & $55.5 \pm 25.7$ & $92.3 \pm 59.9$ *a \\
\hline Isoleucine & $147 \pm 39$ & $181 \pm 37 *^{*}$ \\
\hline Leucine & $218 \pm 65$ & $260 \pm 83$ \\
\hline Lysine & $261 \pm 103$ & $333 \pm 132$ \\
\hline Phenylalanine & $101 \pm 12$ & $113 \pm 35$ \\
\hline Threonine & $169 \pm 27$ & $203 \pm 38$ \\
\hline Tryptophan & $39.6 \pm 6.7$ & $34.7 \pm 11.7$ \\
\hline Valine & $324 \pm 47$ & $357 \pm 66$ \\
\hline \multicolumn{3}{|c|}{ Dispensable Amino Acids, $\mu \mathrm{M}$} \\
\hline Alanine & $644 \pm 103$ & $841 \pm 85^{*}$ \\
\hline Asparagine & $107 \pm 24$ & $137 \pm 53$ \\
\hline Aspartate & $38.4 \pm 11.8$ & $34.6 \pm 6.8$ \\
\hline Citrulline & $96.9 \pm 36.1$ & $90.8 \pm 29.1$ \\
\hline Glutamate & $175 \pm 52$ & $246 \pm 62$ * \\
\hline Glutamine & $403 \pm 82$ & $468 \pm 181$ \\
\hline Hydroxyproline & $115 \pm 15$ & $128 \pm 15^{*}$ \\
\hline Ornithine & $131 \pm 89$ & $122 \pm 17$ \\
\hline Proline & $827 \pm 176$ & $921 \pm 262$ \\
\hline Tyrosine & $212 \pm 38$ & $259 \pm 80$ \\
\hline
\end{tabular}

Results are mean \pm S.D. ( $n=6$ per group). $* P<0.05 ;{ }^{a}$ Sex included in the model 
$(P=0.04)$ were lower but cystathionine concentrations were $35 \%$ higher $(P=0.001)$ in IUGR piglets (Table 2.3); sex was a significant covariate for hepatic cystathionine and homocysteine concentrations.

Hepatic enzyme activities. Sulfur amino acid enzyme specific activities in piglet livers are displayed in Table 2.4. Compared to large littermates, IUGR livers had lower activities of the remethylation enzyme BHMT $(P=0.012)$, as well as the transsulfuration enzyme, cystathionine $\gamma$-lyase (CGL) $(P=0.04)$. BHMT $(P=0.07)$ and CGL $(P=0.22)$ only tended to correlate with body weight. Total hepatic enzyme capacities (Table 2.5) were lower in IUGR for BHMT $(P=0.006)$ and CGL $(P=0.014)$ versus large piglets. Hepatic transglutaminase activity tended to be higher $(P=0.078)$ in IUGR piglets $(1.56 \pm 0.34$ $\mathrm{mU} / \mathrm{g}$ liver) compared to large littermates $(1.26 \pm 0.13 \mathrm{mU} / \mathrm{g}$ liver $)$.

BHMT and CGL gene expression. The expressions of BHMT and CGL were normalized to $\beta$-actin expression in each sample and normalized to a calibrator sample to allow for direct comparison between all piglets, giving expression values in arbitrary units (AU). BHMT expression did not differ between IUGR $(1.00 \pm 0.24 \mathrm{AU})$ and large piglets $(0.99$ $\pm 0.21 \mathrm{AU})(P=0.96)$. Large piglets had higher CGL expression than IUGR $(1.24 \pm 0.54$ AU versus $0.85 \pm 0.54 \mathrm{AU}$, respectively) $(P=0.01)$.

Global DNA methylation in the liver. Global DNA methylation was estimated by measuring the DPM/0.5 $\mu \mathrm{g}$ DNA in Hpa II digests. The DNA methylation in IUGR piglets $(3894 \pm 469 \mathrm{DPM} / 0.5 \mu \mathrm{g}$ DNA) did not differ from that in large piglets $(3928 \pm$ 
Table 2.3 Liver concentrations of free amino acids in large and runt littermate piglets

\begin{tabular}{|c|c|c|}
\hline & Large & Runt \\
\hline \multicolumn{3}{|c|}{ Sulfur Metabolism Amino Acids, nmol/g } \\
\hline Methionine & $326 \pm 84$ & $348 \pm 107$ \\
\hline S-adenosyl-methionine & $68.4 \pm 29.0$ & $79.8 \pm 31.7$ \\
\hline S-adenosyl-homocysteine & $58.2 \pm 20.6$ & $69.2 \pm 23.9$ \\
\hline SAM/SAH & $1.19 \pm 0.36$ & $1.19 \pm 0.35$ \\
\hline Homocysteine & $739 \pm 240$ *a & $532 \pm 264$ \\
\hline Cystathionine & $2.69 \pm 0.68$ & $3.63 \pm 0.29$ *a \\
\hline Cysteine & $2637 \pm 930$ & $2503 \pm 430$ \\
\hline Taurine & $8447 \pm 1138$ * & $6475 \pm 900$ \\
\hline Serine & $2239 \pm 292$ & $2228 \pm 583$ \\
\hline Glycine & $5542 \pm 836$ & $5366 \pm 1167$ \\
\hline \multicolumn{3}{|c|}{ Indispensable Amino Acids, $\mathrm{nmol} / \mathrm{g}$} \\
\hline Arginine & $78.5 \pm 21.1$ & $70.7 \pm 24.1$ \\
\hline Histidine & $36.1 \pm 11.4$ & $38.1 \pm 21.2$ \\
\hline Isoleucine & $486 \pm 81$ & $535 \pm 125$ \\
\hline Leucine & $1059 \pm 236$ & $1213 \pm 199$ \\
\hline Lysine & $571 \pm 134$ & $482 \pm 191$ \\
\hline Phenylalanine & $412 \pm 90$ & $453 \pm 120$ \\
\hline Threonine & $757 \pm 171$ & $747 \pm 215$ \\
\hline Valine & $1446 \pm 221$ & $1464 \pm 218$ \\
\hline \multicolumn{3}{|c|}{ Dispensable Amino Acids, nmol/g } \\
\hline Alanine & $3124 \pm 659$ & $3222 \pm 581$ \\
\hline Aspartate & $2628 \pm 404$ & $2770 \pm 656$ \\
\hline Citrulline & $348 \pm 94$ & $326 \pm 143$ \\
\hline Glutamate & $1959 \pm 241$ & $2409 \pm 719$ \\
\hline Glutamine & $455 \pm 91$ & $392 \pm 164$ \\
\hline Hydroxyproline & $242 \pm 27$ & $243 \pm 37$ \\
\hline Ornithine & $591 \pm 228$ & $510 \pm 228$ \\
\hline Proline & $1874 \pm 301$ & $1925 \pm 368$ \\
\hline Tyrosine & $502 \pm 166$ & $566 \pm 156$ \\
\hline
\end{tabular}

Results are mean \pm S.D. ( $n=6$ per group). $* P<0.05 ;$ a Sex included in the model 
Table 2.4 Specific activities (nmol product/min/mg total liver protein) of hepatic enzymes of methionine and homocysteine metabolism in large and runt littermate piglets

\begin{tabular}{|c|c|c|c|}
\hline & Large & Runt & $\begin{array}{l}\text { Correlation to } \\
\text { Body Weight }\end{array}$ \\
\hline$\underline{\text { Remethylation }}$ & & & $\underline{r}$ \\
\hline Methionine synthase & $0.29 \pm 0.10$ & $0.29 \pm 0.08$ & 0.01 \\
\hline $\begin{array}{l}\text { Betaine:homocysteine } \\
\text { methyltransferase }\end{array}$ & $0.35 \pm 0.06^{*}$ & $0.25 \pm 0.06$ & $0.53^{a}$ \\
\hline Methylenetetrahydrofolate reductase & $0.23 \pm 0.02$ & $0.23 \pm 0.02$ & -0.24 \\
\hline \multicolumn{4}{|l|}{ Methionine Transsulfuration } \\
\hline Methionine adenosyltransferase & $0.37 \pm 0.15$ & $0.36 \pm 0.06$ & -0.28 \\
\hline Cystathionine $\beta$-synthase & $3.81 \pm 0.70$ & $3.68 \pm 2.08$ & -0.01 \\
\hline Cystathionine $y$-lyase & $5.29 \pm 1.53^{*}$ & $4.23 \pm 1.72$ & $0.44 \mathrm{~b}$ \\
\hline
\end{tabular}

Results are mean \pm S.D. ( $n=6$ per group).

* $P<0.05$

${ }^{\mathrm{a}} P=0.07,{ }^{\mathrm{b}} P=0.22$, linear regression 
Table 2.5 Total hepatic capacities (nmol of product $/ \mathrm{min} / \mathrm{kg}$ body weight) of enzymes of large and runt littermate piglets, corrected for body weight

\begin{tabular}{|c|c|c|c|}
\hline & Large & Runt & $\begin{array}{l}\text { Correlation to } \\
\text { Body Weight (r) }\end{array}$ \\
\hline \multicolumn{4}{|l|}{ Remethylation } \\
\hline Methionine synthase & $2.02 \pm 0.72$ & $1.96 \pm 0.58$ & 0.05 \\
\hline $\begin{array}{l}\text { Betaine:homocysteine } \\
\text { methyltransferase }\end{array}$ & $2.43 \pm 0.64$ * & $1.71 \pm 0.46$ & $0.49^{a}$ \\
\hline Methylenetetrahydrofolate reductase & $1.57 \pm 0.20$ & $1.59 \pm 0.16$ & -0.07 \\
\hline \multicolumn{4}{|l|}{ Methionine Transsulfuration } \\
\hline Methionine adenosyltransferase & $2.49 \pm 1.01$ & $2.49 \pm 0.51$ & -0.27 \\
\hline Cystathionine $\beta$-synthase & $26.7 \pm 6.9$ & $25.4 \pm 14.8$ & 0.03 \\
\hline Cystathionine $y$-lyase & $36.6 \pm 11.3^{*}$ & $29.2 \pm 13.0$ & $0.43^{b}$ \\
\hline
\end{tabular}

Results are mean \pm S.D. ( $n=6$ per group).

* $P<0.05$

${ }^{\mathrm{a}} P=0.10,{ }^{\mathrm{b}} P=0.15$, linear regression 
$314 \mathrm{DPM} / 0.5 \mu \mathrm{g}$ DNA $)(\mathrm{P}=0.9)$ and birth weight did not correlate with global methylation $(\mathrm{P}=0.6)$.

\subsection{Discussion}

Consistent with epidemiological data, we [16-17] and others [18-19] have demonstrated that the IUGR runt pig develops biomarkers for metabolic syndrome early in adulthood, compared to higher birth weight littermates. Runts are born to adequately nourished mothers as a result of a decrease in fetal nutrient delivery via reduced blood supply [33]. This porcine model of IUGR allows for the examination of the consequences of a poor intrauterine environment on early postnatal metabolism, while controlling for maternal nutrition. The IUGR neonate's epigenetic profile is likely responsible for the permanent changes in gene expression which translate to higher risk for diseases later in life [14]. Because the methyl groups required for DNA methylation are generated by the methionine and folate cycles, we hypothesized that as a result of a poor intrauterine environment (i.e. runts), the activities of the key enzymes in these cycles are altered.

Indeed, this study demonstrated that sulfur amino acid metabolism in IUGR pigs differed from their large littermates. Specific activities of enzymes controlling the disposal of homocysteine, namely BHMT and CGL, were significantly lower in IUGR piglets. Moreover, the overall capacity of BHMT and CGL per kg of body weight was also significantly lower in IUGR than large piglets, despite the significantly lower body weight in IUGR piglets. Taken as a whole, the double bottleneck of reduced capacity to remethylate and transsulfurate homocysteine in IUGR piglets could potentially limit flux 
through these pathways. If IUGR neonates have a reduced ability to cope with excess sulfur amino acids, as suggested by this study in IUGR piglets, then protein-rich diets could perturb transmethylation reactions; moreover, diets based on casein, which is rich in methionine (2.70\%) and poor in cysteine (0.41\%) [34], could be particularly worrisome.

BHMT is involved in the removal of homocysteine via the remethylation pathway (Figure 2.1) [35]. Remethylation allows methionine to be regenerated from homocysteine by using methyl groups from serine via the folate cycle (via MS) or by using methyl groups from betaine (via BHMT). MS is considered the main enzyme involved in the remethylation process, whereas BHMT has been considered to be the minor pathway [35]. However, BHMT activity is known to increase to compensate for decreased MS activity as a result of folate deficiency [36]. The converse is also true [36]; even though we did not observe a higher MS capacity in IUGR pigs, it is possible that flux via MS was increased in IUGR piglets to compensate for lower BHMT capacity. Moreover, because decreased choline and betaine intakes are associated with higher risk for neural tube defects, independent of folate intakes [37,38], the role of BHMT in overall methylation status has likely been underestimated.

When remethylation is limited, transsulfuration increases to accommodate the flux from transmethylation; otherwise, homocysteine concentrations escalate [35]. CBS and CGL are involved in the catabolism of homocysteine to cysteine in a two-step process (Figure 2.1); homocysteine is first condensed with serine by CBS to form cystathionine, and then cystathionine is catabolized to cysteine and $\alpha$-ketobutyrate by CGL, also known as 
cystathionase [35]. CBS activity did not differ between IUGR and large piglets. However, because CGL activity was significantly lower in IUGR than large piglet livers, the ability of IUGR piglets to clear cystathionine and synthesize cysteine and taurine was reduced. Indeed, IUGR piglets in our study had lower concentrations of plasma total cysteine and hepatic taurine with an apparent accumulation in hepatic cystathionine. It has previously been suggested that CGL is rate-limiting for cysteine and taurine synthesis and its lower activity in neonates (particularly premature neonates) has led to the hypothesis that cysteine may be conditionally essential in early life because methionine cannot be transsulfurated adequately $[10,11]$. Our data support this clinical observation and suggest that IUGR further limits the activity of this enzyme, thereby limiting the IUGR neonate's capacity to remove cystathionine and synthesize cysteine and taurine. This limited capacity again questions the use of casein as a protein source in neonates; because casein is rich in methionine and poor in cysteine, the conversion of methionine to cysteine is critical to maintaining sulfur amino acid adequacy when casein-based diets are fed. Cysteine could become the first limiting amino acid even in the presence of excess methionine, if this conversion is limited.

Because IUGR piglets had lower capacity to both remethylate and transsulfurate homocysteine, we expected homocysteine concentrations to be elevated. However, homocysteine concentrations were similar in plasma and were actually lower in livers of IUGR piglets. The lower hepatic accumulation of homocysteine could be due to sufficient MS capacity to deal with any excess homocysteine and/or due to adequate CBS and low CGL activities which led to the hepatic accumulation of cystathionine. Alternatively, 
IUGR pigs likely have a lower methionine flux, as a result of the IUGR pig's lower protein metabolism due to reduced intakes [39]; indeed, a lower protein turnover in IUGR pigs is supported by their lower plasma urea concentrations in this study. Moreover, hyperhomocysteinemia could have been avoided because these piglets were sow-fed, and sow milk contains more appropriate amounts of total protein as well as methionine and cysteine (ie methionine to cysteine ratio of 1.40 , compared to 0.81 in human milk) [40]. It is possible that with high protein feeding or with feeding of casein-based diets (methionine to cysteine ratio of 6.60) [34], the reduced BHMT and CGL capacities may limit remethylation to methionine and eventually lead to hyperhomocysteinemia.

To assess the level of regulation of enzyme activity, gene expression of BHMT and CGL were analyzed in livers by real-time reverse transcriptase-PCR. CGL activity differences between the IUGR and large piglets were due to regulation at the transcriptional level, as CGL expression was significantly lower in the IUGR piglet livers. In contrast, liver BHMT expression was not significantly different between groups; this would suggest that the differences in BHMT activity between IUGR and large piglets may be due to some type of post-transcriptional mechanism. One such possible mechanism for the downregulation of BHMT activity in IUGR pigs could be related to liver transglutaminases, which have been shown to intra- and inter-molecularly cross link BHMT subunits and thereby reduce BHMT activity in vitro [41]. Indeed, IUGR piglets in this study tended to have higher transglutaminase activity $(P=0.078)$. Post-transcriptional mechanisms of regulation may be more transient than regulation at an expression level and may be related to the availability of substrate. This type of regulation in BHMT activity would be 
congruent with the very high levels of BHMT found in the liver and could be related to BHMT's role in maintaining remethylation flux in response to MS activity and folate deficiency $[35,36]$.

Because we have recently found that IUGR Yucatan miniature piglets develop early biomarkers for chronic diseases in adulthood [16,17], ultimately we were interested in whether changes in sulfur amino acid metabolism in IUGR piglets would translate into changes in DNA methylation, possibly explaining the higher risk for developing diseases later in life. Because dietary methyl group donor (folate, vitamin B12, choline, and methionine) supplementation can permanently alter epigenetically determined phenotypes [42,43], sulfur amino acid metabolism pathways must be involved in this programming. However, we did not observe any changes in hepatic global DNA methylation or in concentrations of SAM, SAH or its ratio. SAM/SAH ratio has been called the 'methylation index' and is sometimes considered a reflection of methyl group availability [44]. However, it should be noted that global methylation status, which can affect overall chromosomal stability and may contribute to the development of cancer [13], should be differentiated from promoter-specific methylation, which can modify expression of specific genes and is more likely to be the mechanism involved in programming of risk for adult diseases $[13,14]$. So, although we did not observe any changes in global methylation status, it is still possible that promoter-specific changes occurred. Once we identify epigenetically regulated candidate genes, we will use bisulfite sequencing to confirm this. 
Reduced prenatal growth in Yucatan miniature piglets impairs their remethylation capacity as well as their ability to remove cystathionine and synthesize cysteine and taurine, which could have important implications on long term health outcomes. This research has immediate implications in the design of postnatal nutritional therapies for IUGR infants. For example, the strategy of feeding protein-rich (and especially caseinrich) diets to infants in order to stimulate growth may need to be re-evaluated. Furthermore, it is hoped that this research will contribute to the body of knowledge aimed at preventative measures that will help decrease the incidence of the implicated chronic diseases in the fetal origins of adult disease phenomenon. 


\section{$2.6 \quad$ References}

[1] Barker DJ. Fetal origins of coronary heart disease. BMJ. 1995;311:171-4.

[2] McMillen IC, Robinson JS. Developmental origins of the metabolic syndrome: prediction, plasticity, and programming. Physiol Rev. 2005;85:571-633.

[3] Bertram CE, Hanson MA. Animal models and programming of the metabolic syndrome. Brit Med Bull. 2001;60:103-21.

[4] Hales CN, Ozanne SE. The dangerous road of catch-up growth. J Physiol. 2003;547:5-10.

[5] Rees WD, Hay SM, Buchan V, Antipatis C, Palmer RM. The effects of maternal protein restriction on the growth of the rat fetus and its amino acid supply. Br J Nutr. 1999;81:243-50.

[6] Rees WD, Hay SM, Brown DS, Antipatis C, Palmer RM. Maternal protein deficiency causes hypermethylation of DNA in the livers of rat fetuses. J Nutr. 2000;130:1821-6.

[7] Rees WD. Manipulating the sulfur amino acid content of the early diet and its implications for long-term health. Proc Nutr Soc. 2002;61:71-7.

[8] de la Calle M, Usandizaga R, Sancha M, Magdaleno F, Herranz A, Cabrillo E. Homocysteine, folic acid and B-group vitamins in obstetrics and gynaecology. Eur J Obstet Gynecol Reprod Biol. 2003;107:125-34.

[9] Osganian SK, Stampfer MJ, Spiegelman D, Rimm E, Cutler JA, Feldman HA, Montgomery DH, Webber LS, Lytle LA, Bausserman L, Nader PR. Distribution of and factors associated with serum homocysteine levels in children: Child and Adolescent Trial for Cardiovascular Health. JAMA. 1999;281:1189-96.

[10] Zlotkin SH, Anderson GH. The development of cystathionase activity during the first year of life. Pediatr Res. 1982;16:65-8.

[11] Viña J, Vento M, García-Sala F, Puertes IR, Gascó E, Sastre J, Asensi M, Pallardó FV. L-cysteine and glutathione metabolism are impaired in premature infants due to cystathionase deficiency. Am J Clin Nutr. 1995;61:1067-9.

[12] Gahl MJ, Benevenga NJ, Crenshaw TD. Rates of lysine catabolism are inversely 
related to rates of protein synthesis when measured concurrently in adult female rats induced to grow at different rates. J Nutr. 1998;128:1503-11.

[13] Kim YI. Nutritional epigenetics: impact of folate deficiency on DNA methylation and colon cancer susceptibility. J Nutr. 2005;135:2703-9.

[14] Waterland RA, Jirtle RL. Early nutrition, epigenetic changes at transposons and imprinted genes, and enhanced susceptibility to adult chronic diseases. Nutrition. 2004;20:63-8.

[15] Wainfan E, Dizik M, Stender M, Christman JK. Rapid appearance of hypomethylated DNA in livers of rats fed cancer-promoting, methyl-deficient diets. Cancer Res. 1989;49:4094-7.

[16] Myrie SB, McKnight LL, Van Vliet BN, Bertolo RF. Low birth weight is associated with reduced nephron number and increased blood pressure in adult Yucatan miniature swine. Neonatology 2011; In Press.

[17] Myrie SB, McKnight LL, Van Vliet BN, Bertolo RF. Early development of excess visceral fat is associated with the development of metabolic syndrome in small birth weight pigs. Appl Physiol Nutr Metab. 2008;33:627.

[18] Poore KR, Fowden AL. The effect of birth weight on hypothalamo-pituitary-adrenal axis function in juvenile and adult pigs. J Physiol. 2003;547:107-16.

[19] Poore KR, Fowden AL. The effects of birth weight and postnatal growth patterns on fat depth and plasma leptin concentrations in juvenile and adult pigs. J Physiol. 2004;558:295-304.

[20] Puiman P, Stoll B. Animal models to study neonatal nutrition in humans. Curr Opin Clin Nutr Metab Care. 2008;11:601-6.

[21] Vester B, Rasmussen K. High performance liquid chromatography method for rapid and accurate determination of homocysteine in plasma and serum. Eur J Clin Chem Clin Biochem. 1991;29:549-54.

[22] Ratnam S, Wijekoon EP, Hall B, Garrow TA, Brosnan ME, Brosnan JT. Effects of diabetes and insulin on betaine-homocysteine S-methyltransferase expression in rat liver. Am J Physiol Endocrinol Metab. 2006;290:E933-9.

[23] Seo SS. High performance liquid chromatographic determination of homocysteine and cystathionine in biological samples by derivatization with 6-aminoquinolyl-N- 
hydroxylsuccinimidyl carbamate (AQC). J Korean Chem Soc. 2005;49:278-82.

[24] Bidlingmeyer BA, Cohen SA, Tarvin TL. Rapid analysis of amino acids using precolumn derivatization. J Chromatogr. 1984;336:93-104.

[25] Koblin DD, Watson JE, Deady JE, Stokstad EL, Eger EI 2nd. Inactivation of methionine synthetase by nitrous oxide in mice. Anesthesiology. 1981;54:318-24.

[26] Garrow TA. Purification, kinetic properties, and cDNA cloning of mammalian betaine-homocysteine methyltransferase. J Biol Chem. 1996;271:22831-8.

[27] Engbersen AM, Franken DG, Boers GH, Stevens EM, Trijbels FJ, Blom HJ. Thermolabile 5,10-methylenetetrahydrofolate reductase as a cause of mild hyperhomocysteinemia. Am J Hum Genet. 1995;56:142-50.

[28] Duce AM, Ortiz P, Cabrero C, Mato JM. S-adenosyl-L-methionine synthetase and phospholipid methyltransferase are inhibited in human cirrhosis. Hepatology. 1988;8:65-8.

[29] Taoka S, Ohja S, Shan X, Kruger WD, Banerjee R. Evidence for heme-mediated redox regulation of human cystathionine beta-synthase activity. J Biol Chem. 1998;273:25179-84.

[30] Stipanuk MH. Effect of excess dietary methionine on the catabolism of cysteine in rats. J Nutr. 1979;109:2126-39.

[31] Pfaffl MW. A new mathematical model for relative quantification in real-time RTPCR. Nucleic Acids Res. 2001;29:e45.

[32] Pogribny I, Yi P, James SJ. A sensitive new method for rapid detection of abnormal methylation patterns in global DNA and within CpG islands. Biochem Biophys Res Commun. 1999;262:624-8.

[33] Holt RI, Byrne CD. Intrauterine growth, the vascular system, and the metabolic syndrome. Semin Vasc Med. 2002;2:33-43.

[34] National Research Council. Nutrient Requirements of Swine. 10th ed. Washington, DC: National Acadamies Press; 1998 [chapter 11].

[35] Stipanuk MH. Sulfur amino acid metabolism: pathways for production and removal of homocysteine and cysteine. Annu Rev Nutr. 2004;24:539-77. 
[36] Niculescu MD, Zeisel SH. Diet, methyl donors and DNA methylation: interactions between dietary folate, methionine and choline. J Nutr. 2002;132:2333-5S.

[37] Shaw GM, Finnell RH, Blom HJ, Carmichael SL, Vollset SE, Yang W, Ueland PM. Choline and risk of neural tube defects in a folate-fortified population. Epidemiology. 2009;20:714-9.

[38] Shaw GM, Carmichael SL, Yang W, Selvin S, Schaffer DM. Periconceptional dietary intake of choline and betaine and neural tube defects in offspring. Am $\mathbf{J}$ Epidemiol. 2004;160:102-9.

[39] Ritacco G, Radecki SV, Schoknecht PA. Compensatory growth in runt pigs is not mediated by insulin-like growth factor I. J Animal Sci. 1997;75:1237-43.

[40] Davis TA, Nguyen HV, Garcia-Bravo R, Fiorotto ML, Jackson EM, Lewis DS, Lee DR, Reeds PJ. Amino acid composition of human milk is not unique. J Nutr. 1994;124:1126-32.

[41] Ichikawa A, Ohashi Y, Terada S, Natsuka S, Ikura K. In vitro modification of betaine-homocysteine S-methyltransferase by tissue-type transglutaminase. Int $\mathbf{J}$ Biochem Cell Biol. 2004;36:1981-92.

[42] Waterland RA, Jirtle RL. Transposable elements: targets for early nutritional effects on epigenetic gene regulation. Mol Cell Biol. 2003;23:5293-300.

[43] Waterland RA, Dolinoy DC, Lin JR, Smith CA, Shi X, Tahiliani KG. Maternal methyl supplements increase offspring DNA methylation at Axin Fused. Genesis. 2006;44:401-6.

[44] Van den Veyver IB. Genetic effects of methylation diets. Annu Rev Nutr. 2002;22:255-82. 
CHAPTER 3: Partitioning of [methyl- $\left.{ }^{3} \mathrm{H}\right]$ methionine to methylated products and protein is altered during high methyl demand conditions in young Yucatan miniature pigs

J Nutr. 2013 Jun;143(6):804-9.

Laura E. McBreairty, Ross A. McGowan, Janet A. Brunton, Robert F. Bertolo

Chapter 3 was designed by L. McBreairty and R. Bertolo and L. McBreairty conducted the research, analyzed the data and prepared the manuscript with guidance from R. Bertolo. The final manuscript was read and approved by all authors. 


\subsection{Abstract}

Methionine is the main source of methyl groups that are partitioned to synthesize various methylated products including creatine, phosphatidylcholine (PC) and methylated DNA. Whether increased methylation of one product can divert methionine from protein synthesis or other methylation products was the aim of this experiment. We used an excess of guanidinoacetate (GAA) to synthesize creatine to create a higher demand for available methyl groups in normal weight $(\mathrm{NW})(n=10)$ and intrauterine growthrestricted (IUGR) $(n=10)$ piglets. Anesthetized piglets $(15-18 \mathrm{~d}$ old) were intraportally infused with either GAA or saline for $2 \mathrm{~h}$. A bolus of $\mathrm{L}-\left[\right.$ methyl- $\left.{ }^{3} \mathrm{H}\right]$ methionine was intraportally infused at $1 \mathrm{~h}$ and hepatic metabolites were analyzed for methyl- ${ }^{3} \mathrm{H}$ incorporation $1 \mathrm{~h}$ later. Overall, 50-75\% of label was recovered in creatine and PC with negligible amounts in DNA. In both NW and IUGR piglets, excess GAA led to a 72$125 \%$ increase in methyl incorporation into creatine $(P<0.05)$ with a concomitant decrease by $76-86 \%$ in methyl incorporation into PC $(P<0.05)$ as well as a $38-41 \%$ decrease in methyl incorporation into protein $(P<0.05)$, suggesting methyl groups were limited for PC synthesis and that methionine was diverted from protein synthesis. Compared to NW, IUGR piglets had lower methyl incorporation into PC $(P<0.05)$, but not DNA or protein, suggesting IUGR affects methyl metabolism and could potentially impact lipid metabolism. The partitioning of methionine is sensitive to methyl supply in the neonate, which has implications in infant diet composition and growth. 


\subsection{Introduction}

Methionine is an indispensable amino acid that can be utilized either for protein synthesis or as a methyl group donor for transmethylation reactions. In order to provide a methyl group, methionine is first adenylated to form S-adenosylmethionine (SAM) which is partitioned among an estimated 50 methyltransferases, including guanidinoacetate methyltransferase (GAMT), phosphatidylethanolamine N-methyltransferase (PEMT) and DNA methyltransferase (DNMT) (1).

Two of the most quantitatively important methylation reactions are the synthesis of phosphatidylcholine (PC) from phosphatidylethanolamine (PE) via PEMT and the synthesis of creatine from guanidinoacetate (GAA) via GAMT. Creatine can be consumed in the diet while the remainder of the whole body requirement needs to be endogenously synthesized. Suckling neonates only consume $25 \%$ of their requirement from milk and thus need to synthesize the remaining $75 \%$ (2). Moreover, if dietary choline is insufficient to meet PC synthesis requirements, then a growing neonate must rely on methylation of $\mathrm{PE}$ to meet its $\mathrm{PC}$ needs. As these two reactions utilize the majority of available methyl groups (3), it is important to understand how demand for methyl groups by these two pathways can impact partitioning of methyl supply for all methyltransferases, including DNMT.

DNMT transfers a methyl group to cytosine residues in $\mathrm{CpG}$ dinucleotide sequences, which, especially when found in a promoter region, can regulate gene expression (4). These methylation patterns are initially established during early development but have 
been shown to be susceptible to postnatal epigenetic modification in response to environmental changes (5). Epigenetic modifications have been implicated in the developmental origins of adult diseases hypothesis, which describes how an insult to the developing fetus or neonate can result in a higher susceptibility to chronic diseases in later life. This hypothesis was originally based on epidemiological studies which demonstrated an association between low birth weight (i.e., IUGR neonates) and disease in later life (6). Since then, it has been well established that nutritional insults early in life can 'program' an organism's metabolism, leading to adult diseases (7). Moreover, it has been demonstrated that DNA methylation patterns are sensitive to changes in dietary methyl supply (8) and IUGR piglets have decreased levels of DNMT-1 mRNA compared to normal birth weight piglets (9). As many other methylation reactions compete for these methyl groups, it is important to understand how the methyl groups are partitioned amongst the various methyltransferase reactions when supply is limited and how this partitioning changes in IUGR neonates.

In order to study the effects of limited methyl supply on transmethylation partitioning, we increased the demand for methyl groups required to synthesize creatine. Creatine is synthesized via two reactions by the enzymes arginine:glycine amidinotransferase (AGAT) and GAMT. AGAT forms GAA and ornithine in the kidney by transferring the amidino group from arginine to glycine. GAA is then transported to the liver and methylated via SAM to produce creatine and S-adenosyl-L-homocysteine (SAH). The regulation of creatine synthesis is by AGAT, due to the feedback inhibitory effect of creatine on this enzyme. In contrast, creatine synthesis from GAA via GAMT has been 
shown in rats to be proportional to GAA availability (10). This suggests that an excess of GAA in the liver would drive creatine synthesis and thus potentially increase the demand for available methyl groups. Because certain infant formulas (i.e., soy-based) are void of creatine, some neonates must rely solely on endogenous synthesis for their entire creatine requirement, potentially impacting the available methyl supply. Because neonatal piglets consume $\sim 25 \%$ of their creatine needs via sow milk (2), we developed an acute model in which the piglet must synthesize this additional creatine by infusing an equimolar amount of GAA. By creating a high demand for methyl groups, it is possible to determine the impact on other methylation reactions that also compete for the remaining methyl groups.

As fetal undernutrition has been shown to have a lasting impact on offspring, the IUGR 'runt' piglet has been established as a model to study early programming of adult diseases (11-14). Moreover, although we found no difference in the remethylation of homocysteine to methionine via MS, we have demonstrated that IUGR piglets have limited capacity to remethylate homocysteine to methionine via betaine:homocysteine methyltransferase (BHMT), which could have consequences on the availability of methyl groups for transmethylation reactions (15). The first objective of this study was to determine whether methyl groups can become limiting in the neonate and to determine the change in partitioning of methionine and methyl groups during high methyl demand (HMD). The second objective was to determine if the partitioning of methyl groups under high and normal demand conditions differs in IUGR neonates. 


\subsection{Materials and Methods}

Reagents. L-[Methyl- $\left.{ }^{3} \mathrm{H}\right]$ methionine was obtained from American Radiolabeled Chemicals, Inc. (St. Louis, MO). All other chemicals were of analytical grade and were from Sigma (St. Louis, MO) or Fisher Scientific (Fair Lawn, NJ).

Animals. All animal handling procedures were approved by the Institutional Animal Care Committee in accordance with the guidelines of the Canadian Council on Animal Care. IUGR $(n=10)$ and normal weight $(\mathrm{NW})(n=10)$ suckling Yucatan miniature piglets (15$18 \mathrm{~d}$ old) were obtained from Memorial University of Newfoundland breeding colony. Anesthesia was induced with an intramuscular injection of ketamine hydrochloride (20 $\mathrm{mg} / \mathrm{kg})$ and acepromazine $(0.5 \mathrm{mg} / \mathrm{kg})$ and maintained with isoflurane (1-2\%) in oxygen (1.5 L/min). A catheter was inserted in the jugular vein and blood was sampled before and every 7-15 min after the bolus infusion. After laparotomy using cautery, the portal vein was isolated and catheterized for infusions to ensure hepatic exposure to GAA and tracer was consistent among pigs and not influenced by extraction from extra-hepatic tissues, which might be different in IUGR. The abdominal cavity was then irrigated with warm saline, closed and kept warm with a heat lamp. A 2-h constant portal venous infusion of either $15 \mathrm{mg} \cdot \mathrm{kg}^{-1} \cdot \mathrm{h}^{-1} \mathrm{GAA}$ (HMD groups) or saline (equivalent volume of $20 \mathrm{~mL} / \mathrm{h})($ Control groups) was initiated and after $1 \mathrm{~h}$, a $11.1 \mathrm{MBq}(300 \mu \mathrm{Ci})$ per $\mathrm{kg}$ body weight bolus of L-[methyl- $\left.{ }^{3} \mathrm{H}\right]$ methionine was infused into the portal vein. An infusion of 
$15 \mathrm{mg} \cdot \mathrm{kg}^{-1} \cdot \mathrm{h}^{-1}$ of GAA for $2 \mathrm{~h}$ provides one-third of the GAA required to synthesize a piglet's total daily creatine requirement (2). Sixty min after the bolus infusion, the abdomen was reopened and cautery was used to excise a sample of liver which was quickly freeze-clamped in liquid nitrogen. Samples of other tissues (i.e., small intestinal mid-jejunum, gastrocnemius muscle and brain) were then removed and freeze clamped. A labelling period of $60 \mathrm{~min}$ following the bolus of L-[methyl- $\left.{ }^{3} \mathrm{H}\right]$ methionine was chosen to permit sufficient incorporation in various products; in a pilot experiment, serial sampling of liver at 30, 45 and 60 min revealed that incorporation of label in DNA and PC increased linearly to $60 \mathrm{~min}$ while incorporation into creatine was constant (data not shown). This suggests creatine may be leaving the liver at a faster rate than PC.

Plasma and liver amino acid analyses. Serial plasma samples were analyzed for methionine specific radioactivity (SRA); all other plasma and liver amino acid analyses were determined on samples taken 1 hour following infusion of L-[methyl$\left.{ }^{3} \mathrm{H}\right]$ methionine. Plasma creatine and GAA concentrations were determined by HPLC following derivatization with ninhydrin (16). SAM and SAH concentrations were determined by HPLC (17). Methionine concentration was determined by HPLC using phenylisothiocyanate derivatization (18). Plasma samples were first deproteinized with $0.5 \%$ trifluoroacetic acid in methanol. Liver samples were homogenized in perchloric acid; the supernatant was used to determine free methionine and SAM and the protein pellet was hydrolyzed in $6 \mathrm{M} \mathrm{HCl}$ for $24 \mathrm{~h}$ and used to determine tissue-bound methionine. SRA of methionine and SAM (DPM/ $/ \mu \mathrm{mol})$ was determined by fraction 
collecting the respective peak and DPM were determined by scintillation counting (Perkin Elmer Canada Ltd, Woodbridge, ON, Canada).

Hepatic analyses of methylated products. Creatine SRA was determined using a modified method by Lamarre et al. (19). Tissue was homogenized in a $50 \mathrm{mM}$ Tris buffer (pH 7.4) and homogenates were deproteinized with trifluoroacetic acid. Creatine was separated with an isocratic mobile phase of $0.1 \%$ trifluoroacetic acid and $3 \%$ methanol and the creatine fraction collected to determine SRA as above.

For PC analyses, lipids were extracted from liver homogenates using the Folch method (20). Lipids were separated via thin layer chromatography using a silica G-60 thin-layer chromatography (TLC) plate and a solvent system of chloroform:methanol:acetic acid:water (25:15:4:2) followed by iodine visualization. Total phosphorus was determined using a modified Bartlett method (21). Perchloric acid was added to each sample which was then heated at $180^{\circ} \mathrm{C}$ for $2 \mathrm{~h}$. A $5 \%$ ammonium molybdate solution and a Fisk and SubbaRow reagent (1-amino-2-naphthol-4-sulfonic acid, sodium metabisulfite and sodium sulfite) were added to each tube which were then placed in a boiling water bath for $12 \mathrm{~min}$. Absorbance was read at $815 \mathrm{~nm}$ for quantification of phosphorus. A portion of the sample was used for scintillation counting and data were expressed as SRA $(\mathrm{DPM} / \mu \mathrm{mol})$.

To extract DNA, tissues were homogenized in $50 \mathrm{mM}$ Tris (pH 8), 1\% Sodium dodecyl sulfate $100 \mathrm{mM}$ EDTA and $100 \mathrm{mM} \mathrm{NaCl}$. Proteinase $\mathrm{K}$ was then added (to final concentration of $0.8 \mathrm{~g} / \mathrm{L}$ ) and samples were incubated overnight at $56^{\circ} \mathrm{C}$, followed by 
phenol extraction. DNA was precipitated with isopropanol and sodium acetate followed by resuspension of DNA in $10 \mathrm{mM}$ Tris buffer ( $\mathrm{pH}$ 8) with $0.1 \mathrm{mM}$ EDTA. DNA concentration was determined using a NanoDrop spectrophotometer (Thermo Scientific, Wilmington, DE) and DPM were determined with liquid scintillation counting to calculate SRA (DPM/ $\mu \mathrm{g})$.

Calculations. Rate of ${ }^{3} \mathrm{H}$-methyl incorporation into methylated products and liver protein was calculated as:

$$
\text { Rate of }{ }^{3} \mathrm{H} \text {-methyl incorporation product }=\left(\mathrm{SRA}_{\text {product }} / \mathrm{SRA}_{\text {precursor }}\right) / \text { time } \times 100 \text {, }
$$

where the precursor was hepatic SAM for methylated products (i.e. creatine, PC, DNA) and hepatic free methionine for protein.

Statistical analyses. Data are presented as means \pm SD. Groups were compared using two-way analysis of variance (ANOVA) with methyl demand and IUGR as main factors with Bonferroni post-tests when main effects were identified by the two-way ANOVA (GraphPad Prism 4.0 for Windows, GraphPad Software, San Diego, CA). $P$ values for main factors and interaction effects are presented in tables and differences were considered significant at $P<0.05$.

\subsection{Results}

Metabolite concentrations. A typical mono-exponential decay curve for methionine SRA over time is shown in Figure 3.1. In terminal plasma, GAA concentration increased in the HMD piglets $(P<0.0001)$ with no change in creatine concentration; IUGR pigs had 


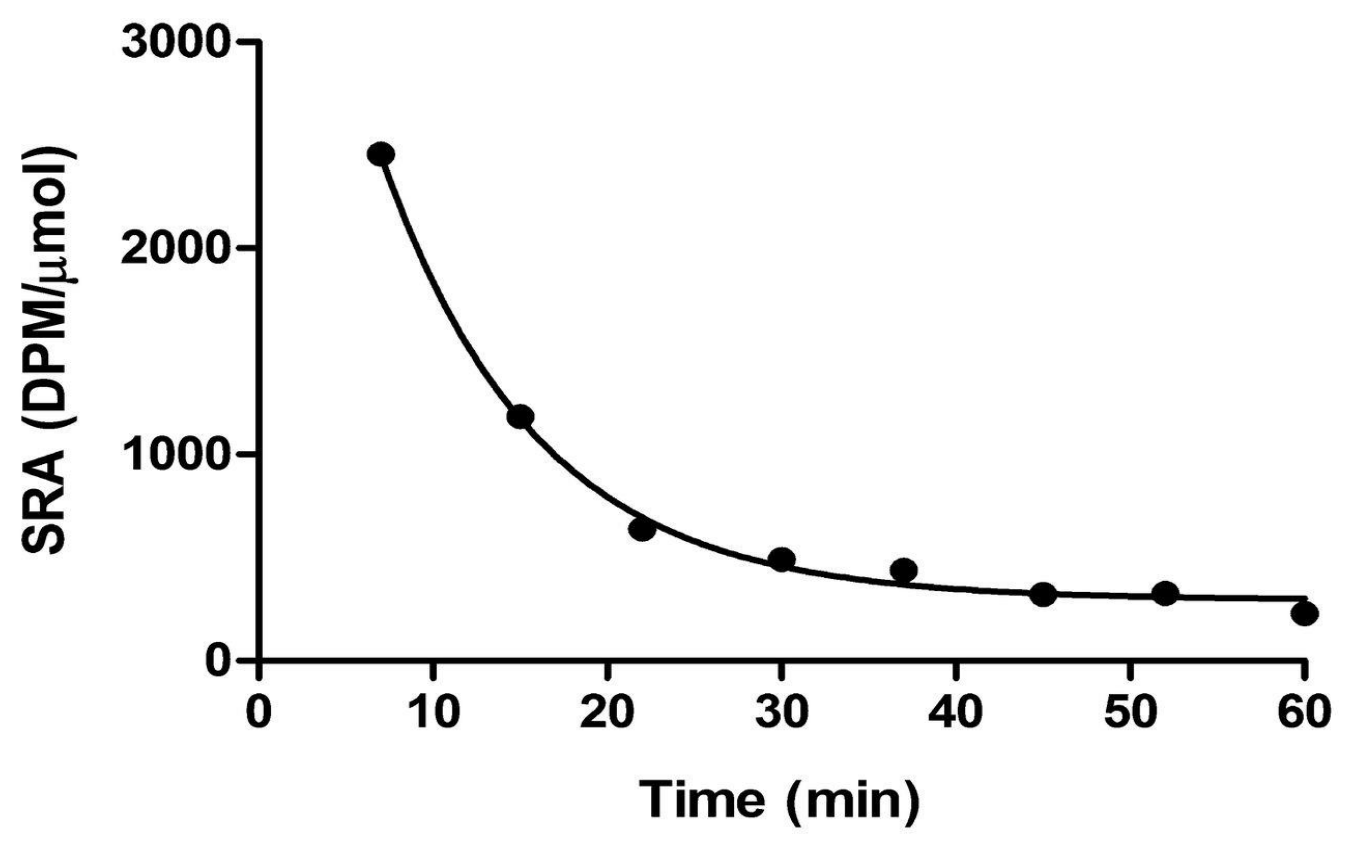

Figure 3.1 Typical mono-exponential decay curve for methionine SRA over time in a pig infused with a $11.1 \mathrm{MBq}(300 \mu \mathrm{Ci})$ per $\mathrm{kg}$ body weight bolus of L-[methyl$\left.{ }^{3} \mathrm{H}\right]$ methionine directly into the portal vein. 
higher arginine $(P=0.006)$ and methionine concentrations $(P=0.019)$ (Table 3.1). In the liver, methionine concentration was unchanged but arginine concentration was higher in HMD pigs $(P<0.02)$ (Table 3.2). HMD treatment led to lower hepatic SAM $(P<0.0001)$ and higher hepatic SAH $(P=0.011)$ concentrations (Table 3.2). As a result, SAM/SAH ratio was lower in both HMD groups $(P=0.0002)$.

Rate of ${ }^{3} \mathrm{H}$-methyl incorporation into products. The ${ }^{3} \mathrm{H}$-methyl incorporation rate into hepatic creatine doubled with GAA infusion in the HMD groups $(P=0.0001)$, regardless of BW (Table 3.3). In contrast, the ${ }^{3} \mathrm{H}$-methyl incorporation rate into hepatic PC was lower in both HMD groups $(P<0.0001)$ (Table 3.3). Moreover, there was also a significant interaction effect with BW so that within the control infusion groups, IUGR pigs had lower ${ }^{3} \mathrm{H}$-methyl incorporation into PC than NW pigs $(P<0.05)$, whereas ${ }^{3} \mathrm{H}$ methyl incorporation into PC was similar between IUGR and NW pigs with HMD treatment (Table 3.3). The ${ }^{3} \mathrm{H}$-methyl incorporation rate into protein was lower with HMD in both NW and IUGR piglets compared to controls $(P=0.02)$ (Table 3.3). There was no effect of HMD or birth weight on the ${ }^{3} \mathrm{H}$-methyl incorporation rate into DNA (Table 3.3).

Tissue creatine concentrations and specific radioactivity. HMD treatment led to $72-125 \%$ higher hepatic creatine concentrations in both IUGR and NW groups $(P=0.0006)$, but did not affect creatine concentrations in the muscle, small intestine or brain (Table3. 4). However, IUGR pigs had lower creatine concentrations in the small intestine, regardless of methyl status (main effect $P=0.014$ ). Creatine SRA (corrected for time) of both muscle $(P=0.029)$ and liver $(P<0.0001)$ were higher in HMD piglets with no 
Table 3.1 Plasma concentrations of metabolites in intrauterine growth-restricted (IUGR) and normal weight (NW) piglets under control or high methyl demand (HMD) conditions $^{1}$

\begin{tabular}{|c|c|c|c|c|c|c|c|}
\hline & $\begin{array}{c}\text { NW } \\
\text { Control }\end{array}$ & $\begin{array}{l}\text { NW } \\
\text { HMD }\end{array}$ & $\begin{array}{l}\text { IUGR } \\
\text { Control }\end{array}$ & $\begin{array}{l}\text { IUGR } \\
\text { HMD }\end{array}$ & BW & $\mathrm{Tr}$ & $\begin{array}{c}\text { BW } x \\
\text { Tr }\end{array}$ \\
\hline & \multicolumn{4}{|c|}{$\mu \mathrm{M}$} & \multicolumn{3}{|c|}{$P$ value } \\
\hline Methionine & $39 \pm 9 a$ & $38 \pm 11 a$ & $63 \pm 24 b$ & $82 \pm 47 b$ & 0.019 & ns & ns \\
\hline Arginine & $134 \pm 11$ & $160 \pm 47$ & $207 \pm 61$ & $221 \pm 59$ & 0.006 & ns & ns \\
\hline Creatine & $235 \pm 43$ & $308 \pm 94$ & $284 \pm 91$ & $283 \pm 33$ & ns & ns & ns \\
\hline Guanidinoacetate & $4.2 \pm 1.1^{a}$ & $91.4 \pm 37.0^{b}$ & $3.6 \pm 1.2^{\mathrm{a}}$ & $121 \pm 50^{b}$ & ns & 0.0001 & ns \\
\hline
\end{tabular}

${ }^{1}$ Data are given as means $\pm \mathrm{SD} ; n=5$. BW, birth weight; Tr, treatment. Groups were compared using two-way ANOVA with methyl demand (Tr) and BW (IUGR versus NW) as main factors with Bonferroni post-tests. $P$ values for main factors and interaction effects are presented in last three columns and means with different superscripts are significantly different after post-test, $P<0.05$. 
Table 3.2 Hepatic concentrations of metabolites in intrauterine growth-restricted (IUGR) and normal weight (NW) piglets under control or high methyl demand (HMD) conditions $^{1}$

\begin{tabular}{|c|c|c|c|c|c|c|c|}
\hline & $\begin{array}{c}\text { NW } \\
\text { Control }\end{array}$ & $\begin{array}{l}\text { NW } \\
\text { HMD }\end{array}$ & $\begin{array}{l}\text { IUGR } \\
\text { Control }\end{array}$ & $\begin{array}{l}\text { IUGR } \\
\text { HMD }\end{array}$ & BW & $\mathrm{Tr}$ & $\begin{array}{c}\text { BW } x \\
\operatorname{Tr}\end{array}$ \\
\hline & \multicolumn{4}{|c|}{$\mathrm{nmol} / \mathrm{g}$ wet weight } & \multicolumn{3}{|c|}{$P$ value } \\
\hline Methionine & $218 \pm 84$ & $243 \pm 80$ & $167 \pm 67$ & $205 \pm 42$ & ns & ns & ns \\
\hline Arginine & $106 \pm 42$ & $143 \pm 58$ & $101 \pm 45$ & $172 \pm 32$ & ns & 0.02 & ns \\
\hline SAM & $57.4 \pm 8.3^{b}$ & $33.7 \pm 6.5^{a}$ & $61.1 \pm 11.0^{b}$ & $43.6 \pm 7.8^{a}$ & ns & 0.0001 & ns \\
\hline SAH & $33.2 \pm 5.3^{a}$ & $49.2 \pm 12.0^{b}$ & $38.1 \pm 11.0^{a b}$ & $48.5 \pm 12.0^{a b}$ & ns & 0.01 & ns \\
\hline SAM/SAH & $1.78 \pm 0.44^{b}$ & $0.74 \pm 0.30^{a}$ & $1.70 \pm 0.54 b$ & $0.93 \pm 0.26^{a}$ & ns & 0.0002 & ns \\
\hline
\end{tabular}

${ }^{1}$ Data are given as means $\pm \mathrm{SD} ; n=5$ except IUGR HMD, $n=4$. BW, birth weight SAM, S-adenosylmethionine; SAH, S-adenosylhomocysteine; Tr, treatment. Groups were compared using two-way ANOVA with methyl demand (Tr) and BW (IUGR versus NW) as main factors with Bonferroni post-tests. $P$ values for main factors and interaction effects are presented in last three columns and means with different superscripts are significantly different after post-test, $P<0.05$. 
Table 3.3 Rate of ${ }^{3} \mathrm{H}$-methyl incorporation into transmethylation products and protein (corrected for precursor and time) and metabolite SRA data ${ }^{1}$ in intrauterine growthrestricted (IUGR) and normal weight (NW) piglets under control or high methyl demand (HMD) conditions ${ }^{2,3}$

\begin{tabular}{|c|c|c|c|c|c|c|c|}
\hline & $\begin{array}{c}\text { NW } \\
\text { Control }\end{array}$ & $\begin{array}{l}\text { NW } \\
\text { HMD }\end{array}$ & $\begin{array}{l}\text { IUGR } \\
\text { Control }\end{array}$ & $\begin{array}{l}\text { IUGR } \\
\text { HMD }\end{array}$ & BW & $\operatorname{Tr}$ & $\begin{array}{c}\text { BW x } \\
\text { Tr }\end{array}$ \\
\hline \multicolumn{5}{|c|}{ Rate of ${ }^{3} \mathrm{H}$-methyl incorporation } & \multicolumn{3}{|c|}{$P$ value } \\
\hline Creatine & $42.9 \pm 7.5^{a}$ & $74.0 \pm 19 b$ & $38.3 \pm 17.5^{a}$ & $85.4 \pm 20^{b}$ & ns & 0.0001 & ns \\
\hline PC & $4.04 \pm 1.1^{c}$ & $0.57 \pm 0.42^{a}$ & $2.08 \pm 1.2^{b}$ & $0.50 \pm 0.12^{\mathrm{a}}$ & 0.03 & 0.0001 & 0.04 \\
\hline DNA & $271 \pm 79$ & $220 \pm 130$ & $158 \pm 100$ & $178 \pm 85$ & 0.12 & ns & ns \\
\hline Protein & $13.0 \pm 6.6$ & $8.1 \pm 1.0$ & $17.2 \pm 6.3$ & $10.4 \pm 4.0$ & ns & 0.03 & ns \\
\hline & \multicolumn{4}{|c|}{ SRA } & \multicolumn{3}{|c|}{$P$ value } \\
\hline Creatine & $226 \pm 36^{a}$ & $444 \pm 71^{b}$ & $245 \pm 111 \mathrm{a}$ & $450 \pm 100^{b}$ & ns & $<0.0001$ & ns \\
\hline PC & $21.1 \pm 4.5^{c}$ & $3.1 \pm 1.4^{a}$ & $12.8 \pm 6.6^{b}$ & $2.9 \pm 0.7^{a}$ & 0.04 & $<0.0001$ & 0.05 \\
\hline DNA & $1.42 \pm 0.39$ & $1.26 \pm 0.45$ & $0.94 \pm 0.48$ & $0.95 \pm 0.43$ & 0.07 & ns & ns \\
\hline $\begin{array}{l}\text { Bound } \\
\text { Methionine }\end{array}$ & $22.3 \pm 17.0$ & $16.5 \pm 12.1$ & $33.0 \pm 24.0$ & $25.0 \pm 17.1$ & ns & ns & ns \\
\hline SAM & $513 \pm 82$ & $605 \pm 120$ & $677 \pm 180$ & $525 \pm 210$ & ns & ns & 0.04 \\
\hline $\begin{array}{l}\text { Free } \\
\text { Methionine }\end{array}$ & $156 \pm 80$ & $188 \pm 100$ & $242 \pm 170$ & $221 \pm 64$ & ns & ns & ns \\
\hline
\end{tabular}

${ }^{\mathrm{T}}$ Corrected Rate of ${ }^{3} \mathrm{H}$-methyl incorporation $=\left(\mathrm{SRA}_{\text {product }} / \mathrm{SRA}_{\text {precursor }}\right) /$ hours $\times 100$,

$\mathrm{SRA}=\mathrm{DPM} / \mathrm{nmol}$, except DNA where SRA=DPM $/ \mu \mathrm{g}$ 
${ }^{2}$ Precursor was hepatic SAM for methylated products (i.e. creatine, PC, DNA) and hepatic free methionine for protein.

${ }^{3}$ Data are given as means $\pm \mathrm{SD} ; n=5$ except IUGR HMD, $n=4$. BW, birth weight; PC, phosphatidylcholine; SAM, S-adenosylmethionine; Tr, treatment. Groups were compared using two-way ANOVA with methyl demand (Tr) and BW (IUGR versus NW) as main factors with Bonferroni post-tests. $P$ values for main factors and interaction effects are presented in last three columns and means with different superscripts are significantly different after post-test, $P<0.05$. 
Table 3.4 Tissue creatine concentration and specific radioactivity (SRA) (corrected for time $)^{1}$ in intrauterine growth-restricted (IUGR) and normal weight (NW) piglets under control or high methyl demand (HMD) conditions ${ }^{2}$

\begin{tabular}{|c|c|c|c|c|c|c|c|}
\hline & $\begin{array}{c}\text { NW } \\
\text { Control }\end{array}$ & $\begin{array}{l}\text { NW } \\
\text { HMD }\end{array}$ & $\begin{array}{l}\text { IUGR } \\
\text { Control }\end{array}$ & $\begin{array}{l}\text { IUGR } \\
\text { HMD }\end{array}$ & BW & $\mathrm{Tr}$ & $\begin{array}{l}\operatorname{Tr} \mathbf{x} \\
\text { BW }\end{array}$ \\
\hline & \multicolumn{4}{|c|}{$\mu \mathrm{mol} / \mathrm{g}$ wet weight } & \multicolumn{3}{|c|}{$P$ value } \\
\hline Liver & $0.56 \pm 0.26^{a}$ & $0.96 \pm 0.23^{b}$ & $0.48 \pm 0.10^{a}$ & $0.83 \pm 0.03^{b}$ & ns & 0.0006 & ns \\
\hline Muscle & $5.15 \pm 1.40$ & $4.98 \pm 1.16$ & $6.09 \pm 2.07$ & $6.10 \pm 1.16$ & ns & ns & ns \\
\hline $\begin{array}{l}\text { Small } \\
\text { intestine }\end{array}$ & $1.28 \pm 0.43$ & $1.46 \pm 0.20$ & $0.93 \pm 0.25$ & $1.09 \pm 0.27$ & 0.01 & ns & ns \\
\hline \multirow[t]{2}{*}{ Brain } & $1.93 \pm 0.17$ & $1.97 \pm 0.37$ & $2.08 \pm 0.78$ & $1.93 \pm 0.09$ & ns & ns & ns \\
\hline & \multicolumn{4}{|c|}{$\mathrm{SRA} / \mathrm{min}$} & \multicolumn{3}{|c|}{$P$ value } \\
\hline Liver & $3630 \pm 660^{a}$ & $7220 \pm 1400^{b}$ & $4090 \pm 800^{a}$ & $7510 \pm 700^{b}$ & ns & $<0.0001$ & ns \\
\hline Muscle & $22.1 \pm 6.3$ & $48.9 \pm 23.6$ & $34.2 \pm 17.3$ & $57.9 \pm 36.5$ & ns & 0.029 & ns \\
\hline $\begin{array}{l}\text { Small } \\
\text { intestine }\end{array}$ & $627 \pm 312$ & $711 \pm 205$ & $653 \pm 174$ & $746 \pm 333$ & ns & ns & ns \\
\hline Brain & $57.5 \pm 10.4$ & $68.5 \pm 20.3$ & $60.9 \pm 28.8$ & $116 \pm 72.0$ & ns & ns & ns \\
\hline
\end{tabular}

${ }^{1} \mathrm{SRA} / \mathrm{min}=(\mathrm{DPM} / \mu \mathrm{mol} / \mathrm{min})$.

${ }^{2}$ Data are given as means $\pm \mathrm{SD} ; n=5$. BW, birth weight; $\mathrm{Tr}$, treatment. Groups were compared using two-way ANOVA with methyl demand (Tr) and BW (IUGR versus NW) as main factors with Bonferroni post-tests. $P$ values for main factors and interaction effects are presented in last three columns and means with different superscripts are significantly different after post-test, $P<0.05$. 
differences among groups in the intestine or brain (although creatine SRA in the brain tended to be higher during HMD, $P=0.08$ ). Interestingly, the creatine SRA was 9- to 17fold higher in the small intestine than in the brain or muscle.

Partitioning of methyl groups among methylation reactions. To estimate the fractional recovery of methyl groups partitioned to each product (i.e., creatine, PC, DNA and protein) (Table 3.5), we first determined the $\mathrm{DPM}_{\text {product }} / \mathrm{g}$ liver by multiplying the hepatic product concentration by the raw uncorrected SRA values found in Table 3.3, which was then divided by the sum of the $\mathrm{DPM}_{\text {product }} / \mathrm{g}$ liver for all 4 products and multiplied by $100 \%$. The hepatic product concentrations were pooled estimates across treatments for DNA $(500 \mu \mathrm{g} / \mathrm{g}), \mathrm{PC}(16 \mu \mathrm{mol} / \mathrm{g})$ and methionine $(10 \mu \mathrm{mol} / \mathrm{g})$; because hepatic creatine concentrations were different among treatments, treatment means from Table 3.4 were used for creatine.

\subsection{Discussion}

The objective of this study was to determine the partitioning of methyl groups in a situation of high methyl demand by increasing the synthesis of creatine; the methylation of GAA to form creatine is quantitatively the most important consumer of methyl groups (3). Because creatine synthesis depends on GAA availability with no apparent feedback regulation, we infused one-third of the GAA required to synthesize a piglet's total daily creatine requirement (2) in order to acutely consume a large amount of hepatic methyl groups and create a situation of HMD. Indeed, the infusion of GAA into the piglet liver 
Table 3.5 Percent of ${ }^{3} \mathrm{H}$-methyl-labelled product remaining in the liver 60 min after infusion with of L-[methyl- $\left.{ }^{3} \mathrm{H}\right]$ methionine in intrauterine growth-restricted (IUGR) and normal weight $(\mathrm{NW})$ piglets under control or high methyl demand (HMD) conditions ${ }^{1,2}$

\begin{tabular}{|c|c|c|c|c|}
\hline & $\begin{array}{c}\text { NW } \\
\text { Control }\end{array}$ & $\begin{array}{l}\text { NW } \\
\text { HMD }\end{array}$ & $\begin{array}{l}\text { IUGR } \\
\text { Control }\end{array}$ & $\begin{array}{l}\text { IUGR } \\
\text { HMD }\end{array}$ \\
\hline & \multicolumn{4}{|c|}{$\%$} \\
\hline Protein & 32 & 26 & 51 & 37 \\
\hline Creatine & 18 & 66 & 18 & 56 \\
\hline PC & 49 & 8 & 31 & 7 \\
\hline DNA & 0.10 & 0.09 & 0.07 & 0.07 \\
\hline $\begin{array}{l}\text { Total radioactivity in } \\
\text { products (DPM/g) }\end{array}$ & 687900 & 641300 & 652900 & 669600 \\
\hline \multicolumn{5}{|c|}{${ }^{1} \%=\left(\mathrm{DPM}_{\text {Product }} / \mathrm{g}\right) /\left(\mathrm{DPM}_{\text {Sum of all products }} / \mathrm{g}\right) \times 100$} \\
\hline
\end{tabular}


for only two hours led to both $\sim 70 \%$ greater hepatic total creatine concentration and a doubling of the methyl incorporation into creatine, regardless of BW. These data suggest that even in neonates, methylation of GAA to creatine is not regulated by feedback inhibition. An increase in creatine synthesis from GAA requires an increased proportion of the available methyl groups; we hypothesized that if the methyl demand is large enough, then the remaining methyl group pool will become limiting for other methylation reactions.

Total body creatine is $70 \%$ greater in 11-day-old piglets than at 4 days old, emphasizing the importance of creatine in the neonate (2). It has also been determined that only $\sim 25 \%$ of the creatine accrued between 4 and $11 \mathrm{~d}$ of age could be derived from suckled milk, which means $\sim 75 \%$ was endogenously synthesized. Obviously, endogenous creatine synthesis is critical for a growing neonate, so a sufficient methyl supply is imperative; indeed, the proportion of methyl supply consumed by creatine increased from $18 \%$ to 56 $66 \%$ with HMD (Table 3.5). In a growing immature neonate, it is possible that either arginine (i.e., precursor for GAA synthesis) or methionine (i.e., source of methyl groups) could be limiting creatine synthesis to only $75 \%$ of requirement based on total creatine accretion, given these amino acids are essential in the neonate. But by providing preformed GAA in the current study, we have effectively provided excess arginine (via GAA) and isolated methionine (via SAM) as the potentially limiting precursor. Indeed, we observed lower hepatic SAM concentration after GAA was infused, suggesting SAM abundance was becoming limiting. Moreover, hepatic arginine concentrations actually 
increased with GAA infusion, suggesting that arginine was being spared from creatine synthesis after excess GAA was infused.

Because the other major user of methyl groups is PEMT (3), we expected PC synthesis to be most affected by the diminishing methyl supply in the liver. In the rat, it has been estimated that $30 \%$ of PC synthesis occurs via PEMT, whereas the other $70 \%$ is synthesized by the Kennedy pathway which uses choline to form PC (22). However, PEMT does respond to choline supply and demand (23-26). A change in flux through PEMT would impact methionine metabolism because the pathway utilizes 3 methyl groups per PC molecule, perhaps more quantitatively important than creatine synthesis. We were interested in whether PC synthesis via PEMT is affected by supply of methyl groups in the liver. Indeed, the increased methyl demand created by higher creatine synthesis resulted in lower methyl incorporation rate into PC such that the proportion of methyl supply consumed by PC decreased from $49 \%$ to $8 \%$ in the measured products in NW piglets (Table 3.5). There are two possible explanations for this result: 1) the drive towards greater creatine synthesis could be utilizing a significant portion of available methyl groups and thus creating a deficit in methyl supply for this methylation reaction; or alternatively, 2) the increased creatine production could result in a higher liver concentration of SAH, which is a competitive inhibitor of the PEMT pathway (27). In rats, a change in SAM/SAH ratio from 5.6 to 0.6 lowered incorporation of L-[methyl$\left.{ }^{14} \mathrm{C}\right]$ methionine into PC by $75 \%$ (27), due to an increase in SAH concentration from 8 to $2050 \mathrm{nmol} / \mathrm{g}$. Similar to studies in rats (28), GAA supplementation in our piglets led to a reduction in hepatic SAM concentration and a modest rise in hepatic SAH concentration 
(from $\sim 35$ to $\sim 49 \mathrm{nmol} / \mathrm{g}$ ), with a $\sim 50 \%$ reduction in SAM/SAH ratio (Table 3.2). It is possible that the $85 \%$ lower PC incorporation of ${ }^{3} \mathrm{H}$-methyl (in NW piglets) was partially due to more SAH competing with SAM for PEMT, but given the dramatically higher SAH concentrations necessary to evoke this response in rats (27), it is unlikely that competitive inhibition was a major factor in our results. Therefore, we postulate that the lower conversion rate via PEMT is likely due to a rapidly limiting methyl supply as a consequence of increased creatine synthesis.

In addition to its role in transmethylation reactions, methionine is also in great demand for protein synthesis, especially in the growing neonate. Because methionine is an essential amino acid that is first limiting in many dietary proteins, we hypothesized that a neonate would be particularly sensitive to a significant re-partitioning of methionine flux to methylation reactions. Indeed, in this study, when methionine was diverted to meet the high methyl demands for creatine synthesis during GAA infusion, 40\% less methionine was incorporated into protein, in the absence of changes in hepatic methionine concentration or SRA. This could be due to either a decrease in protein synthesis independent of available methionine supply or, more likely, diversion of the methionine pool away from protein synthesis to meet the high methyl demand for creatine synthesis. This result is particularly profound as it suggests that an increase in methylation demand can limit growth in a neonate. Neonatal piglets appear to have a lower fraction of methionine diverted to protein synthesis and a higher requirement for methionine flux through transmethylation compared to 1-month-old piglets (29). Considering up to twothirds of methyl from methionine was recovered in PC and creatine alone (Table 3.5), it is 
possible that transmethylation reactions are prioritized over protein synthesis in NW neonates. This delicate balance of multiple demands for limited methionine demonstrates that nutrients involved in transmethylation reactions (i.e., creatine, PC), as well as in remethylation (i.e., folate, betaine, choline, vitamins $\mathrm{B}_{6}$ and $\mathrm{B}_{12}$ ), need to be considered when determining sulfur amino acid requirements of neonates.

Because we have shown that IUGR piglets have a reduced capacity to remethylate homocysteine to methionine (15), we investigated whether IUGR piglets have lower rates of ${ }^{3} \mathrm{H}$-methyl incorporation into transmethylation products. Interestingly, we observed that even under control conditions, IUGR resulted in a $\sim 50 \%$ lower methyl incorporation into PC (Table 3.3), perhaps due to a higher relative choline intake which occurs in IUGR to facilitate compensatory growth (11). With high methyl demand, PC synthesis via PEMT was reduced to a similarly low level in both NW and IUGR pigs, suggesting a minimal level of PE methylation was reached. This is particularly important in a growing neonate as PEMT plays a key role in the distribution of long-chain fatty acids, including docosahexaenoic acid, from the liver to other tissues (30). Interestingly, half of ${ }^{3} \mathrm{H}$-methyl was diverted to protein synthesis in IUGR pigs, compared to only one-third in NW pigs (Table 3.5). Although SAM/SAH ratios were not different, it would appear there was a lower total transmethylation flux (i.e., to PC and creatine) with IUGR with more methionine partitioned to protein synthesis. Although hypomethylation of DNA is associated with programming of adult disease (7), which has been demonstrated in IUGR piglets by us $(11,12)$ and others $(13,14)$, we found no difference in methyl incorporation into DNA among groups. 
In conclusion, an increase in available GAA results in greater methyl incorporation into creatine and reduced methionine incorporation into protein. The partitioning of available methionine between its primary maintenance role as a methyl donor and its role in growth via protein synthesis has important implications when determining amino acid recommendations for neonates. For example, the requirement of methionine for creatine synthesis will vary dramatically in infants fed creatine-free soy-based formula versus those fed bovine milk-based formulas providing up to $36 \%$ of creatine needs (31). And because of its potential to both spare arginine and increase muscle creatine, GAA is also currently being investigated as a supplement to improve performance in animal production $(32,33)$. Moreover, the current study has demonstrated that methyl supply can become limiting in the neonate and that this leads to a re-partitioning of methyl groups among methylation reactions. Indeed, the increase in methylation of GAA for creatine synthesis resulted in a decreased supply of methyl groups which led to dramatically reduced methyl incorporation into PC. Furthermore, neonates born with IUGR experience lower methylation rates of PC which could potentially have implications for lipid metabolism.

\subsection{Acknowledgments}

The authors thank Dr. Simon Lamarre for his technical assistance with HPLC method development. L.E.M., J.A.B., and R.F.B. conceived and designed the research; and L.E.M. and R.F.B. performed the experiments, analyzed the data, and drafted the manuscript. All authors interpreted the results of the experiments, revised the manuscript, and read and approved the final manuscript 


\subsection{References}

[1] Schubert HL, Blumenthal RM, Cheng X. Many paths to methyltransfer: a chronicle of convergence. Trends Biochem Sci. 2003;28:329-35.

[2] Brosnan JT, Wijekoon EP, Warford-Woolgar L, Trottier NL, Brosnan ME, Brunton JA, Bertolo RF. Creatine synthesis is a major metabolic process in neonatal piglets and has important implications for amino acid metabolism and methyl balance. $\mathbf{J}$ Nutr. 2009;139:1292-7.

[3] Stead LM, Brosnan JT, Brosnan ME, Vance DE, Jacobs RL. Is it time to reevaluate methyl balance in humans? Am J Clin Nutr. 2006;83:5-10.

[4] Bird A. DNA methylation patterns and epigenetic memory. Genes Dev. 2002;16:621.

[5] Plagemann A, Harder T, Brunn M, Harder A, Roepke K, Wittrock-Staar M, Ziska T, Schellong K, Rodekamp E, Melchior K, et al. Hypothalamic proopiomelanocortin promoter methylation becomes altered by early overfeeding: an epigenetic model of obesity and the metabolic syndrome. J Physiol. 2009;587:4963-76.

[6] Godfrey KM, Barker DJ. Fetal nutrition and adult disease. Am J Clin Nutr. 2000;71:1344S-52S.

[7] McMillen IC, Robinson JS. Developmental origins of the metabolic syndrome: prediction, plasticity, and programming. Physiol Rev. 2005;85:571-633.

[8] Sinclair KD, Allegrucci C, Singh R, Gardner DS, Sebastian S, Bispham J, Thurston A, Huntley JF, Rees WD, Maloney CA, et al. DNA methylation, insulin resistance, and blood pressure in offspring determined by maternal periconceptional B vitamin and methionine status. Proc Natl Acad Sci U S A. 2007;104:19351-6.

[9] Liu JB, Chen DW, Yu B, Mao XB. Effect of maternal folic acid supplementation on hepatic one-carbon unit associated gene expressions in newborn piglets. Mol Biol Rep. 2011;38:3849-56.

[10] da Silva RP, Nissim I, Brosnan ME, Brosnan JT. Creatine synthesis: hepatic metabolism of guanidinoacetate and creatine in the rat in vitro and in vivo. Am $\mathrm{J}$ Physiol Endocrinol Metab. 2009;296:E256-61.

[11] Myrie SB, McKnight LL, Van Vliet BN, Bertolo RF. Low birth weight is associated 
with reduced nephron number and increased blood pressure in adult Yucatan miniature swine. Neonatology. 2011;100:380-6.

[12] McKnight LL, Myrie SB, MacKay DS, Brunton JA, Bertolo RF. Glucose tolerance is affected by visceral adiposity and gender, but not birth weight or early nutrition, in Yucatan miniature pigs. Appl Physiol Nutr Metab. 2012;37:106-14.

[13] Poore KR, Forhead AJ, Gardner DS, Giussani DA, Fowden AL. The effects of birth weight on basal cardiovascular function in pigs at 3 months of age. J Physiol. 2002;539: 969-78.

[14] Poore KR, Fowden AL. The effects of birth weight and postnatal growth patterns on fat depth and plasma leptin concentrations in juvenile and adult pigs. J Physiol. 2004;558(Pt 1):295-304.

[15] MacKay DS, Brophy JD, McBreairty LE, McGowan RA, Bertolo RF. Intrauterine growth restriction leads to changes in sulfur amino acid metabolism, but not global DNA methylation, in Yucatan miniature piglets. J Nutr Biochem. 2012; 23:1121-7.

[16] Buchberger W, Ferdig M. Improved high-performance liquid chromatographic determination of guanidino compounds by precolumn derivatization with ninhydrin and fluorescence detection. J Sep Sci. 2004;27:1309-12.

[17] Ratnam S, Wijekoon EP, Hall B, Garrow TA, Brosnan ME, Brosnan JT. Effects of diabetes and insulin on betaine-homocysteine S-methyltransferase expression in rat liver. Am J Physiol Endocrinol Metab. 2006;290:E933-9.

[18] Bidlingmeyer BA, Cohen SA, Tarvin TL. Rapid analysis of amino acids using precolumn derivatization. J Chromatogr. 1984;336: 93-104.

[19] Lamarre SG, Edison EE, Wijekoon EP, Brosnan ME, Brosnan JT. Suckling rat pups accumulate creatine primarily via de novo synthesis rather than from dam milk. J Nutr. 2012;140:1570-3.

[20] Folch J, Lees M, Sloane Stanley GH. A simple method for the isolation and purification of total lipides from animal tissues. J Biol Chem. 1957;226:497-509.

[21] Bartlett GR. Phosphorus assay in column chromatography. J Biol Chem. 1959;234:466-468.

[22] Li Z, Vance DE. Phosphatidylcholine and choline homeostasis. J Lipid Res. 2008;49:1187-94. 
[23] Schneider WJ, Vance DE. Effect of choline deficiency on the enzymes that synthesize phosphatidylcholine and phosphatidylethanolamine in rat liver. Eur $\mathbf{J}$ Biochem. 1978;85:181-7.

[24] Cui Z, Vance DE. Expression of phosphatidylethanolamine N-methyltransferase-2 is markedly enhanced in long term choline-deficient rats. J Biol Chem 1996;271:283943.

[25] Jacobs RL, Devlin C, Tabas I, Vance DE. Targeted deletion of hepatic CTP:phosphocholine cytidylyltransferase A in mice decreases plasma high density and very low density lipoproteins. J Biol Chem. 2004;279:47402-10.

[26] Jacobs RL, Stead LM, Devlin C, Tabas I, Brosnan ME, Brosnan JT, Vance DE. Physiological regulation of phospholipid methylation alters plasma homocysteine in mice. J Biol Chem. 2005;280:28299-305

[27] Hoffman DR, Marion DW, Cornatzer WE, Duerre JA. S-Adenosylmethionine and Sadenosylhomocysteine metabolism in isolated rat liver. Effects of L-methionine, Lhomocysteine, and adenosine. J Biol Chem. 1980;255:10822-7.

[28] Setoue M, Ohuchi S, Morita T, Sugiyama K. Hyperhomocysteinemia induced by guanidinoacetic acid is effectively suppressed by choline and betaine in rats. Biosci Biotechnol Biochem. 2008;72:1696-703.

[29] Bauchart-Thevret C, Stoll B, Chacko S, Burrin DG. Sulfur amino acid deficiency upregulates intestinal methionine cycle activity and suppresses epithelial growth in neonatal pigs. Am J Physiol Endocrinol Metab. 2009;296:1239-50.

[30] Watkins SM, Zhu X, Zeisel SH. Phosphatidylethanolamine-N-methyltransferase activity and dietary choline regulate liver-plasma lipid flux and essential fatty acid metabolism in mice. J Nutr. 2003;133:3386-91.

[31] Edison EE, Brosnan ME, Aziz K, Brosnan JT. Creatine and guanidinoacetate content of human milk and infant formulas: implications for creatine deficiency syndromes and amino acid metabolism. Br J Nutr. 2013;Feb 7:1-4.

[32] Michiels J, Maertens L, Buyse J, Lemme A, Rademacher M, Dierick NA, De Smet S. Supplementation of guanidinoacetic acid to broiler diets: effects on performance, carcass characteristics, meat quality, and energy metabolism. Poult Sci. 2012;91:402-12. 
[33] Dilger RN, Bryant-Angeloni K, Payne RL, Lemme A, Parsons CM. Dietary guanidino acetic acid is an efficacious replacement for arginine for young chicks. Poult Sci. 2013;92:171-7. 


\section{Chapter 4: Betaine is as effective as folate at re-synthesizing methionine for protein}

synthesis during moderate methionine deficiency in piglets

Laura E. McBreairty ${ }^{1}$, Jason L. Robinson ${ }^{1}$, Scott V. Harding ${ }^{2}$, Edward Randell ${ }^{3}$, Janet A. Brunton $^{1}$, Robert F. Bertolo ${ }^{1 *}$

Chapter 4 was designed by L. McBreairty, J. Robinson and R. Bertolo. L. McBreairty and J. Robinson conducted the animal care and analyzed plasma folate, choline, dimethylglycine and betaine as well as plasma phenylalanine enrichment. Breath samples for IRMS were analyzed by S. Harding at King's College London, London, UK. All other research was conducted by L. McBreairty and L. McBreairty analyzed all data. The manuscript was prepared by L. McBreairty with guidance from R. Bertolo. 


\subsection{Abstract}

Methionine is an essential amino acid that is in high demand in neonates for protein synthesis as well as for transmethylation reactions, such as creatine synthesis and DNA methylation. Transmethylation reactions produce homocysteine, which can be either converted to cysteine or re-methylated to methionine via folate or betaine (synthesized from choline). In the neonatal piglet approximately half of methionine flux is used for transmethylation reactions with $45 \%$ of homocysteine undergoing re-methylation. It is unclear whether both remethylation pathways are of equal importance in the neonate. The objective of this study was to determine whether supplementation with folate, betaine or a combination of both ( $n=6$ per treatment) can equally re-synthesize methionine for protein synthesis when dietary methionine is limiting. We measured ${ }^{13} \mathrm{C}$-phenylalanine oxidation as an indicator of protein synthesis in piglets adapted for 6 days to a low-methionine diet devoid of folate, choline and betaine as well as following 2 days of supplementation. Prior to supplementation, piglets had lower levels of plasma folate, betaine and choline compared to baseline with no change in homocysteine. Post-supplementation, phenylalanine oxidation levels were $20-46 \%$ lower with any methyl donor supplementation $(P=0.006)$ with no difference among groups. Furthermore, both methyl donors led to lower levels of homocysteine following supplementation $(P<0.05)$. These data demonstrate an equal capacity for betaine and folate to remethylate methionine for protein synthesis. 


\subsection{Introduction}

The amino acid methionine is important in the neonate not only for protein synthesis and growth, but in addition, it is adenylated to S-adenosylmethionine (SAM), the universal methyl donor in over 50 transmethylation reactions (1). SAM is utilized to expand body pools of transmethylation products such as phosphatidylcholine (PC), as well as creatine, which increases in the neonatal piglet by $\sim 10 \%$ per day (2). In addition, SAM provides the methyl group used to establish and maintain epigenetic patterns of DNA methylation, which can be permanently affected by the neonatal diet (3). The methionine required for these reactions is significant considering a healthy neonate consuming $14 \mu \mathrm{mol} \mathrm{kg}{ }^{-1} \mathrm{~h}^{-1}$ of methionine has a transmethylation rate of $\sim 20 \mu \mathrm{mol} \mathrm{kg}^{-1} \mathrm{~h}^{-1}$ (4). This high demand for transmethylation reactions highlights the importance in understanding how the dietary supply of methionine and methyl groups affects availability of methionine for growth in the neonate.

The availability of methionine for its various functions is dependent on dietary methionine as well as the remethylation of methionine. During transmethylation, SAM is converted to S-adenosylhomocysteine (SAH) which is further hydrolyzed to form homocysteine, a non-protein amino acid that can either be irreversibly converted to cysteine or remethylated to methionine by receiving a methyl group from 5methyltetrahydrofolate or betaine, the oxidation product of choline [5]. 5Methyltetrahydrofolate provides a methyl group via the ubiquitous enzyme methionine synthase (MS) while betaine-homocysteine methyltransferase (BHMT) transfers a methyl group from betaine, a reaction that is limited to the liver and kidney [6]. Remethylation 
via betaine also produces dimethylglycine (DMG), an inhibitor of BHMT [7], which is oxidized to sarcosine via DMG dehydrogenase using folate as a cofactor [8].

In the neonatal piglet, $\sim 50 \%$ of methionine is converted to SAM while at 1 month old, only $30 \%$ of methionine is utilized for transmethylation reactions [9]. Furthermore, the fraction of homocysteine remethylated by 5-methyltetrahydrofolate and betaine in the neonate is $\sim 45 \%$, whereas only $20 \%$ of homocysteine undergoes remethylation at 1 month. This shows the significant demand placed on methionine for transmethylation reactions during the first weeks of life and demonstrates the importance of the remethylation nutrients, folate and betaine, to maintain methionine availability. Although the minimum dietary methionine requirement has been established in the human neonate, this value was determined under conditions of excess dietary cysteine [10] which has been shown in piglets to spare the methionine requirement by up to $40 \%$ [11]. This sparing effect emphasizes that the methionine requirement is not static and nutrients involved in both methionine demand (i.e. cysteine) and supply (i.e. folate, betaine) should be considered when determining the dietary methionine requirement.

Methionine availability will depend on dietary levels of these methyl-related nutrients. For the growing neonate, the concentrations of these nutrients are highly variable among infant formulas and breast milk. Serum free choline is higher in breast fed compared to formula fed infants and the choline concentration of breast milk is influenced by maternal choline status [12]. Although the average choline concentration in breast milk is $\sim 1200$ $\mathrm{nmol} / \mathrm{ml}$, the concentration of betaine is only $7 \mathrm{nmol} / \mathrm{ml}$ [13] making choline the primary source of betaine in the neonate. Infant formulas are often derived from cow's milk 
which has a higher casein/whey ratio than human breast milk. Because casein is high in methionine while whey is high in cysteine, cow's milk also has a higher methionine/cysteine ratio of $\sim 3$ versus $\sim 0.8$ found in human milk [14]. Studies investigating the relationship between these remethylation nutrients have demonstrated that dietary choline deficiency leads to lower hepatic folate [15] while folate deficiency results in hepatic depletion of choline [16], further emphasizing the need to assess the relationship between nutrients involved in methionine metabolism when considering individual nutrient requirements.

Because of the high demand placed on methionine during early development and the variability of methyl donors in the neonatal diet, the objective of this study was to determine how important remethylation is to methionine availability. Moreover, we wanted to compare the effectiveness of folate, betaine or a combination of both to remethylate methionine. In order to elicit a response with remethylation, we employed a diet that was moderately deficient in methionine and used the indicator amino acid oxidation (IAAO) technique to detect changes in protein synthesis. The IAAO technique is based on the concept that when one amino acid is limiting for protein synthesis, the remaining amino acids will be oxidized; by increasing the availability of the limiting amino acid (i.e. more methionine from remethylation), the oxidation of other amino acids will decrease, reflecting a higher incorporation into protein [17]. Using L- $\left.{ }^{13} \mathrm{C}\right]-$ phenylalanine as our indicator amino acid, we were able to determine changes in the rate of phenylalanine oxidation prior to and following methyl donor supplementation, 
consequently reflecting the effect of these methyl donors at increasing the availability of methionine for protein synthesis.

\subsection{Materials and Methods}

Animal protocol. All animal-handling procedures were approved by the institutional animal care committee in accordance with the guidelines of the Canadian Council on Animal Care. Eighteen 5-8 day old Yucatan miniature piglets were obtained from the Memorial University of Newfoundland breeding colony. Upon arrival, general anesthesia was induced with isoflurane $(1-2 \%)$ in oxygen $(1.5 \mathrm{~L} / \mathrm{min})$ and piglets were implanted with two silastic venous catheters (femoral and jugular) for blood sampling and a gastric catheter for intragastric (IG) feeding following recovery [18]. Piglets were administered antibiotics via both venous catheters (Borgal: $20 \mathrm{mg}$ trimethoprim and $100 \mathrm{mg}$ sulfadoxine) (Intervet Canada Ltd, Kirkland, Canada) immediately following surgery and daily for the duration of the study. The analgesic Temgesic $(0.03 \mathrm{mg} / \mathrm{kg}$ of buprenorphine hydrochloride) (Schering-Plough, Whitehouse Station, New Jersey) was also administered immediately following surgery as well as every 12 hours post-surgery until no guarding was observed by piglets. Once post-surgical drugs were administered, piglets were transferred to individual metabolic cages $(1 \mathrm{~m} \mathrm{x} 1 \mathrm{~m})$ equipped with heat lamps in a room maintained at $28{ }^{\circ} \mathrm{C}$ and lit from 0800-2000 hours. Diet was administered using a peristaltic pump attached via a dual port swivel and tether system (Lomir Biomedical, Montreal, Quebec, Canada) that allowed for free movement of piglets around the cage while allowing for continuous IV or IG infusions. Blood was sampled daily using sodium heparin vacutainers and plasma was separated and stored at $-20{ }^{\circ} \mathrm{C}$ for 
future analysis. Piglets were weighed daily and diet infusion rates were adjusted accordingly.

Diet regimen. Immediately following surgery (day 0) piglets were parenterally fed at $50 \%$ of requirement via the jugular catheter. On the morning of day 1 , diet delivery rate was increased to $75 \%$ of the requirement and by evening of the same day, diet delivery was changed to enteral feeding via the IG catheter at $100 \%$ of total requirement. From day 0 to day 5 piglets were fed an adaptation diet which provided adequate methionine $(0.3 \mathrm{~g} \cdot$ $\mathrm{kg}^{-1} \cdot$ day $^{-1}$ ) (Figure 4.1) [19] and was devoid of folate. On day 5, methionine was reduced to a moderately deficient level of $0.2 \mathrm{~g} \cdot \mathrm{kg}^{-1} \cdot$ day $^{-1}$ for the remainder of the 10 day study and alanine was adjusted to maintain an isonitrogenous diet. On day 7, piglets were randomly assigned to receive supplementation with either folate $(n=6)$, betaine $(\mathrm{n}=6)$ or both folate and betaine $(\mathrm{n}=6)$. Folate was supplemented at a rate of $38 \mathrm{ug} \cdot \mathrm{kg}^{-1}$. day $^{-1}$ providing $200 \%$ of the daily folate requirement in a piglet (NRC, 1998) and betaine was provided at a rate of $235 \mathrm{mg} \cdot \mathrm{kg}^{-1} \cdot \mathrm{day}^{-1}$. There is currently no specified requirement for betaine in piglets and the dose provided in this study is the molar equivalent of the methionine requirement of $0.3 \mathrm{~g} \mathrm{~kg}^{-1} \mathrm{day}^{-1}$. Although the molar betaine supplementation level used in this study was higher than folate, betaine can only be synthesized via choline oxidation and cannot be re-synthesized following transfer of its methyl group, while the methyl group provided by folate can be regenerated via serine [20]. Both adaptation and test diets provided $16 \mathrm{~g} \cdot \mathrm{kg}^{-1} \cdot \mathrm{day}^{-1}$ of protein supplied by crystalline amino acids as previously described (Table 4.1) [18]. Non-protein energy was provided in a 1:1 ratio of carbohydrate in the form of dextrose and fat provided as 


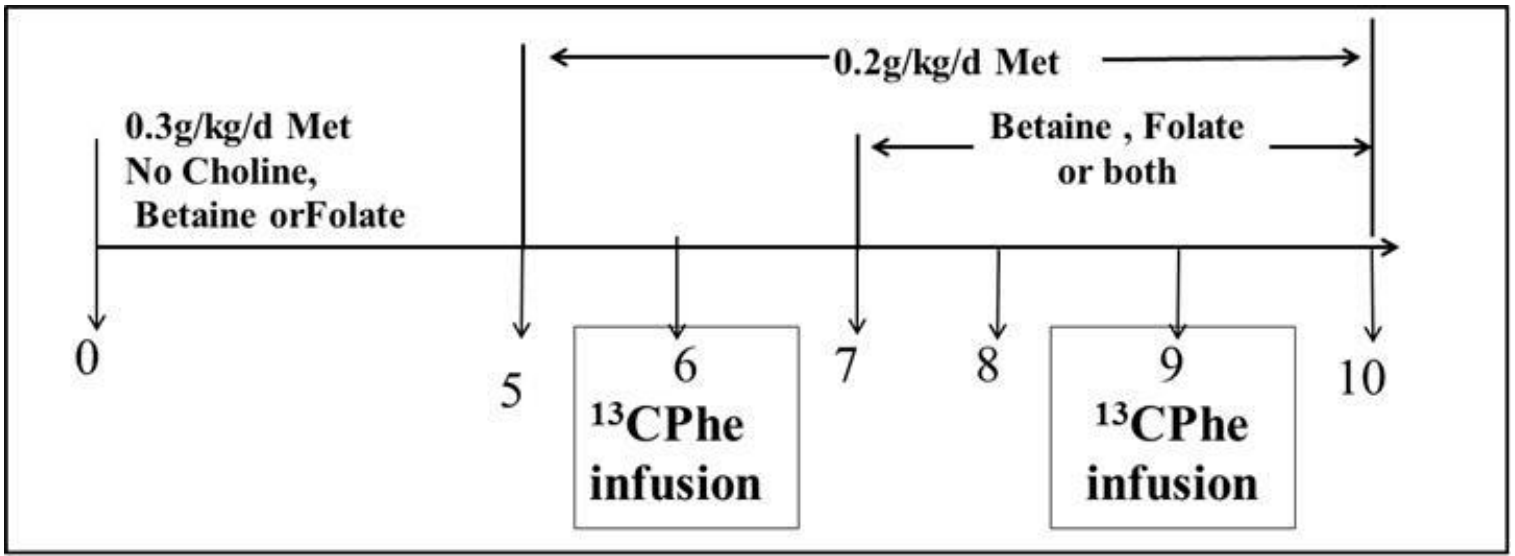

Figure 4.1. Diet and infusion protocol. Abbreviations: Met, methionine; Phe, phenylalanine. 
Table 4.1 Amino acid composition of elemental diet.

\begin{tabular}{|l|r|}
\hline Amino Acid & g AA/kg.d \\
\hline Alanine & 1.663 \\
\hline Arginine & 0.942 \\
\hline Aspartic acid & 0.942 \\
\hline Cysteine & 0.224 \\
\hline Glutamic acid & 1.631 \\
\hline Glycine & 0.479 \\
\hline Histidine & 0.479 \\
\hline Isoleucine & 0.718 \\
\hline Leucine & 1.616 \\
\hline Lysine-HCl & 1.607 \\
\hline Methionine & 0.300 \\
\hline Phenylalanine & 0.824 \\
\hline Proline & 1.287 \\
\hline Serine & 0.868 \\
\hline Taurine & 0.075 \\
\hline Tryptophan & 0.329 \\
\hline Tyrosine & 0.117 \\
\hline Valine & 0.823 \\
\hline Threonine & 0.823 \\
\hline & \\
\hline
\end{tabular}


soybean oil which was administered into the diet line via a syringe pump at a rate of 0.12 $\mathrm{ml} \cdot \mathrm{kg}^{-1} \cdot \mathrm{h}^{-1}$. Vitamins (Multi-12K Pediatric, Sabex, Boucherville, Canada) and minerals were provided in the diet at $>100 \%$ of the requirement and diet was administered at a rate of $11.3 \mathrm{ml} \cdot \mathrm{kg}^{-1} \cdot \mathrm{h}^{-1}$. Diet was made under aseptic conditions as previously described [18].

Isotope Infusion protocol. On days 6 and 9 of the study, piglets were moved to individual and sealed Plexiglas boxes $(60 \times 40 \times 40 \mathrm{~cm})$ fitted with a tether and swivel system to allow for blood collection via venous catheters, delivery of isotope and continuous delivery of diet. A primed $(7 \mathrm{mg} / \mathrm{kg})$, constant $(2.4 \mathrm{mg} / \mathrm{kg}$ administered every 30 minutes) infusion of $\mathrm{L}-\left[{ }^{13} \mathrm{C}\right]$-phenylalanine (99\%, Cambridge Isotope Laboratories, Andover, MA) was given intragastrically via the diet line for 6 hours [21]. Blood was sampled every 30 minutes and heparinized plasma was separated and stored at $-20{ }^{\circ} \mathrm{C}$ for later analysis of L- $\left[{ }^{13} \mathrm{C}\right]$-phenylalanine enrichment. Breath samples were collected and the rate of $\mathrm{CO}_{2}$ production was determined via an indirect calorimetry system (Qubit systems, Kingston ON, Canada). A vacuum pump was used to draw air from the boxes at a fixed known rate controlled by a 16 series mass flow controller precision gas flow controller (Qubit systems, Kingston ON, Canada). Individual 20 minute breath samples were collected using a 4-channel gas switcher to direct flow from a specified box into a midget bubbler (Kimble Chase Kontes, TN, USA) containing sodium hydroxide (1 mol/L). Following the collection, the sodium hydroxide was quickly poured into an empty glass vacutainer and the seal was immediately replaced. A syringe was used to evacuate air from the vacutainer which was then placed in a $4{ }^{\circ} \mathrm{C}$ fridge until further 
analysis for ${ }^{13} \mathrm{CO}_{2}$ enrichment. Following collection of breath, the channel gas switcher was used to direct air towards a Model CD-3A $\mathrm{CO}_{2}$ analyzer (AEI technologies, Naperville, Il, USA) to determine the concentration of $\mathrm{CO}_{2}$ in the box and $\mathrm{CO}_{2}$ production rate via the calorimetry system software (Qubit systems C960 multichannel gas exchange system software, Kingston On, Canada).

Plasma Metabolites. Total homocysteine and cysteine concentrations were determined according to [22]. Concentrations of choline and betaine were quantified using an HPLC MS/MS as described elsewhere [23,24]. Breifly, plasma samples were mixed with 3 volumes of acetonitrile containing $100 \mu \mathrm{M}$ of $\mathrm{D}_{11}$-Betaine and $\mathrm{D}_{9}$-Choline. The supernatant was extracted and injected onto an Atlantis HILIC Silica $3 \mu \mathrm{M} 2.1 \times 100 \mathrm{~mm}$ column and samples were analyzed on a Waters Alliance 2795 HPLC system (Water Corporation, Milford, MA, USA) using a Micromass Quattro Ultima tandem mass spectrometer (triple-quad) (Water Corporation, Milford, MA, USA). The compounds were detected in multiple-reaction monitoring mode using the following $\mathrm{m} / \mathrm{z}$ transitions: $\mathrm{D}_{11}$-Betaine $129 \rightarrow 68$, Betaine $118 \rightarrow 59$, $\mathrm{D}_{9}$-Choline $113 \rightarrow 69$, Choline $104 \rightarrow 60$. Plasma concentrations were calculated using dialyzed plasma spiked with choline and betaine standards, and expressed relative to $\mathrm{D}_{11}$-betaine and $\mathrm{D}_{9}$-choline. Concentrations were computed using MassLynx Software (Waters Corporation: Milford, MA). Plasma folate concentrations were determined using folate kit (Abbott, B1P740) and Architect Clinical Chemistry Analyzers.

$\mathrm{CO}_{2}$ enrichment in breath. Breath $\mathrm{CO}_{2}$ was analysed for ${ }^{13} \mathrm{C}$ isotope enrichment by isotope ratio mass spectrometry - Delta XP isotope ratio mass spectrometer interfaced to a 
Gas Bench II (Thermo Fisher Scientific, Bremen, Germany). Briefly, 200 ul of the $\mathrm{NaOH}$ solution containing the sequestered $\mathrm{CO}_{2}$ was transferred to Exetainers (Labco Limited, Lampeter, Wales, UK) and capped. Using a 27 gauge needle and syringe, $300 \mathrm{ul}$ of 1 $\mathrm{mol} / \mathrm{L} \mathrm{HCl}$ was added to each exetainer through the air tight septum. Samples were vortexed and allowed to stand at room temperature for 30 minutes before analysis by isotope ratio mass spectrometery. Mean ${ }^{13} \mathrm{CO}_{2}$ enrichment was compared against standardized reference gas which was calibrated against Vienna Pee Dee Belemnite.

Plasma Enrichment of $\left[{ }^{13} \mathrm{C}\right]$ phenylalanine. The plasma enrichment of $\left[{ }^{13} \mathrm{C}\right]$ phenylalanine was analyzed using a modified gas chromatography-mass spectrometry (GCMS) method of Lamarre [25]. $50 \mu \mathrm{L}$ of plasma was mixed with $135 \mu \mathrm{L}$ of $133 \mathrm{mM}$ pentafluorobenzyl bromide and $25 \mu \mathrm{L}$ of $0.5 \mathrm{M}$ phosphate buffer (pH 8) in an eppendorf tube. Samples were placed into a $60{ }^{\circ} \mathrm{C}$ oven for 60 minutes to allow for alkylation of phenylalanine by pentafluorobenzyl bromide. $335 \mu \mathrm{L}$ of hexane was added to terminate derivitization. After a second mixing, the organic phase was transferred to a GCMS vial. Derivatized samples were analyzed using a GCMS equipped with an autosampler (Agilent Technologies). A $2 \mu \mathrm{L}$ aliquot of the organic phase was injected onto a DM5MS column $(0.25 \mathrm{~mm} \times 30 \mathrm{~m} \times 0.22 \mu \mathrm{m})$. The GC (6890N Network GC System) oven was preheated to $50{ }^{\circ} \mathrm{C}$ and equipped with helium carrier gas. A temperature of $50{ }^{\circ} \mathrm{C}$ was held for $3 \mathrm{~min}$ and was increased to $280{ }^{\circ} \mathrm{C}$ at a rate of $30{ }^{\circ} \mathrm{C} / \mathrm{min}$ which was then held for 4 min. After column separation, $20 \mathrm{eV}$ of collision energy was used to ionize samples upon entering a quadrapole MS (5973 inert Mass Selective Detector). Selected-ion monitoring mode was used to monitor specific ions for phenylalanine $(\mathrm{m} / \mathrm{z}=434$ and 
435). Area under the curve for each ion was recorded and used to calculate the ratio of $[\mathrm{M}+1]$ phenylalanine as compared to $[\mathrm{M}+0]$ phenylalanine.

Calculations. Phenylalanine flux, rate of phenylalanine oxidation and percent phenylalanine oxidized were calculated according to equations by Zello [26];

Phenylalanine flux $(\mathrm{Q})$ :

$\mathrm{Q}=\mathrm{i}\left[\left(\mathrm{E}_{\mathrm{i}} / \mathrm{E}_{\mathrm{p}}\right)-1\right]$

Where $E_{i}$ was the enrichment of $L_{-}\left[{ }^{13} \mathrm{C}\right]$-phenylalanine infused (MPE), $E_{p}$ was the enrichment of plasma L- $\left[{ }^{13} \mathrm{C}\right]$-phenylalanine above baseline at isotopic plateau (MPE) and $\mathrm{i}$ was the rate of $\mathrm{L}-\left[{ }^{13} \mathrm{C}\right]$-phenylalanine infused $\left(\mu \mathrm{mol} \cdot \mathrm{kg}^{-1} \cdot \mathrm{h}^{-1}\right)$.

The rate of phenylalanine oxidation $\left(\mathrm{Phe}_{\mathrm{ox}}\right)$ :

$\mathrm{Phe}_{\mathrm{ox}}=\left[\left(\mathrm{FCO}_{2} \times \mathrm{ECO}_{2} \times 44.6 \times 60\right) /(\mathrm{W} \times 0.93 \times 100)\right] \times\left(1 / \mathrm{E}_{\mathrm{p}}-1 / \mathrm{E}_{\mathrm{i}}\right) \times 100 ;$

Where $\mathrm{FCO}_{2}=\mathrm{CO}_{2}$ production rate $\left(\mathrm{cm}^{3} / \mathrm{min}\right)$ determined by Qubit system software as described above, $\mathrm{ECO}_{2}={ }^{13} \mathrm{CO}_{2}$ enrichment in expired breath at isotopic steady state (atom percent excess) determined by isotope ratio mass spectrometry and $\mathrm{W}$ was the weight $(\mathrm{kg})$ of the piglet. The constants $44.6 \mathrm{pmol} / \mathrm{cm}^{3}$ and $60 \mathrm{~min} / \mathrm{h}$ converted $\mathrm{FCO}_{2}$ to micromoles per hour, and the factor 100 changed atom percent excess to a fraction. 0.93 was used to account for $\mathrm{CO}_{2}$ retention in piglets [27].

The $\%$ dose of L- $\left[{ }^{13} \mathrm{C}\right]$-phenylalanine oxidized $\left(\% \mathrm{Phe}_{\mathrm{ox}}\right)$ :

$\% \mathrm{Phe}_{\text {ox }}\left[\left(\mathrm{FCO}_{2} \times \mathrm{ECO}_{2} \times 44.6 \times 60\right) /(\mathrm{W} \times 0.93 \times 100)\right] / \mathrm{i} \times 100 \%$ 
Non-oxidative disposal (NOD) and phenylalanine released from protein (PB) were calculated according to House et al. [28] based on the following equation:

$\mathrm{Q}=\mathrm{NOD}+\mathrm{Phe}_{\mathrm{ox}}=\mathrm{PB}+\mathrm{I}$

Where $\mathrm{Q}=$ phenylalanine flux as described above, $\mathrm{NOD}=$ non-oxidative disposal of phenylalanine, $\mathrm{Phe}_{\mathrm{ox}}=$ phenylalanine oxidation, $\mathrm{PB}=$ phenylalanine released from protein and I = phenylalanine intake. Using our previously calculated phenylalanine flux and oxidation values, we were able to solve for NOD and PB.

Statistics. Data are presented as means \pm SD. The effect of methyl donor supplementation was assessed using a two-way ANOVA to compare groups; the two main effects were treatment (ie various methyl donors) and rescue (ie pre- and postsupplementation). Differences were considered significant at $P<0.05$ (GraphPad Prism 4.0 for Windows, GraphPad Software, San Diego, CA).

\subsection{Results}

Piglet weight. Piglet weight was higher post-rescue versus pre-rescue with no differences in weight among supplementation groups (Figure 4.2). 


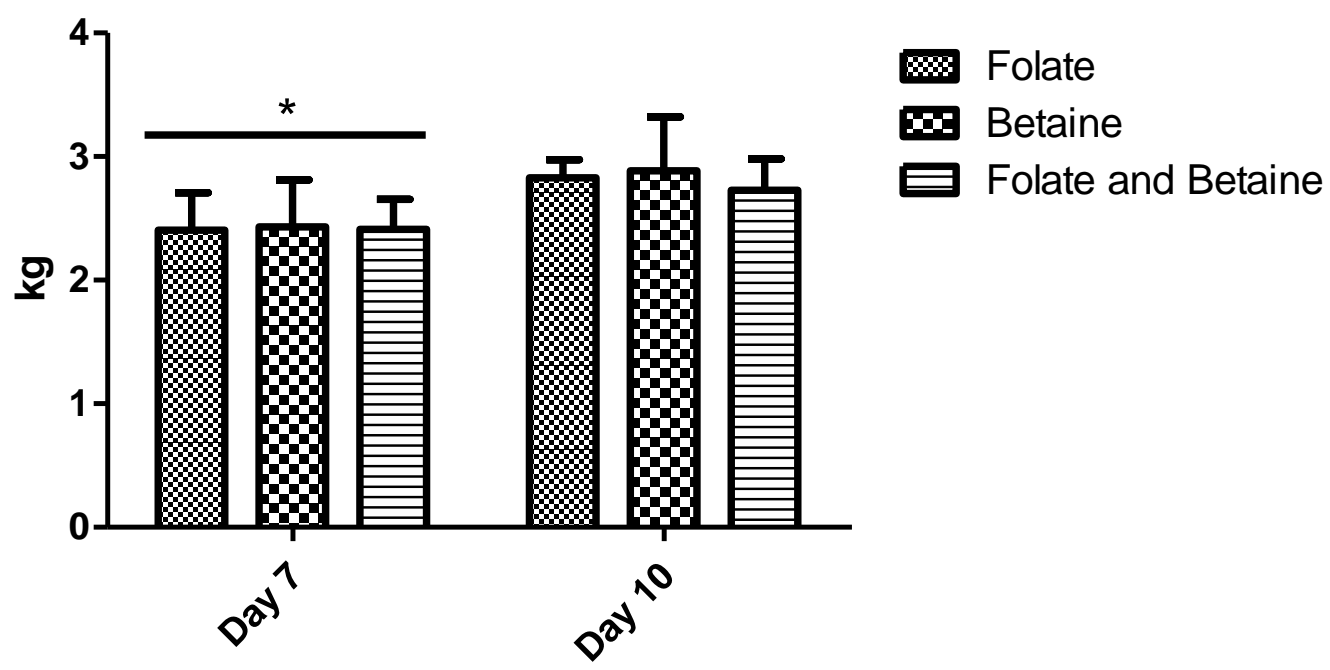

Figure 4.2 Weight of piglets receiving a methyl group deficient diet moderately deficient in methionine (Day 7) as well as following supplementation with folate, betaine or a combination of both (Day 10). * represents main effect of rescue. 
Plasma metabolites following methyl deficiency. Because all piglets on day 7 were receiving the same diet, these data include all pigs. As a baseline reference, plasma concentrations of folate, betaine and choline were measured in a separate group of 5-8 day old sow fed piglets $(n=14)$ undergoing the same initial surgery and were compared to day 7 piglets from this study. On day 7 , plasma folate $(16.1 \pm 7.8 \mathrm{ng} / \mathrm{ml})$ and choline $(6.9$ $\pm 6.8 \mu \mathrm{M}$ ) concentrations were lower than the day 0 reference group (folate: $45.7 \pm 22.3$ ng/ml; choline: $23.2 \pm 14.1 \mu \mathrm{M}$ ). In all animals on day 7 , plasma betaine concentration was below the level of detection of $0.55 \mu \mathrm{M}$, compared to the betaine concentration of $48.7 \pm 27.1 \mu \mathrm{M}$ in the day 0 reference group. Plasma homocysteine concentration on day $7(30.0 \pm 14.5 \mu \mathrm{M})$ was similar to reference group data $(28.8 \pm 13.6 \mu \mathrm{M})$.

Plasma metabolites following supplementation. There was a main effect of rescue on plasma homocysteine concentration with $12-65 \%$ lower levels post-rescue versus prerescue $(P=0.0009)$ with no treatment $\mathrm{x}$ rescue interaction.

Phenylalanine infusion. There was a main effect of rescue on both the rate of phenylalanine oxidation $(P=0.006)$ and $\%$ phenylalanine oxidized $(P=0.004)$, with 20 $46 \%$ lower levels in both measures during the post-rescue infusion, with no treatment $x$ rescue interaction. There were no differences in non-oxidative disposal, protein breakdown or phenylalanine flux following supplementation (Table 4.2).

\subsection{Discussion}

Methionine metabolism is especially important during early development when higher levels of both protein synthesis and transmethylation via SAM create a high demand for 
Table 4.2 Phenylalanine kinetics following a primed, constant infusion of L- $\left[{ }^{13} \mathrm{C}\right]-$ phenylalanine in piglets both after 6 days of receiving a methyl group deficient diet moderately deficient in methionine and following supplementation with either folate, betaine or a combination of both.

\begin{tabular}{|c|c|c|c|c|c|c|c|}
\hline & \multicolumn{2}{|c|}{ Folate } & \multicolumn{2}{|c|}{ Betaine } & \multicolumn{2}{|c|}{ Folate and Betaine } & \multirow{2}{*}{$\frac{\boldsymbol{P} \text {-Value }}{\text { Rescue }}$} \\
\hline & Pre-rescue & Post-rescue & Pre-rescue & Post-rescue & Pre-rescue & Post-rescue & \\
\hline$\% \mathrm{Phe}_{\mathrm{ox}}$ & $1.37 \pm 0.59$ & $0.74 \pm 0.30$ & $1.54 \pm 0.77$ & $0.83 \pm 0.63$ & $1.30 \pm 0.41$ & $1.08 \pm 0.54$ & 0.004 \\
\hline & \multicolumn{7}{|c|}{$\mathrm{umol} \cdot \mathrm{kg}^{-1} \cdot h^{-1}$} \\
\hline Phe $_{\text {ox }}$ & $6.38 \pm 2.82$ & $4.35 \pm 1.77$ & $7.70 \pm 3.90$ & $4.56 \pm 3.75$ & $6.85 \pm 2.12$ & $4.79 \pm 2.46$ & 0.006 \\
\hline NOD & $477 \pm 107$ & $612 \pm 156$ & $498 \pm 74$ & $573 \pm 111$ & $544 \pm 110$ & $472 \pm 74$ & ns \\
\hline$P n B D$ & $275 \pm 108$ & $408 \pm 157$ & $297 \pm 75$ & $370 \pm 111$ & $343 \pm 111$ & $268 \pm 74$ & ns \\
\hline Flux & $483 \pm 108$ & $616 \pm 157$ & $505 \pm 75$ & $577 \pm 111$ & $550 \pm 111$ & $477 \pm 74$ & ns \\
\hline Intake & 29.05 & 29.05 & 29.05 & 29.05 & 29.05 & 29.05 & ns \\
\hline
\end{tabular}

Data are means $\pm \mathrm{SD} ; \mathrm{n}=6$ Means with different superscripts are significantly different within rows, $P<0.05$; ns, not significant. Phe $_{\mathrm{ox}}$, rate of phenylalanine oxidation; $\%$ Phe $_{\mathrm{ox}}$, percentage of phenylalanine dose oxidized; NOD, non-oxidative disposal; Pn BD, protein breakdown. Data were analyzed by 2-way ANOVA with main effects of treatment (ie various methyl donors) and rescue; only rescue was significant for all outcomes so these $P$-values are presented. 
the amino acid which must be partitioned between these two functions. The objective of this study was to determine the importance of remethylation on methionine availability and to evaluate the relative effectiveness of the two methyl donor nutrients, folate and betaine, in remethylating methionine. We fed a methyl-deficient diet with a moderately deficient level of methionine for 6 days to minimize available methionine making it first limiting for protein synthesis. After 2 days of supplementation with folate, betaine or both, we hypothesized that the increased remethylation will increase available methionine and stimulate protein synthesis, which was measured by indicator amino acid (ie phenylalanine) oxidation. Supplementation with folate, betaine or a combination of both equally lowered the rate of phenylalanine oxidation and the percent of phenylalanine dose oxidized, indicating that folate and betaine have an equal capacity to remethylate methionine for protein synthesis.

Although both folate and betaine function as remethylation nutrients, there are few studies comparing folate and betaine and their respective capacity to reform methionine. Experiments in rat hepatocytes have demonstrated that homocysteine is partitioned equally between both remethylation pathways [29]. Furthermore, following an intravenous bolus infusion of $\left[{ }^{2} \mathrm{H}_{7}\right]$ methionine in folate or choline deficient rats, plasma $\left[{ }^{2} \mathrm{H}_{4}\right]$ homocysteine was higher in folate deficient animals during the 120 minute experiment compared to both choline deficient and control groups; however, levels of remethylated methionine in the plasma were not different among the three groups. In keeping with our findings, these results suggest an equal capacity for folate and betaine to remethylate methionine while higher levels of $\left[{ }^{2} \mathrm{H}_{4}\right]$ homocysteine following folate 
deficiency is likely the result of hepatic and renal localization of BHMT while MS is ubiquitous [30]. Our study adds to this body of knowledge by comparing the capacity of these two nutrients in neonatal animals and similar to adult rats, both nutrients can equally reform methionine for protein synthesis when methionine is first limiting.

In order to determine the capacity for folate and betaine to reform methionine, it was first necessary to limit the availability of these remethylation nutrients. To create a deficiency in these nutrients, we fed piglets an IG elemental diet moderately deficient in methionine and devoid of folate, betaine and choline for 6 days. The effectiveness of the methyl group deficient diet is evident by the lower plasma levels of related metabolites on day 7 compared to baseline. Although bacterial folate synthesis in the large intestine can contribute to plasma folate status [31], we still observed a significant $65 \%$ reduction in plasma folate. Moreover, in addition to a $70 \%$ lower plasma concentration of choline, betaine was depleted by day 7 .

Studies have demonstrated that folate deficiency leads to an increase in plasma homocysteine concentrations; $[33,34]$ however, we did not observe this outcome, possibly as a result of the concurrent $\sim 30 \%$ restriction in dietary methionine, potentially limiting flux through transmethylation and subsequent formation of homocysteine. Deletion of the BHMT gene in mice leads to higher levels of homocysteine in the plasma and interestingly, supplementation with folate does not lead to normalization of homocysteine concentrations in these animals [35], highlighting the importance of betaine as a remethylation nutrient. We did observe a 'rescue' effect of methyl nutrients to lower 
homocysteine concentrations, but could not discern the effectiveness of folate versus betaine on this outcome.

Our data demonstrate that folate and betaine, either individually or together, equally increased protein synthesis as well as lowered plasma homocysteine in piglets receiving a diet that was first limited in methionine, suggesting that these nutrients have an equal capacity to remethylate methionine when limiting in the neonatal diet. One limitation of this study is the lack of an experimental group receiving no supplementation which would demonstrate whether the lower phenylalanine oxidation on day 9 is a result of supplementation or age. However, because the age range of the piglets studied is 4 days and there is no difference in protein synthesis in 1 versus 3 week old piglets (9), it is likely that the lower phenylalanine oxidation on day 9 is due to provision of methyl donors, rather than an age-related change. Moreover, our infusions and oxidation rates are corrected for body weight, so these changes are not due to growth. The observation that folate and betaine can affect the availability of methionine is important as the levels of both sulfur amino acids and remethylation nutrients are variable in the neonatal diet. This makes it important for future studies to further investigate the methionine requirement of the neonate in relation to other nutrients that converge on methionine metabolism.

\section{Authorship}

L.E.M, J.L.R, R.F.B and J.A.B were involved in formulating the research question and designing the experiment. L.E.M and J.L.R carried out the experiments and L.E.M, J.L.R, S.V.H and E.R conducted the analytical work. L.E.M, J.L.R, R.F.B and J.A.B analyzed and interpreted the data. L.E.M and R.F.B drafted the manuscript and all authors read and reviewed the final version. 


\subsection{References}

1. Schubert HL, Blumenthal RM, Cheng X. (2003) Many paths to methyltransfer: a chronicle of convergence. Trends Biochem Sci 28, 329-335.

2. Brosnan JT, Wijekoon EP, Warford-Woolgar L, et al. (2009) Creatine synthesis is a major metabolic process in neonatal piglets and has important implications for amino acid metabolism and methyl balance. J Nutr 139, 1292-1297.

3. Plagemann A, Harder T, Brunn M, et al. (2009) Hypothalamic proopiomelanocortin promoter methylation becomes altered by early overfeeding: an epigenetic model of obesity and the metabolic syndrome. J Physiol 587, 49634976.

4. Thomas B, Gruca LL, Bennett C, et al. (2008) Metabolism of methionine in the newborn infant: response to the parenteral and enteral administration of nutrients. Pediatr Res 64, 381-386.

5. Pajares MA, Pérez-Sala D. (2006) Betaine homocysteine S-methyltransferase: just a regulator of homocysteine metabolism. CMLS 63, 2792-2803.

6. Finkelstein JD. (1990) Methionine metabolism in mammals. J Nutr Biochem 1, 228-237.

7. Skiba WE, Taylor MP, Wells MS, et al. (1982) Human hepatic methionine biosynthesis. Purification and characterization of betaine:homocysteine Smethyltransferase. J Biol Chem 257, 14944-14948.

8. Wittwer AJ, Wagner C. (1981) Identification of the folate-binding proteins of rat liver mitochondria as dimethylglycine dehydrogenase and sarcosine dehydrogenase. Flavoprotein nature and enzymatic properties of the purified proteins. J Biol Chem 256, 4109-4115.

9. Bauchart-Thevret C, Stoll B, Chackom S, et al. (2009) Sulfur amino acid deficiency upregulates intestinal methionine cycle activity and suppresses epithelial growth in neonatal pigs. Am J Physiol Endocrinol Metab 296, 12391250 .

10. Huang L, Hogewind-Schoonenboom JE, van Dongen MJ, et al. (2012) Methionine requirement of the enterally fed term infant in the first month of life in the presence of cysteine. Am J Clin Nutr 95, 1048-1054. 
11. Shoveller AK, Brunton JA, House JD, et al. (2003) Dietary cysteine reduces the methionine requirement by an equal proportion in both parenterally and enterally fed piglets. J Nutr 133, 4215-4224.

12. Ilcol YO, Ozbek R, Hamurtekin E, et al. (2005) Choline status in newborns, infants, children, breast-feeding women, breast-fed infants and human breast milk. J Nutr Biochem 16, 489-499.

13. Fischer LM, da Costa KA, Galanko J, et al. (2010) Choline intake and genetic polymorphisms influence choline metabolite concentrations in human breast milk and plasma. Am J Clin Nutr 92, 336-346.

14. Davis TA, Nguyen HV, Garcia-Bravo R, et al. (1994) Amino acid composition of human milk is not unique. $J$ Nutr 124, 1126-1132.

15. Selhub J, Seyoum E, Pomfret EA, Zeisel SH. (1991) Effects of choline deficiency and methotrexate treatment upon liver folate content and distribution. Cancer Res 51, 16-21.

16. Kim YI, Miller JW, da Costa KA, et al. (1994) Severe folate deficiency causes secondary depletion of choline and phosphocholine in rat liver. J Nutr 124, 21972203.

17. Elango R, Ball RO, Pencharz PB. (2008) Indicator amino acid oxidation: concept and application. $J$ Nutr 138, 243-246.

18. Dodge ME, Bertolo RF, Brunton JA. (2012) Enteral feeding induces early intestinal adaptation in a parenterally fed neonatal piglet model of short bowel syndrome. J Parenter Enteral Nutr 36, 205-212.

19. Shoveller AK, Brunton JA, Pencharz PB, et al. (2003) The methionine requirement is lower in neonatal piglets fed parenterally than in those fed enterally. J Nutr 133,1390-1397.

20. Davis SR, Stacpoole PW, Williamson J, et al. (2004) Tracer-derived total and folate-dependent homocysteine remethylation and synthesis rates in humans indicate that serine is the main one-carbon donor. Am J Physiol Endocrinol Metab 286, E272-E279.

21. Moehn S, Bertolo RF, Pencharz PB, et al. (2005) Development of the indicator amino acid oxidation technique to determine the availability of amino acids from dietary protein in pigs. $J$ Nutr $\mathbf{1 3 5}, \mathbf{2 8 6 6 - 2 8 7 0 .}$ 
22. Vester B, Rasmussen K. (1991) High performance liquid chromatography method forrapid and accurate determination of homocysteine in plasma and serum. Eur J Clin Chem Clin Biochem 29, 549-554.

23. Holm PI. (2004) Betaine and folate status as cooperative determinants of plasma homocysteine in humans. Arterioscler Thromb Vasc Biol 25, 379-385.

24. Kirsch SH, Herrmann W, Rabagny Y, et al. (2010) Quantification of acetylcholine, choline, betaine, and dimethylglycine in human plasma and urine using stable-isotope dilution ultra performance liquid chromatography-tandem mass spectrometry. J Chromatogr B 878, 3338-3344.

25. Lamarre SG, Saulnier RJ, Blier PU, Driedzic WR. (2104) A rapid and convenient method for measuring the fractional rate of protein synthesis in ectothermic animal tissues using a stable isotope tracer. Comp Biochem Physiol B Biochem Mol Biol (Epublication ahead of print version).

26. Zello GA, Pencharz PB, Ball RO. (1993) Dietary lysine requirement of young adult males determined by oxidation of L-[1-13C]phenylalanine. Am J Physiol 264, E677-E685

27. Wykes LJ, House JD, Ball RO, et al. (1994) Aromatic amino acid metabolism of neonatal piglets receiving TPN: effect of tyrosine precursors. Am J Physiol 267, E672-E679.

28. House JD, Pencharz PB, Ball RO. Phenylalanine requirements determined by using L-[1-14C]phenylalanine in neonatal piglets receiving total parenteral nutrition supplemented with tyrosine. Am J Clin Nutr 65, 984-993.

29. Finkelstein JD, Martin JJ. (1984) Methionine metabolism in mammals. Distribution of homocysteine between competing pathways. J Biol Chem 259, 9508-9513.

30. Shinohara Y, Hasegawa H, Ogawa K, et al. (2006) Distinct effects of folate and choline deficiency on plasma kinetics of methionine and homocysteine in rats. Metabolism 55, 899-906.

31. Asrar FM, O'Connor DL. (2005) Bacterially synthesized folate and supplemental folic acid are absorbed across the large intestine of piglets. J Nutr Biochem 16, 587-593. 
32. Cui Z, Vance DE. (1996) Expression of phosphatidylethanolamine Nmethyltransferase-2 is markedly enhanced in long term choline-deficient rats. $J$ Biol Chem 271, 2839-2843.

33. Kang SS, Wong PW, Norusis M. (1987) Homocysteinemia due to folate deficiency. Metabolism 36, 458-462.

34. Miller J, Nadeau M, Smith J, et al. (1994) Folate-deficiency-induced homocysteinaemia in rats: disruption of S-adenosylmethionine's co-ordinate regulation of homocysteine metabolism. J Biochem 298, 415-419.

35. Teng Y, Cerdena I, Zeisel SH. (2012) Homocysteinemia in mice with genetic betaine homocysteine S-methyltransferase deficiency is independent of dietary folate intake. J Nutr 142, 1964-1967. 
CHAPTER 5: Guanidinoacetate is effective at increasing muscle creatine stores but limits methionine availability in Yucatan miniature pigs

Laura E. McBreairty, Jason L. Robinson, Kayla R. Furlong, Janet A. Brunton, Robert F. Bertolo

Chapter 5 was designed by L. McBreairty and R. Bertolo. L. McBreairty, J. Robinson and K. Furlong conducted animal work and K. Furlong determined specific radioactivity for creatine, DNA and phosphatidylcholine for control and creatine supplemented animals. All other research was conducted by L. McBreairty and data were analyzed by L. McBreairty. The manuscript was prepared by L. McBreairty with guidance from R. Bertolo.

Submitted to PLoS One January 2015 


\subsection{Abstract}

Background: Creatine is an important energy buffer in tissues with a high energy demand such as muscle and brain, and is consequently a highly consumed nutritional supplement. Creatine is synthesized via the S-adenosylmethionine dependent methylation of guanidinoacetate (GAA), which is proportional to GAA availability.

Objectives: The first objective of this study was to determine the effectiveness of GAA at increasing tissue creatine stores. Because SAM is required for other methylation reactions, we also wanted to determine whether an increased creatine synthesis would lead to a lower availability of methyl groups for other methylated products.

Methods: Three month-old pigs $(n=18)$ were fed control, GAA- or creatine-supplemented diet twice daily. On day 18, anesthesia was induced 2-3 hours post feeding and a bolus of [methyl- $\left.{ }^{3} \mathrm{H}\right]$ methionine was intravenously infused. After $30 \mathrm{~min}$, the liver was analyzed for methyl- ${ }^{3} \mathrm{H}$ incorporation into protein, creatine, PC and DNA.

Results: Although both creatine and GAA led to higher hepatic creatine concentration, only supplementation with GAA led to higher levels of muscle creatine $(P<0.05)$. Only GAA supplementation resulted in lower methyl- ${ }^{3} \mathrm{H}$ incorporation into $\mathrm{PC}$ and protein as well as lower hepatic SAM concentration compared to the controls. This suggests that creatine synthesis resulted in a limited methyl supply for PC and protein synthesis.

Conclusions: Although GAA is more effective than creatine at supporting muscle creatine accretion, further research should be conducted into the long term consequences of a limited methyl supply and its effects on protein and PC homeostasis. 


\subsection{Introduction}

In the cell, creatine functions as an energy buffer via its conversion to phosphocreatine and subsequent restoration of ATP by the enzyme creatine kinase. In an omnivorous adult, both diet and endogenous synthesis play an equal role in replenishing the daily creatine loss (1) of approximately $1.7 \%$ per day (2). Endogenous creatine synthesis is primarily a dual organ process originating in the kidney with the synthesis of GAA from arginine and glycine by the enzyme AGAT. GAA is taken up primarily by the liver and converted to creatine by GAMT which transfers a methyl group to GAA from SAM, a universal methyl donor synthesized from methionine (3).

Creatine has been extensively studied as a nutritional supplement to improve exercise and sports performance (4-6) and has recently gained attention as a potential neuroprotectant and therapeutic agent for neurodegenerative disease (7-9). The agriculture industry has also been interested in creatine as a feed supplement due to its role in energy metabolism and its demonstrated ability to spare arginine (10). Supplementation of creatine in pigs leads to greater weight gain (11), as well as higher levels of phosphocreatine in loin muscle, which consequently improves the negative effects of post mortem lactate formation (12). More recently, GAA's favorable cost and stability attributes have led to consideration of GAA as an alternative to creatine supplementation (13). In chicks fed an arginine-deficient diet, both GAA and creatine supplementation resulted in a higher gain:feed ratio (14). Moreover, GAA supplementation to a creatine-deficient diet in 
chicks effectively increased levels of muscle creatine and breast muscle yield (15). Human studies have also demonstrated a dose response effect of GAA supplementation on plasma levels of both GAA and creatine, but tissue levels were not measured (16). The first objective of this study was to determine whether GAA or creatine was more effective at enhancing the tissue stores of creatine in pigs.

However, the possible metabolic consequences of GAA supplementation must also be examined. Hepatic synthesis of creatine utilizes a significant proportion of methyl groups (17), which could potentially limit methyl availability for other important transmethylation products such as phosphatidylcholine (PC) and methylated DNA. Furthermore, because the methyl group donated by SAM originates from methionine, increasing methyl group demand for creatine synthesis could potentially limit methionine availability for protein synthesis. Indeed, we have recently shown in suckling piglets that an acute hepatic infusion of GAA doubled methyl incorporation into creatine and simultaneously reduced methyl incorporation into PC by $80 \%$, and methyl incorporation into protein by $40 \%$ (18). Supplemental creatine also has the potential to spare methyl groups via negative feedback on AGAT activity (19), lowering GAA production and the demand for methyl groups used in creatine synthesis. Indeed, because creatine synthesis is not feedback regulated in rats (20) and piglets (18), GAA supplementation will consume methyl groups without feedback regulation on GAMT. The second objective of this study was to determine the effect of dietary GAA and creatine supplementation on the partitioning of methionine among transmethylation products and protein synthesis. 


\subsection{Materials and Methods}

Reagents. L-[Methyl $\left.-{ }^{3} \mathrm{H}\right]$ methionine was obtained from American Radiolabeled Chemicals, Inc. (St. Louis, MO). All other chemicals were of analytical grade and were from Sigma (St. Louis, MO) or Fisher Scientific (Fair Lawn, NJ).

Animals. All animal handling procedures were approved by the Institutional Animal Care Committee in accordance with the guidelines of the Canadian Council on Animal Care. Eighteen Yucatan miniature pigs (14-16 weeks old) were obtained from Memorial University of Newfoundland breeding colony and weight-matched to control (n=6), GAA supplemented $(n=6)$ or creatine supplemented $(n=6)$ groups. Pigs were group housed and they received a standard pig grower diet which was fed twice daily. Supplemental GAA $(157 \mathrm{mg} / \mathrm{kg} /$ day) or creatine monohydrate $(200 \mathrm{mg} / \mathrm{kg} /$ day) was mixed with an aliquot of grower feed and hand fed to experimental groups during each feeding for 18-19 days. The supplementation level in this study roughly corresponds to a typical creatine dosing schedule (i.e., $20 \mathrm{~g} / \mathrm{d}$ loading, $2-5 \mathrm{~g} / \mathrm{d}$ maintenance) used by humans to increase muscle creatine levels and achieve positive ergogenic effects $(21,22)$. On the final day of supplementation, pigs received their morning feeding and within 2-3 hours, anesthesia was induced with isoflurane $(1-2 \%)$ in oxygen $(1.5 \mathrm{~L} / \mathrm{min})$. Catheters were inserted into the right and left jugular veins; pigs received an intravenous bolus infusion of $0.75 \mathrm{mCi}$ $\mathrm{L}$-[methyl- $\left.{ }^{3} \mathrm{H}\right]$ methionine via one catheter while the other was used to sample blood before and every $7 \mathrm{~min}$ after the bolus infusion. Thirty min following the infusion, a laparotomy was performed using cautery and the liver, right kidney, heart, brain and sample of bicep femoris muscle were immediately excised and freeze clamped. A 
labeling period of $30 \mathrm{~min}$ following the bolus of L-[methyl- $\left.{ }^{3} \mathrm{H}\right]$ methionine was chosen based on a previous study (18) demonstrating that incorporation of label into DNA and PC was linear from 30-60 min while incorporation into creatine was constant during that time (data not shown).

Plasma and tissue metabolite concentrations (See A.4 and A.5). Plasma creatine and GAA and liver GAA concentrations were determined by HPLC following derivatization with ninhydrin (23). SAM and S-adenosyl-L-homocysteine (SAH) concentrations were determined by HPLC (24). Plasma and liver amino acid concentrations were determined by HPLC using phenylisothiocyanate derivatization (25). Plasma samples were first deproteinized with $0.5 \%$ trifluoroacetic acid in methanol. Liver samples were homogenized in perchloric acid; the supernatant was used to determine free amino acids and the protein pellet was hydrolyzed in $6 \mathrm{M} \mathrm{HCl}$ for $24 \mathrm{~h}$ and used to determine tissuebound amino acids. The SRA of SAM (DPM/ $\mu$ mol) was determined by fraction collecting the peak and DPM were determined by scintillation counting (Perkin Elmer Canada Ltd, Woodbridge, ON, Canada).

Hepatic analyses of methylated products (See A.1-A.4). Creatine SRA and total creatine concentration was determined using a modified method (18) of Lamarre et al., (26). For PC analyses, lipids were extracted from liver using the method by Folch et al. (27) and separated via thin layer chromatography as previously described (18). Total phosphorus was determined using a modified Bartlett method (28) and PC SRA was determined by scintillation counting (18). DNA was extracted and SRA (DPM/ $\mu \mathrm{g}$ ) was determined as previously described (18). 
Calculations. The rate of ${ }^{3} \mathrm{H}$-methyl incorporation into methylated products and liver protein in 30 min was calculated as:

$$
\text { Rate of }{ }^{3} \mathrm{H} \text {-methyl incorporation } \text { product }=\left(\mathrm{SRA}_{\text {product }} / \mathrm{SRA}_{\text {precursor }}\right) \times 100 \text {, }
$$

where the precursor was hepatic SAM. Due to contamination of the tissue free methionine pool with labelled methionine from blood, SAM was also used as a representative precursor for protein synthesis as it is well equilibrated with intracellular free methionine.

Statistical analyses. Data are presented as means \pm SD. Groups were compared using one-way ANOVA with Newman-Keuls Multiple Comparison post-tests when main effects were identified. Hepatic GAA concntrations were not normally distributed as determined by the D'Agostino Pearson normality test and non-parametric Kruskal-Wallis analysis was used to determine differences among groups with Dunns post-tests when main effects were identified (GraphPad Prism 4.0 for Windows, GraphPad Software, San Diego, CA). Differences were considered significant at $P<0.05$.

\subsection{Results}

Body weight. The percent body weight gain from day 0 to day 18 of supplementation was $23 \% \pm 6 \%, 22 \% \pm 4 \%$ and $28 \% \pm 5 \%$ for control, creatine supplemented and GAA supplemented pigs, respectively, with no difference among groups.

Tissue and plasma creatine and GAA. Compared to control pigs, GAA and creatine supplementation led to a 7.3- and 3.9-fold higher hepatic creatine concentrations, 
respectively, and hepatic creatine was $\sim 1.9$-fold higher with GAA versus creatine supplementation (Table 5.1). Muscle creatine was $19 \%$ higher in GAA supplemented pigs compared to control pigs while creatine supplementation was intermediate with no difference from control or GAA diets. Both creatine and GAA supplementation led to a higher creatine concentration in the kidney versus to the control group, while the creatine concentration in the heart was not different among groups. GAA concentration was higher in the kidney following GAA supplementation compared to both other groups with no differences in the heart or muscle (Table 5.1). Hepatic GAA was highr in pigs supplemented with GAA compared to controls (Figure 5.1). Plasma creatine concentrations were $66 \%$ higher than control with GAA supplementation and $140 \%$ higher with creatine supplementation; moreover, creatine supplementation led to $40 \%$ higher creatine concentrations compared to GAA supplementation (Table 5.2). Plasma GAA concentrations were higher with GAA supplementation compared to both creatine and control groups (Table 5.2).

Rate of ${ }^{3}$ H-methyl incorporation into transmethylation products. In GAA supplemented pigs, the rate of ${ }^{3} \mathrm{H}$-methyl incorporation into creatine was 3.9-fold and 2.7-fold higher than control and creatine supplemented pigs, respectively (Table 5.3). Compared to control supplemented groups, GAA supplementation also resulted in a $78 \%$ lower ${ }^{3} \mathrm{H}$ methyl incorporation into PC and $55 \%$ lower ${ }^{3} \mathrm{H}$-methyl incorporation into 
Table 5.1 Tissue distribution of creatine and GAA ${ }^{1}$ in pigs fed a control, creatine supplemented or GAA supplemented diet for 18 days $^{2}$

\begin{tabular}{|c|c|c|c|}
\hline & Control & Creatine & GAA \\
\hline & \multicolumn{3}{|c|}{ Creatine, $\mu \mathrm{mol} / \mathrm{g}$ wet weight } \\
\hline Liver & $0.429 \pm 0.14 a$ & $1.674 \pm 0.61^{b}$ & $3.125 \pm 1.32^{c}$ \\
\hline Muscle & $39.9 \pm 2.42^{a}$ & $44.08 \pm 4.10^{\mathrm{ab}}$ & $47.63 \pm 4.25^{b}$ \\
\hline Kidney & $0.418 \pm 0.08^{a}$ & $1.132 \pm 0.38^{b}$ & $0.853 \pm 0.19 \mathrm{~b}$ \\
\hline \multirow[t]{2}{*}{ Heart } & $19.22 \pm 4.49$ & $18.07 \pm 2.87$ & $19.34 \pm 3.99$ \\
\hline & \multicolumn{3}{|c|}{ GAA, nmol/g wet weight } \\
\hline Liver & $7.38 \pm 2.7^{a}$ & $16.8 \pm 10^{a b}$ & $1323 \pm 1796^{b}$ \\
\hline Muscle & $44.2 \pm 14$ & $73.7 \pm 43$ & $92.0 \pm 36$ \\
\hline Kidney & $81.21 \pm 23^{a}$ & $97.21 \pm 29 a$ & $230 \pm 83^{b}$ \\
\hline Heart & $60.5 \pm 41$ & $73.6 \pm 32$ & $93.4 \pm 20$ \\
\hline
\end{tabular}

${ }^{1}$ GAA, guanidinoacetate

${ }^{2}$ Data are means $\pm \mathrm{SD} ; n=6$. Means with different superscripts are significantly different within rows, $P<0.05$. 


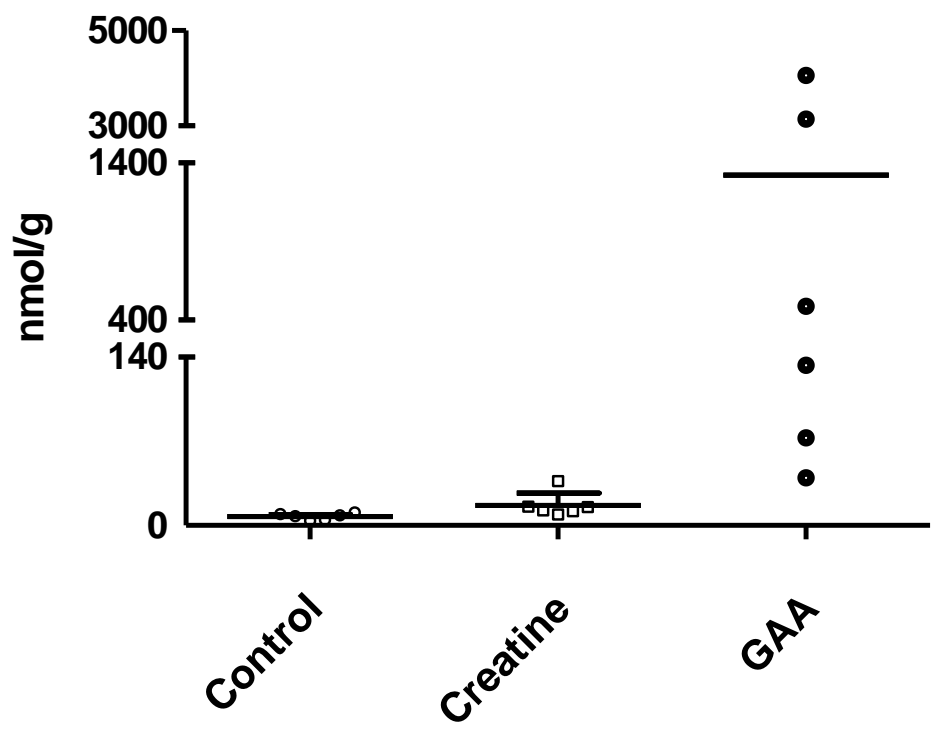

Figure 5.1 Hepatic GAA concentration in pigs fed a control, creatine supplemented or GAA supplemented diet for 18 days. Abbreviations: GAA; guanidinoacetate. 
Table 5.2 Plasma concentrations of metabolites in pigs fed a control, creatine supplemented or $\mathrm{GAA}^{1}$ supplemented diet for 18 days $^{2}$

\begin{tabular}{llll}
\hline & Control & Creatine & GAA \\
& & $\mu \mathrm{mol} / \mathrm{L}$ & \\
& & & \\
Homocysteine & $17.8 \pm 1.5^{\mathrm{a}}$ & $16.1 \pm 1.7^{\mathrm{a}}$ & $34.2 \pm 13.3^{\mathrm{b}}$ \\
Cysteine & $50.3 \pm 7.4$ & $48.5 \pm 7.2$ & $60.4 \pm 9.5$ \\
Glutathione & $43.6 \pm 6.8$ & $49.5 \pm 8.7$ & $37.1 \pm 6.2$ \\
Creatine & $112 \pm 45^{\mathrm{a}}$ & $264 \pm 59^{\mathrm{c}}$ & $186 \pm 37^{\mathrm{b}}$ \\
& & & \\
GAA & $4.3 \pm 1.4^{\mathrm{a}}$ & $4.1 \pm 1.1^{\mathrm{a}}$ & $49.0 \pm 45.4^{\mathrm{b}}$ \\
\hline
\end{tabular}

${ }^{1}$ GAA, guanidinoacetate

${ }^{2}$ Data are means $\pm \mathrm{SD} ; n=6$. Means with different superscripts are significantly different within rows, $P<0.05$. 
Table 5.3 Rate of ${ }^{3} \mathrm{H}$-methyl incorporation into transmethylation products and protein after 30 minutes (corrected for SAM) in pigs fed a control, creatine supplemented or GAA supplemented diet for 18 days ${ }^{1}$

\begin{tabular}{lccc}
\hline & Control & Creatine & GAA \\
& \multicolumn{3}{c}{ Rate of 3 H-methyl incorporation ${ }^{2}$} \\
Creatine & $23.2 \pm 7.0^{\mathrm{a}}$ & $32.5 \pm 12.6^{\mathrm{a}}$ & $89.4 \pm 45.3^{\mathrm{b}}$ \\
PC & & & \\
& & & \\
DNA & $24.24 \pm 1.40^{\mathrm{b}}$ & $3.34 \pm 0.86^{\mathrm{b}}$ & $0.95 \pm 0.51^{\mathrm{a}}$ \\
& & & \\
Protein & $2.73 \pm 0.87^{\mathrm{b}}$ & $2.48 \pm 0.69^{\mathrm{b}}$ & $1.22 \pm 0.42^{\mathrm{a}}$ \\
\end{tabular}

${ }^{1}$ Data are means $\pm \mathrm{SD} ; n=6$. Means with different superscripts are significantly different within rows, $P<0.05$. GAA, guanidinoacetate; PC, phosphatidylcholine; SAM, $S$ adenosylmethionine; SRA, specific radioactivity.

${ }^{2}$ Corrected rate of ${ }^{3} \mathrm{H}$-methyl incorporation $=\left(\mathrm{SRA}_{\text {product }} / \mathrm{SRA}_{\text {precursor }}\right) \times 100$ 
protein, with no difference between creatine supplemented and control pigs. There were no differences in ${ }^{3} \mathrm{H}$-methyl incorporation into DNA or in the SRA of SAM among groups (Table 5.3)

Plasma and liver metabolite concentrations. Supplementation with GAA resulted in a 44\% lower hepatic SAM concentration versus both control and creatine supplemented groups; there were no differences in hepatic SAH or SAM/SAH ratio among groups (Table 5.4). There were also no differences in hepatic methionine, arginine or PC among groups. GAA supplemented pigs had a 1.9-2.1-fold higher plasma homocysteine compared to control and creatine supplemented pigs, with no difference in plasma cysteine or glutathione among groups (Table 5.2).

\subsection{Discussion}

We supplemented young pigs with equimolar amounts of either GAA or creatine for 18 days and found that while both GAA and creatine supplementation led to higher creatine concentrations in the liver and kidney compared to control pigs, GAA supplementation was more effective than creatine at increasing hepatic creatine concentrations. Although GAA supplemented pigs had a higher concentration of muscle creatine compared to control pigs, there was no difference in muscle creatine between creatine and GAA supplemented pigs suggesting that GAA is not more effective than creatine at increasing muscle creatine stores.

Because of the positive ergogenic and therapeutic effects of creatine, the use of dietary creatine supplementation to increase muscle concentrations has been a growing area of 
Table 5.4 Hepatic concentrations of metabolites in pigs fed a control, creatine supplemented or GAA supplemented diet for 18 days ${ }^{1}$

\begin{tabular}{lccc}
\hline & Control & Creatine & GAA \\
& & nmol/g wet weight & \\
Arginine & $43.2 \pm 4.6$ & $64.3 \pm 35.5$ & $41.6 \pm 4.1$ \\
Methionine & $99.1 \pm 38.4$ & $99.3 \pm 30.1$ & $86.6 \pm 28.5$ \\
SAM & $56.9 \pm 8.4^{b}$ & $66.5 \pm 22 . .6^{b}$ & $31.9 \pm 16.5^{\mathrm{a}}$ \\
SAH & $15.1 \pm 2.8$ & $15.4 \pm 2.6$ & $18.3 \pm 11.8$ \\
& & & \\
\hline SAM/SAH & $3.94 \pm 1.24$ & $4.35 \pm 1.50$ & $2.46 \pm 1.68$ \\
& & & $144 \pm 47$ \\
SAM SRA & $114 \pm 28$ & $127 \pm 33$ & $6.9 \pm 2.9$ \\
PC (umol/g) & $8.1 \pm 2.2$ & $8.5 \pm 2.4$ &
\end{tabular}

${ }^{1}$ Data are means \pm SDs; $n=6$. Means with different superscripts are significantly different within rows, $P<0.05$. DPM, disintegrations per minute; GAA, guanidinoacetate; PC, phosphatidylcholine; SAH, S-adenosylhomocysteine; SAM, Sadenosylmethionine 
interest. Although experiments in both humans and animals have demonstrated that dietary creatine supplementation can be an effective means to increase muscle creatine (22), some studies have yielded inconsistent findings (29). Similar to our results, the relative increase in tissue creatine following supplementation is higher in tissues with low levels of basal creatine (i.e., kidney and liver) compared to tissues with high basal creatine concentrations (i.e., skeletal muscle, heart and brain) (29, 30). Although supplementation with either creatine or GAA had no significant effect on muscle, it is interesting that GAA supplementation was more effective than creatine supplementation at increasing concentrations in the liver. Because the liver is the primary site for creatine synthesis, the higher level of hepatic creatine following GAA supplementation is a result of endogenous synthesis in the liver.

Skeletal muscle has a limited capacity to store creatine (22) and it has been proposed that individuals classified as "non-responders" to creatine supplementation have higher initial creatine concentrations (31). Because of both the limited creatine storage capacity of skeletal muscle (22) and the high relative basal creatine concentration of the bicep femoris muscle (32) sampled in this study, it is possible that despite an increase in plasma creatine concentrations, the creatine concentration of the muscle sampled in this study was at a maximal creatine storage capacity prior to supplementation. Indeed, others have shown that white gastrocnemius muscle had lower creatine uptake following supplementation when compared to a pre-supplementation rate, a finding that was not observed in other muscle types with lower basal creatine concentrations (33). Higher 
concentrations of extracellular creatine have been shown to downregulate creatine transport into rat muscle, with $50 \%$ inhibition occuring at physiological creatine concentrations (34). Thus, it is possible that the higher plasma creatine levels found in our creatine and GAA supplemented pigs led to downregulation of the creatine transporter.

We previously demonstrated in an acute model of GAA supplementation that creatine synthesis is not feedback regulated at GAMT (18), and others have produced the same effect in rats (20). In this study, we investigated whether chronic supplementation of GAA would increase creatine synthesis thereby limiting methyl group availability for other methylation reactions. As expected, dietary supplementation with GAA led to a higher rate of incorporation of methyl groups into creatine (Table 5.3). Concomitantly, the chronic dietary supplementation with GAA also resulted in reduced methyl incorporation into both PC and protein, with no change in incorporation into DNA. These results are in keeping with our previous findings of increased methyl incorporation into creatine and lower methyl incorporation into PC and protein (protein synthesis) following an acute intraportal infusion of GAA in piglets (18). Interestingly, chronic creatine supplementation in this study did not affect methyl group partitioning and does not appear to spare methyl groups for other transmethylation reactions.

Although an omnivorous adult human typically synthesizes half of their creatine requirement (1), it is not known whether this is similar in a weaned pig. In this study, the pig grower diet provided $0.05 \mathrm{mmol} / \mathrm{kg} /$ day of creatine via meat meal (35), which is $\sim 5 \%$ of the total creatine accrued by a growing piglet (i.e., $\sim 0.8 \mathrm{mmol} / \mathrm{kg} /$ day) (36). With minimal creatine provided in the diet, it is likely that the pigs in this study must have 
synthesized the vast majority of their creatine needs. Based on this assumption, the GAA concentration in our diet $(1.53 \mathrm{mmol} / \mathrm{kg} / \mathrm{day})$ provided approximately twice the amount required to synthesize the daily creatine requirement. Doubling the methyl group requirement for creatine synthesis via GAA supplementation helps explain the limited methyl availability for other transmethylation reactions. This hypothesis is supported by the lower hepatic SAM concentration in GAA supplemented pigs which interestingly was not accompanied by a lower hepatic concentration of the transmethylation product SAH, a known inhibitor of transmethylation reactions (37). Given the higher levels of plasma homocysteine with GAA supplementation, it is likely that SAH was readily converted to homocysteine and exported into the plasma.

In this study we demonstrated that GAA supplementation leads to higher levels of creatine in the muscle compared to control pigs but is not more effective than creatine at increasing muscle creatine stores. The higher methyl group utilization for creatine synthesis following supplementation with GAA can lead to a limited methyl group supply for other transmethylation reactions. Although a 6 week GAA supplementation trial in humans concluded that GAA is safe with a low incidence of biochemical abnormalities and an acceptable side-effects profile (38), the potential for GAA supplementation to limit protein and PC synthesis in a growing animal is concerning and warrants consideration. However, total hepatic PC concentration was not different in GAA supplemented pigs, likely because PEMT is thought to be responsible for only $\sim 30 \%$ of hepatic PC synthesis, with the remainder synthesized by the enzyme CDP-choline:1,2diacylglycerol cholinephosphotransferase (39). It is possible that this alternate pathway 
for PC synthesis compensated for lower PC synthesis via PEMT. Because we supplemented with GAA twice daily, it is possible that the limited methyl group availability is an acute post-prandial response to GAA, so future studies should investigate long term outcomes with respect to methyl group incorporation and protein synthesis. In particular, the $40 \%$ lower incorporation into protein with GAA supplementation is likely an acute effect considering growth was not affected in these pigs, although body composition was not assessed. In spite of the effectiveness of GAA at enhancing creatine stores, more research is needed to clarify the potentially detrimental effects of GAA supplementation. 


\subsection{References}

[1] Stead LM, Brosnan JT, Brosnan ME, Vance DE, Jacobs RL. Is it time to reevaluate methyl balance in humans? Am J Clin Nutr. 2006;83:5-10.

[2] Wyss M, Kaddurah-Daouk R. Creatine and creatinine metabolism. Physiol Rev. 2000;80:1107-213.

[3] Walker JB. Creatine: biosynthesis, regulation, and function. Adv Enzymol Relat Areas Mol Biol. 1979;50:177-242.

[4] Bemben MG, Lamont HS. Creatine supplementation and exercise performance: recent findings. Sports Med. 2005;35:107-25.

[5] Barber JJ, McDermott AY, McGaughey KJ, Olmstead JD, Hagobian TA. Effects of combined creatine and sodium bicarbonate supplementation on repeated sprint performance in trained men. J Strength Cond Res. 2013;27:252-8.

[6] Dabidi Roshan V, Babaei H, Hosseinzadeh M, Arendt-Nielsen L. The effect of creatine supplementation on muscle fatigue and physiological indices following intermittent swimming bouts. J Sports Med Phys Fitness. 2013;53:232-9.

[7] Peña-Altamira E, Crochemore C, Virgili M, Contestabile A. Neurochemical correlates of differential neuroprotection by long-term dietary creatine supplementation. Brain Res. 2005;1058:183-8.

[8] Bender A, Samtleben W, Elstner M, Klopstock T. Long-term creatine supplementation is safe in aged patients with Parkinson disease. Nutr Res. 2008;28:172-8.

[9] Hersch SM, Gevorkian S, Marder K, Moskowitz C, Feigin A, Cox M, Como P, Zimmerman C, Lin M, Zhang L, et al. Creatine in Huntington disease is safe, tolerable, bioavailable in brain and reduces serum 8OH2'dG. Neurology. 2006;66:250-2.

[10] Austic RE, Nesheim MC. Arginine and creatine interrelationships in the chick. Poult Sci. 1972;51:1098-105. 
[11] Young JF, Bertram HC, Rosenvold K, Lindahl G, Oksbjerg N. Dietary creatine monohydrate affects quality attributes of Duroc but not Landrace pork. Meat Sci. 2005;70:717-25.

[12] Lindahl G, Young JF, Oksbjerg N, Andersen HJ. Influence of dietary creatine monohydrate and carcass cooling rate on colour characteristics of pork loin from different pure breeds. Meat Sci. 2006;72:624-34.

[13] Baker DH. Advances in protein-amino acid nutrition of poultry. Amino Acids. 2009;37:29-41.

[14] Dilger RN, Bryant-Angeloni K, Payne RL, Lemme A, Parsons CM. Dietary guanidino acetic acid is an efficacious replacement for arginine for young chicks. Poult Sci. 2013;92:171-7.

[15] Michiels J, Maertens L, Buyse J, Lemme A, Rademacher M, Dierick NA, De Smet S. Supplementation of guanidinoacetic acid to broiler diets: Effects on performance, carcass characteristics, meat quality, and energy metabolism. Poult Sci. 2012;91:402-12.

[16] Ostojic SM, Stojanovic M, Drid P, Hoffman JR. Dose-response effects of oral guanidinoacetic acid on serum creatine, homocysteine and B vitamins levels. Eur J Nutr. 2014 [Epub ahead of print].

[17] Stead LM, Au KP, Jacobs RL, Brosnan ME, Brosnan JT. Methylation demand and homocysteine metabolism: effects of dietary provision of creatine and guanidinoacetate. Am J Physiol Endocrinol Metab. 2001;281:E1095-100.

[18] McBreairty LE, McGowan RA, Brunton JA, Bertolo RF. Partitioning of [methyl$\left.{ }^{3} \mathrm{H}\right]$ methionine to methylated products and protein is altered during high methyl demand conditions in young Yucatan miniature pigs. J Nutr. 2013;143:804-9.

[19] McGuire DM, Gross MD, van Pilsum JF, Towle HC. Repression of rat kidney Larginine:glycine amidinotransferase synthesis by creatine at a pretranslational level. J Biol Chem. 1984;259:12034-8.

[20] da Silva RP, Nissim I, Brosnan ME, Brosnan JT. Creatine synthesis: hepatic metabolism of guanidinoacetate and creatine in the rat in vitro and in vivo. Am J Physiol Endocrinol Metab. 2009;296: E256-61. 
[21] Gordon A, Hultman E, Kaijser L, Kristjansson S, Rolf CJ, Nyquist O, Sylvén C. Creatine supplementation in chronic heart failure increases skeletal muscle creatine phosphate and muscle performance. Cardiovasc Res. 1995;30:413-8.

[22] Harris RC, Söderlund K, Hultman E. Elevation of creatine in resting and exercised muscle of normal subjects by creatine supplementation. Clin Sci (Lond). 1992;83:367-74.

[23] Buchberger W, Ferdig M. Improved high-performance liquid chromatographic determination of guanidino compounds by precolumn derivatization with ninhydrin and fluorescence detection. J Sep Sci. 2004;27:1309-12.

[24] Ratnam S, Wijekoon EP, Hall B, Garrow TA, Brosnan ME, Brosnan JT. Effects of diabetes and insulin on betaine-homocysteine S-methyltransferase expression in rat liver. Am J Physiol Endocrinol Metab. 2006;290:E933-9.

[25] Bidlingmeyer BA, Cohen SA, Tarvin TL. Rapid analysis of amino acids using pre-column derivatization. J Chromatogr. 1984;336:93-104.

[26] Lamarre SG, Edison EE, Wijekoon EP, Brosnan ME, Brosnan JT. Suckling rat pups accumulate creatine primarily via de novo synthesis rather than from dam milk. J Nutr. 2012;140:1570-3.

[27] Folch J, Lees M, Sloane Stanley GH. A simple method for the isolation and purification of total lipides from animal tissues. J Biol Chem. 1957;226:497-509.

[28] Bartlett GR. Phosphorus assay in column chromatography. J Biol Chem. 1959;234:466-8.

[29] Greenhaff PL, Bodin K, Soderlund K, Hultman E. Effect of oral creatine supplementation on skeletal muscle phosphocreatine resynthesis. Am J Physiol. 1994;266:E725-30.

[30] Horn M, Frantz S, Remkes H, Laser A, Urban B, Mettenleiter A, Schnackerz K, Neubauer S. Effects of chronic dietary creatine feeding on cardiac energy metabolism and on creatine content in heart, skeletal muscle, brain, liver and kidney. J Mol Cell Cardiol. 1998;30:277-84.

[31] Syrotuik DG, Bell GJ. Acute creatine monohydrate supplementation: a descriptive physiological profile of responders vs. nonresponders. J Strength Cond Res. 2004;18:610-7. 
[32] Mora L, Sentandreu MÁ, Toldrá F. Contents of creatine, creatinine and carnosine in porcine muscles of different metabolic types. Meat Sci. 2008;79:709-15.

[33] Brault JJ, Terjung RL. Creatine uptake and creatine transporter expression among rat skeletal muscle fiber types. Am J Physiol Cell Physiol. 2003;284:C1481-9.

[34] Loike JD, Zalutsky DL, Kaback E, Mir AF, Miranda AF, Silverstein SC. Extracellular creatine regulates creatine transport in rat and human muscle cells. Proc Natl Acad Sci USA. 1998;85:807-11.

[35] Harris RC, Lowe JA, Warnes K, Orme CE. The concentration of creatine in meat, offal and commercial dog food. Res Vet Sci. 1997;62:58-62.

[36] Brosnan JT, Wijekoon EP, Warford-Woolgar L, Trottier NL, Brosnan ME, Brunton JA, Bertolo RF. Creatine synthesis is a major metabolic process in neonatal piglets and has important implications for amino acid metabolism and methyl balance. J Nutr. 2009;139:1292-7.

[37] Hoffman DR, Cornatzer WE, Duerre JA. Relationship between tissue levels of Sadenosylmethionine, S-adenosylhomocysteine, and transmethylation reactions. Can J Biochem. 1979;57:56-65.

[38] Ostojic SM, Niess B, Stojanovic M, Obrenovic M. Creatine metabolism and safety profiles after six-week oral guanidinoacetic acid administration in healthy humans. Int J Med Sci. 2013;10:141-7.

[39] Li Z, Vance DE. Phosphatidylcholine and choline homeostasis. J Lipid Res. 2008;49:1187-94. 


\section{Chapter 6. General Discussion}

The research presented in this thesis focuses on methionine metabolism and requirements during development, while considering other nutrients that converge on methionine metabolic pathways. Our main objective was to investigate how variation in either the supply or demand of methionine can impact methionine availability for its various functions. The following discussion serves to highlight and bridge the primary findings of this thesis while addressing questions that warrant further investigation.

\subsection{IUGR and methionine metabolism}

Epidemiological studies supporting the fetal programming hypothesis and the association of low birth weight with disease in later life have led to extensive research in animal models to elucidate the specific mechanisms that result in the adverse effects in adulthood. Studies involving protein restriction have led to the hypothesis that one of the specific nutrient perturbations responsible for these outcomes may be an imbalance of dietary methionine in relation to other amino acids (Langley-Evans, 2000; Rees et al., 2006). Furthermore, it has been demonstrated that high homocysteine concentrations during gestation are associated with growth restriction (Gadhok et al., 2011). Because IUGR is associated with epigenetic changes to DNA methylation (MacLennan et al. 2004), the study presented in Chapter 2 was designed to determine whether IUGR piglets have a perturbed methionine metabolism. 
Using neonatal growth restricted and normal weight littermates, we determined that IUGR piglets appear to have a reduced capacity to catabolize homocysteine as demonstrated by lower activity levels of both the remethylation enzyme BHMT and the transsulfuration enzyme CGL. Although hyperhomocysteinemia would be expected in these animals, homocysteine was not elevated and it was in fact lower in the liver of the growth restricted piglets. Dietary intake was not controlled in this study and it is possible that methionine intake in suckling IUGR piglets did not exceed the capacity of BHMT and CGL to dispose of homocysteine. In addition to the low methionine/cysteine ratio of 1.4 found in sow's milk (Davis et al., 1994), IUGR piglets likely have lower nutrient absorption resulting from the disturbed morphology of the small intestine (D'Inca et al., 2010; Wang et al., 2005) and the lower expression of jejunal neutral amino acid transporters in the first week of life (Yang et al., 2012). Furthermore, methionine has been suggested as a first limiting amino acid in piglets due to a significant first pass use of methionine by the gut (Stoll et al., 1998).

When considering the high methionine flux in the neonate (Bauchart-Thevret, et al. 2009; Thomas et al., 2008), the lower BHMT activity found in IUGR piglets suggest that methionine may be limiting in these animals. Although plasma and hepatic levels of methionine, as well as hepatic levels of SAM, were not different between normal weight and growth restricted piglets, metabolite concentration is a static measure giving limited information about in vivo dynamic flux. Neonatal piglets fed a diet deficient in sulfur amino acids have similar levels of hepatic methionine compared to controls; however, methionine flux, including remethylation rate, is lower (Bauchart-Thevret et al., 2009). 
Although we found no difference in DNA methylation in IUGR piglets, it is possible that methionine availability was limited for other more quantitatively significant transmethylation reactions or protein synthesis. This speculation led us to ask, is methionine limiting for protein synthesis or transmethylation reactions in IUGR piglets?

\subsubsection{IUGR and methionine partitioning}

The study presented in Chapter $\mathbf{3}$ was in part designed to address some of the uncertainties remaining from the work presented in Chapter 2. Specifically, we wanted to determine whether methionine is limiting for either protein synthesis or transmethylation reactions in IUGR piglets, as well as to determine if the partitioning of methionine among transmethylation reactions is different in these animals. Using a bolus intraportal infusion of $\left[{ }^{3} \mathrm{H}\right]$ methyl-methionine in 21 day old IUGR and normal weight piglets, we determined that of the label recovered, $51 \%$ of hepatic methionine was partitioned towards protein synthesis in IUGR piglets compared to $32 \%$ in normal weight animals. Although the methionine incorporation into hepatic protein was not significantly higher in IUGR piglets, growth restriction led to lower incorporation of methyl groups into PC. Because IUGR piglets have been shown to have a higher feed efficiency (Ritacco et al. 1997), it is possible that more methionine is partitioned towards protein synthesis for compensatory growth; however, this hypothesis has been contradicted by demonstration of no difference in hepatic protein synthesis following growth restriction (Davis et al. 1997). Furthermore, it has also been demonstrated that catch up growth following growth restriction is accompanied by greater adiposity compared to littermates (Myrie et al., 2012). In Chapter 2 we hypothesized that IUGR piglets have a lower total 
methionine flux and this may limit the availability of methionine for PEMT as protein synthesis is pritorized when sulfur amino acids are limiting (Bauchart-Thevret et al., 2009).

Alternatively, because protein synthesis is prioritized over transmethylation during sulfur amino acid deficiency (Bauchart-Thevret et al., 2009), it is possible that lower methionine availability in IUGR piglets led to a higher fraction of methionine flux towards protein synthesis, consequently limiting availability of methionine for synthesis of PC; however, in Chapter 3 we determined partitioning of methionine and can only speculate on absolute rates of methionine flux. Future work should focus on use of the established primed/constant stable isotope methionine infusion (Bauchart-Thevret et al., 2009) to calculate whole body methionine kinetics in IUGR piglets. Determination of absolute rates of remethylation, transsulfuration, transmethylation and protein synthesis would allow us to determine whether methionine is limiting in these animals resulting in a lower methionine metabolism.

Although determining methionine kinetics would offer valuable insight into methionine metabolism in IUGR, the question of whether MS functions to compensate for lower BHMT activity could not be evaluated from the quantification of a single remethylation rate accounting for both remethylation pathways. When considering nutrient requirements in the neonate, this is an important question because deficiency of one remethylation nutrient (folate or betaine/choline) leads to compensation of the alternate remethylation pathway, resulting in lower levels of the corresponding nutrient (Kim et al., 1994; Selhub et al. 1991). If flux through MS is increased in IUGR piglets to compensate 
for lower activity of BHMT, more dietary folate may be required in these animals to maintain folate stores and it is possible that flux through MS could become limited by folate availability. Piglets are born with low folate stores and plasma folate concentration increases $\sim 3$-fold in the neonatal piglet during the first 2 days (Barkow et al., 2001) making it important to determine whether folate status is affected by IUGR during the first few days of life.

Although we did not demonstrate elevated homocysteine in IUGR piglets in this thesis, as highlighted in Chapter 2, the methionine/cysteine ratio of bovine casein, commonly used in infant formula, is $2-3$ fold higher than in sow's milk. Because of the lower hepatic activity of BHMT and CGL in growth restricted piglets, a casein based diet may result in an insufficient capacity to metabolize homocysteine resulting in hyperhomocysteinemia. Furthermore, because levels of cysteine and taurine were low in sow fed IUGR piglets due to lower CGL activity, a diet requiring a higher flux through transsulfuration to meet cysteine requirement may lead to a further reduction in cysteine and taurine compared to normal weight piglets. Although $\sim 90 \%$ of Canadian women initiate breastfeeding, after 3 months only 50\% of infants are exclusively breast fed (Chalmers et al., 2009) making it important to understand how casein based infant formulas affect methionine metabolism in IUGR. Comparing methionine kinetics in casein fed and sow fed IUGR piglets would provide further insight into an optimal diet following growth restriction. Additionally, early folate status should also be investigated in IUGR piglets consuming a casein based diet as flux through MS may be higher to accommodate a higher methionine flux in these animals. 
Although the Kennedy pathway is used to synthesize $70 \%$ of hepatic PC, the fatty acid composition of PC produced via PEMT is distinct from that of the Kennedy pathway, with PEMT being responsible for the mobilization of the essential fatty acids $20: 4(n-6)$ and 22:6(n-3) from liver into plasma (Watkins et al., 2003); these fatty acids are very important for brain development during early life Indeed, the DHA content of plasma PC has been suggested to be a surrogate marker for hepatic PEMT activity in humans (Da Costa et al., 2011). Because we found lower incorporation of methyl label into PC in IUGR piglets, future work should investigate whether the fatty acid composition of PC differs between IUGR and normal weight pigs.

Although the $\mathrm{K}_{\mathrm{m}}$ for PC synthesis via PEMT has not been determined in the pig, in the rat the hepatic $\mathrm{K}_{\mathrm{m}}$ for SAM for the rate limiting first step in PC synthesis via PEMTis $18 \mu \mathrm{M}$ (Hoffman et al., 1981) which is $13 \mathrm{nmol} / \mathrm{g}$ considering a $70 \%$ water content of the liver. The hepatic SAM concentration in the rat is $69 \mathrm{nmol} / \mathrm{g}$ (Hoffman and Cornatzer, 1981) and it is possible that the $50 \%$ lower level of hepatic SAM found in both our acute and chronic GAA supplemented pigs was below the $\mathrm{K}_{\mathrm{m}}$ for the first reaction of PC synthesis via PEMT in these animals. The Kennedy pathway can function to compensate for reduced PC synthesis in PEMT knockout mice (Walky et al., 1997), which have minimally affected levels of hepatic PC; however, when fed a high fat diet, these animals develop hepatomegaly and steatosis and it is possible that the lower methyl incorporation into PC in IUGR piglets and during situations of high methyl demand may lead to altered liver morphology on a diet high in fat. 


\subsection{Methionine supply and demand}

Methionine availability is dependent on both the supply of methionine as well as the demand for its various functions. Roughly $50 \%$ of methionine is partitioned towards transmethylation reactions in 1-week old piglets and approximately half of the resulting homocysteine is remethylated to methionine (Bauchart-Thevret et al., 2009). This highlights the quantitatively significant contribution of transmethylation to methionine demand and of remethylation to methionine supply. Because we speculate a lower remethylation capacity as well as a limited dietary supply of methionine in IUGR piglets, we wanted to further investigate the relative capacity of MS and BHMT to supply methionine when dietary methionine is limiting in the neonate. Furthermore, we also wanted to determine how increasing the demand for one transmethylation product affects methionine availability for protein synthesis and other transmethylation reactions.

In Chapter 3 we investigated the effect of increasing methionine demand for creatine synthesis on methionine partitioning in both normal weight and IUGR piglets. Because the synthesis of creatine via GAMT is proportional to the availability of GAA (Da Silva et al., 2009), we decided to use an acute GAA infusion as a means to increase demand for creatine synthesis with the intent to limit methionine availability. Although we hypothesized lower methionine availability in both normal weight and IUGR piglets, an increase in transmethylation flux in IUGR piglets may further limit methionine availability due to limited remethylation capacity. In both normal weight and growth restricted piglets, delivering $1 / 3$ of the GAA needed to synthesize the daily creatine requirement led to an increased incorporation of methyl groups into creatine and a lower 
incorporation of methyl groups into protein and PC. Infants receiving infant formula with minimal creatine, such as soy based formula, must synthesize the vast majority of their creatine requirement (Edison et al., 2013) which may limit methionine availability for growth and synthesis of PC.

In Chapter 4 we focused on methionine supply, with the objective of determining whether folate and betaine have the capacity to reform methionine to increase its availability for protein synthesis when methionine is limiting in the diet. In addition to examining methionine supply via remethylation, it was also our aim to compare the relative capacity of these two pathways in vivo. We concluded that dietary provision of folate, betaine or a combination of both can indeed spare methionine for protein synthesis when methionine is limiting in the diet of neonatal piglets.

To further support these findings, we also determined that folate and betaine could equally lower plasma homocysteine, the precursor for endogenous methionine synthesis. Both betaine and folate have been investigated as a means to lower homocysteine (Keser et al., 2013; McRae, 2013); however, there appear to be no controlled animal experiments directly comparing these nutrients in their capacity to lower homocysteine. Betaine has been shown to be effective at lowering GAA induced hyperhomocysteinemia in rats (Setoue et al., 2008). Furthermore, GAA supplemented humans receiving concurrent supplementation with betaine, folate, and vitamins B6 and B12 exhibit no incidence of hyperhomocysteinemia compared to hyperhomocysteinemia in $\sim 50 \%$ of the control group (Ostojic et al., 2013). Repeating our bolus $\left[{ }^{3} \mathrm{H}\right]$ methyl-methionine infusion in GAA 
supplemented piglets receiving either folate or betaine would help evaluate which remethylation pathway has a higher maximum capacity in the neonate.

The results from Chapter 3 and Chapter $\mathbf{4}$ demonstrate the complexity in determining the methionine requirement as both a high demand for transmethylation products and the supply of remethylation nutrients can affect the availability of methionine for protein synthesis in the growing neonate. The methionine requirement has been established in the piglet as $0.25 \mathrm{~g} \mathrm{~kg}^{-1} \cdot \mathrm{d}^{-1}$ with the provision of excess dietary cysteine; however, the diet used in that study was also devoid of creatine and it provided $115 \%$ of the folate requirement while using a choline rich fat source (Shoveller et al., 2003b). Because dietary cysteine can spare the methionine requirement by $40 \%$ (Shoveller et al, 2003a) our results suggest that other nutrients, such as folate, betaine, and creatine, also have the potential to increase methionine availability and spare the methionine requirement, a concept that has been proposed for humans previously (Fukagawa, 2006).

The IAAO technique presented in Chapter $\mathbf{4}$ can be used to determine the methionine requirement by increasing dietary methionine levels and determining the rate of phenylalanine oxidation until a plateau is reached. This "breakpoint" indicates the maximum amount of phenylalanine that is being incorporated into protein and methionine is no longer limiting (Shoveller et al., 2003b). Determining the methionine requirement in piglets fed diets deficient or replete in folate, betaine or creatine to determine and quantify the capacity of each nutrient to spare methionine would provide insight into the effect of variations of these nutrients on methionine availability in the neonatal diet. 
Although in Chapter 4 we used betaine in our remethylation experiment as a more direct entry into the remethylation pathway compared to choline, betaine intake in infants is minimal and the majority of betaine is produced via choline oxidation (Fischer et al., 2010). Consequently, the question of whether choline supplementation can also spare methionine for protein synthesis should be determined. The effectiveness of choline relative to betaine likely depends on the form of choline used, as $\sim 85 \%$ of choline and phosphocholine are converted to betaine within 24 hours in rats while only $~ 50 \%$ of glycerophosphocholine and $13 \%$ of PC are found as betaine (Holmes-McNary et al., 1996). Based on the composition of human milk, $\sim 65 \%$ of total choline intake is converted to betaine after 24 hours (Ilcol et al., 2005), while a diet providing free choline would lead to a $20 \%$ higher conversion to betaine. Experiments in pigs have demonstrated that either betaine or choline supplementation of diets deficient in methionine equally increase hepatic BHMT activity (Emmert et al., 1998), suggesting choline would have the same capacity as betaine to reform methionine for protein synthesis; however, choline deficiency in rats leads to a doubling of hepatic PEMT activity to form endogenous choline (Cui and Vance, 1996). Although choline likely has a similar capacity as betaine to reform methionine, it is possible that choline supplementation may lead to higher methionine availability for protein synthesis if less is required for PEMT. Future work should not only determine the capacity of choline to increase methionine availability for protein synthesis, but experiments should also determine methionine partitioning during supplementation of a methionine deficient diet 
with folate, betaine or choline to determine whether these nutrients lead to a different distribution of methionine among protein synthesis and transmethylation reactions.

Although there has been extensive research published demonstrating the importance of choline during development (McCann et al., 2006; Zeisel, 2006), the role of choline as a source of methyl groups in the neonate has been less thoroughly examined. Based on average intake (Dewey and Lönnerdal, 1983) and betaine concentrations in breast milk (Fischer et al., 2010), infants consume $\sim 0.13 \mathrm{mg} / \mathrm{kg}$ per day of betaine while the average adult consumes $\sim 5 \mathrm{mg} / \mathrm{kg}$ per day. It appears that without dietary betaine, hepatic betaine levels remain constant pre and post weaning while hepatic BHMT activity increases in suckling rats from weeks 2-3 followed by a decline in activity (Clow et al., 2008). Because piglets are born more mature than the rat, it is possible that this transient increase in BHMT activity occurs during the first 2 weeks of life in the piglet which is in keeping with the higher methionine cycle activity found in 1 week old versus 3 week old piglets (Bauchart-Thevret et al., 2009). It would be of interest to repeat the IAAO experiment performed in Chapter 4 using 3 week old piglets to determine whether our results are age specific. Furthermore, activity levels of hepatic and renal choline dehydrogenase in the rat are $\sim 20 \mathrm{nmol} \mathrm{min}^{-1} \mathrm{mg}^{-1}$ while in the human, hepatic and renal activity levels are 1.3 and $7.1 \mathrm{nmol} \mathrm{min}^{-1} \mathrm{mg}^{-1}$ respectively (Haubrich \& Gerber, 1981). Because activity levels found in human are more similar to pig (Emmert et al., 1998), determining levels of hepatic and renal betaine in suckling piglets would complement experiments examining remethylation capacity during development. 


\subsection{Chronic high methyl demand and creatine supplementation}

The acute high methyl demand experiment presented in Chapter $\mathbf{3}$ led us to question whether a chronic high demand for creatine synthesis would also limit the availability of methionine for protein synthesis. Our intention was to also perform this experiment in $\sim 3$ week old piglets; however, piglet availability was not sufficient at the time of the experiment and 3 month old male pigs were used. For Chapter 5, we supplemented GAA to 3 month old weaned pigs twice per day for $\sim 18$ days, which led to both a lower incorporation of methionine into protein and methyl groups into PC. This demonstrates that both acute and chronic high demand for creatine synthesis can limit the availability of methionine for protein and PC synthesis.

Because creatine supplementation has been shown to lower renal AGAT activity in rats (Da Silva et al., 2009), the second experiment presented in Chapter 5 was developed to determine whether chronic creatine supplementation can lead to lower demand for creatine synthesis and spare methyl groups for other transmethylation reactions. After $\sim 18$ days of creatine supplementation above the requirement for synthesis, we found no sparing effect on availability of methyl groups for protein synthesis or other transmethylation reactions. It is likely that methionine was sufficient in these animals, and repeating the same experiment while providing a diet limiting in methionine would potentially demonstrate a sparing effect of creatine supplementation as discussed above. 


\subsection{Creatine Accretion}

Because creatine has recently been shown to be a multifaceted nutrient with benefits to several diseases as well as serving its more common function as an ergogenic nutrient, we decided to compare the effectiveness of creatine and GAA at increasing tissue stores of creatine using 3 month old pigs. We demonstrated that 18 days of dietary supplementation with GAA is more effective at increasing creatine in the liver than equimolar supplementation with creatine; GAA supplementation also led to higher muscle creatine concentrations than control, with creatine supplementation intermediate.

Despite the important function creatine plays in muscle, information about the muscle's capacity to synthesize creatine is limiting. Mice lacking the creatine transporter have undetectable levels of creatine in the muscle while the level of creatine in the kidney is unchanged, demonstrating that the muscle is likely unable to synthesize creatine (Skelton et al., 2011). Piglets have low levels of GAMT activity in the muscle while AGAT activity is undetectable (Brosnan et al., 2009) suggesting that the capacity for creatine synthesis in the muscle may be limited by GAA synthesis and availability. It is also possible that SAM may be limiting for GAA methylation, since the levels of MAT activity are also low in the muscle of pigs (Brosnan et al., 2009). Future experiments should determine the capacity for creatine synthesis by the muscle when GAA is not limiting.

Another interesting outcome of this study was the lack of effect of creatine supplementation on plasma or tissue levels of GAA. Interestingly, although creatine 
supplementation leads to lower renal and pancreatic AGAT activity in rats, renal and pancreatic GAA concentrations are in fact higher following creatine supplementation, possibly due to an effect of higher plasma creatine concentration on GAA export (Da Silva et al., 2014). From this, we would expect lower levels of hepatic and plasma GAA, which was not found in our creatine supplemented pigs. We speculated in Chapter 5 that unlike rats, the kidney may not be the primary site for GAA production in the pig. Although piglets have significant AGAT activity in the kidney, the AGAT activity in the pancreas is 5 fold higher, suggesting that the pancreas may be the primary site for GAA production (Brosnan et al., 2009) and it is possible that GAA production in pancreases of pigs may not be regulated via feedback inhibition of AGAT. Because the kidney is responsible for an estimated 20\% of total GAA production in humans (Edison et al., 2007), pigs appear to have similarities to humans in whole body creatine metabolism and tissue contribution to GAA production should be further investigated in the piglet.

\subsection{General Conclusions}

The work presented in this thesis demonstrates the complexity in determining how the various components of the methionine cycle interact to affect methionine supply and demand. IUGR piglets have both a lower maximum capacity for remethylation and also appear to have limited methionine availability for PC synthesis suggesting a lower methionine flux in these animals. This thesis also demonstrates that increasing the demand for the synthesis of one transmethylation product can limit methionine availability for other transmethylation reactions as well as protein synthesis. Furthermore, nutrients involved in remethylation can equally increase methionine 
availability for protein synthesis. The synthesis of our results leads us to conclude that both the demand for methionine as well as the endogenous supply via remethylation, must both be considered when determining the recommended levels of dietary methionine in the neonate. This is especially important considering nutrients such as choline and creatine can be highly variable among different forms of infant nutrition. 


\subsection{References}

Barkow, B., Matte, J.J., Böhme, H. and Flachowsky, G. (2001). "Influence of folic acid supplements on the carry-over of folates from the sow to the piglet." Br J Nutr 85(2): 179-84.

Bauchart-Thevret, C., Stoll, B., Chackom, S. and Burrin, D.G. (2009). "Sulfur amino acid deficiency upregulates intestinal methionine cycle activity and suppresses epithelial growth in neonatal pigs.” Am J Physiol Endocrinol Metab 296(6): 1239-50.

Brosnan, J.T., Wijekoon, E.P., Warford-Woolgar, L., Trottier, N.L., Brosnan, M.E., Brunton, J.A. and Bertolo, R.F. (2009). "Creatine synthesis is a major metabolic process in neonatal piglets and has important implications for amino acid metabolism and methyl balance." J Nutr 139(7): 1292-7.

Chalmers, B., Levitt, C., Heaman, M., O'Brien, B., Sauve, R. and Kaczorowski, J. (2009). "Breastfeeding rates and hospital breastfeeding practices in Canada: a national survey of women." Birth 36(2): 122-32.

Clow, K.A., Treberg, J.R., Brosnan, M.E. and Brosnan, J.T. (2008). "Elevated tissue betaine contents in developing rats are due to dietary betaine, not to synthesis." J Nutr 138(9): 1641-6.

Cui, Z. and Vance, D.E. (1996). "Expression of phosphatidylethanolamine Nmethyltransferase-2 is markedly enhanced in long term choline-deficient rats." J Biol Chem 271(5): 2839-43.

da Costa, K., Sanders, L.M., Fischer, L.M. and Zeisel, S.H. (2011). "Docosahexaenoic acid in plasma phosphatidylcholine may be a potential marker for in vivo phosphatidylethanolamine N-methyltransferase activity in humans." Am J Clin Nutr 93(5): 968-74.

da Silva, R.P., Nissim, I., Brosnan, M.E. and Brosnan, J.T. (2009). "Creatine synthesis: hepatic metabolism of guanidinoacetate and creatine in the rat in vitro and in vivo." Am $\mathrm{J}$ Physiol Endocrinol Metab 296(2): E256-61.

da Silva, R.P., Clow, K., Brosnan, J.T. and Brosnan, M.E. (2014). "Synthesis of guanidinoacetate and creatine from amino acids by rat pancreas." Br J Nutr 111(04): 57177. 
Davis, T.A., Fiorotto, M.L., Burrin, D.G., Pond, W.G. and Nguyen, H.V. (1997). "Intrauterine growth restriction does not alter response of protein synthesis to feeding in newborn pigs.” Am J Physiol 272(5 Pt 1): E877-84.

Davis, T.A., Nguyen, H.V., Garcia-Bravo, R., Fiorotto, M.L., Jackson, E.M., Lewis, D.S., Lee, D.R. and Reeds, P.J. (1994). "Amino acid composition of human milk is not unique." J Nutr 124(7): 1126-32.

Dewey, K.G. and Lönnerdal, B. (1983). "Milk and nutrient intake of breast-fed infants from 1 to 6 months: relation to growth and fatness." J Pediatr Gastroenterol Nutr 2(3): 497-506.

D'Inca, R., Kloareg, M., Guen, C.G. and Le Huerou-Luron, I. (2010). "Intrauterine growth restriction modifies the developmental pattern of intestinal structure, transcriptomic profile, and bacterial colonization in neonatal pigs." J Nutr 140(5): 925-31.

Edison, E.E., Brosnan, M.E., Aziz, K. and Brosnan, J.T. (2013). "Creatine and guanidinoacetate content of human milk and infant formulas: implications for creatine deficiency syndromes and amino acid metabolism." Br J Nutr 110(6): 1075-8.

Edison, E.E., Brosnan, M.E., Meyer, C. and Brosnan, J.T. (2007). "Creatine synthesis: production of guanidinoacetate by the rat and human kidney in vivo." Am J Physiol Renal Physiol 293(6): F1799-804.

Emmert, J.L., Webel, D.M., Biehl, R.R., Griffiths, M.A., Garrow, L.S., Garrow, T.A. and Baker, D.H. (1998). "Hepatic and renal betaine-homocysteine methyltransferase activity in pigs as affected by dietary intakes of sulfur amino acids, choline, and betaine." J Anim Sci 76(2): 606-10.

Fischer, L.M., da Costa, K.A., Galanko, J., Sha, W., Stephenson, B., Vick, J. and Zeisel, S.H. (2010). "Choline intake and genetic polymorphisms influence choline metabolite concentrations in human breast milk and plasma." Am J Clin Nutr 92(2): 336-46.

Fukagawa, N.K. (2006). "Sparing of methionine requirements: evaluation of human data takes sulfur amino acids beyond protein.” J Nutr 136(6 Suppl): 1676S-81S.

Gadhok, A.K., Sinha, M., Khunteta, R., Vardey, S.K., Upadhyaya, C., Sharma, T.K. and Jha, M. (2011). "Serum homocysteine level and its association with folic acid and vitamin B12 in the third trimester of pregnancies complicated with intrauterine growth restriction." Clin Lab 57(11-12): 933-8. 
Haubrich, D.R. and Gerber, N.H. (1981). "Choline dehydrogenase. Assay, properties and inhibitors." Bioch Pharmacol 30(21): 2993-3000.

Hoffman, D.R., Cornatzer, W.E. (1981). "Microsomal phosphatidylethanolamine methyltransferase: some physical and kinetic properties.” Lipids 16(7): 533-40.

Hoffman, D.R., Haning, J.A., Cornatzer, W.E. (1981). "Microsomal phosphatidylethanolamine methyltransferase: inhibition by S-adenosylhomocysteine." Lipids 16(8): 561-7.

Holmes-McNary, M.Q., Cheng, W.L., Mar, M.H., Fussell, S. and Zeisel, S.H. (1996). "Choline and choline esters in human and rat milk and in infant formulas." Am J Clin Nutr 64(4): 572-6.

Ilcol, Y.O., Ozbek, R., Hamurtekin, E. and Ulus, I.H. (2005). "Choline status in newborns, infants, children, breast-feeding women, breast-fed infants and human breast milk.” J Nutr Biochem 16(8): 489-99.

Jacobs, R.L., Zhao, Y., Koonen, D.P., Sletten, T., Su, B., Lingrell, S., Cao, G., Peake, D.A., Kuo, M.S., Proctor, S.D., Kennedy, B.P., Dyck, J.R., Vance, D.E. (2010). "Impaired de novo choline synthesis explains why phosphatidylethanolamine Nmethyltransferase-deficient mice are protected from diet-induced obesity." J Biol Chem 285(29): 22403-13.

Keser, I., Ilich, J.Z., Vrkić, N., Giljević, Z. and Colić Barić, I. (2013). "Folic acid and vitamin $\mathrm{B}(12)$ supplementation lowers plasma homocysteine but has no effect on serum bone turnover markers in elderly women: a randomized, double-blind, placebo-controlled trial." Nutr Res 12(1): 20-5.

Kim, Y.I., Miller, J.W., da Costa, K.A., Nadeau, M., Smith, D., Selhub, J., Zeisel, S.H. and Mason, J.B. (1994). "Severe folate deficiency causes secondary depletion of choline and phosphocholine in rat liver.” J Nutr 124(11): 2197-203.

Langley-Evans, S.C. (2000). "Critical differences between two low protein diet protocols in the programming of hypertension in the rat." Int J Food Sci Nutr 51(1): 11-7.

Loike, J.D., Zalutsky, D.L., Kaback, E., Mir, A.F., Miranda, A.F. and Silverstein, S.C. (1988). "Extracellular creatine regulates creatine transport in rat and human muscle cells." Proc Natl Acad Sci USA 85(3): 807-11.

MacLennan, N.K, James, S.J, Melnyk, S., Piroozi, A., Jernigan, S., Hsu, J.L., Janke, S.M., Pham, T.D. and Lane, R.H. (2004). "Uteroplacental insufficiency alters DNA 
methylation, one-carbon metabolism, and histone acetylation in IUGR rats." Physiol Genomics 18(1): 43-50.

McCann, J.C., Hudes, M. and Ames, B.N. (2006). "An overview of evidence for a causal relationship between dietary availability of choline during development and cognitive function in offspring." Neurosci Biobehav Rev 30(5): 696-712.

McRae, M.P. (2013). "Betaine supplementation decreases plasma homocysteine in healthy adult participants: a meta-analysis." J Chiropr Med 12(1): 20-25.

Michiels, J., Maertens, L., Buyse, J., Lemme, A., Rademacher, M., Dierick, N.A. and De Smet, S. (2012). "Supplementation of guanidinoacetic acid to broiler diets: Effects on performance, carcass characteristics, meat quality, and energy metabolism." Poult Sci 91(2): 402-12.

Myrie, S.B., MacKay, D.S., van Vliet, B.N. and Bertolo, R.F. (2012). "Early programming of adult blood pressure in the low birth weight Yucatan miniature pig is exacerbated by a post-weaning high-salt-fat-sugar diet." Br J Nutr 108(07): 1218-25.

Omerovic, E., Bollano, E., Lorentzon, M., Walser, M., Mattsson-Hultén, L. and Isgaard, J. (2003). "Growth hormone induces myocardial expression of creatine transporter and decreases plasma levels of IL-1beta in rats during early postinfarct cardiac remodeling." Growth Horm IGF Res 13(5): 239-45.

Ostojic, S.M., Niess, B., Stojanovic, M. and Obrenovic, M. (2013). "Creatine metabolism and safety profiles after six-week oral guanidinoacetic acid administration in healthy humans." Int J Med Sci 10(2): 141-7.

Rees, W.D., Hay, S.M. and Cruickshank, M. (2006). "An imbalance in the methionine content of the maternal diet reduces postnatal growth in the rat." Metabolism 55(6): 76370.

Ritacco, G., Radecki, S.V. and Schoknecht, P.A. (1997). Compensatory growth in runt pigs is not mediated by insulin-like growth factor I." J Animal Sci 75(5): 1237-43.

Selhub, J., Seyoum, E., Pomfret, E.A. and Zeisel, S.H. (1991). "Effects of choline deficiency and methotrexate treatment upon liver folate content and distribution." Cancer Res 51(1): 16-21.

Setoue, M., Ohuchi, S., Morita, T. and Sugiyama, K. (2008). "Hyperhomocysteinemia induced by guanidinoacetic acid is effectively suppressed by choline and betaine in rats." Biosci Biotechnol Biochem 72(7): 1696-703. 
Shoveller, A.K., Brunton, J.A., House, J.D., Pencharz, P.B. and Ball, R.O. (2003a). "Dietary cysteine reduces the methionine requirement by an equal proportion in both parenterally and enterally fed piglets." J Nutr 133(12): 4215-24.

Shoveller, A.K., Brunton, J.A., Pencharz, P.B. and Ball, R.O. (2003b). "The methionine requirement is lower in neonatal piglets fed parenterally than in those fed enterally." $J$ Nutr 133(5): 1390-7.

Skelton, M.R., Schaefer, T.L., Graham, D.L., Degrauw, T.J., Clark, J.F., Williams, M.T. and Vorhees, C.V. (2011). "Creatine transporter (CrT; Slc6a8) knockout mice as a model of human CrT deficiency.” PLoS One 6(1): e16187.

Stoll, B., Henry, J., Reeds, P.J., Yu, H., Jahoor, F. and Burrin, D.G. (1998). "Catabolism dominates the first-pass intestinal metabolism of dietary essential amino acids in milk protein-fed piglets." J Nutr 128(3): 606-14.

Thomas, B., Gruca, L.L., Bennett, C., Parimi, P.S., Hanson, R.W. and Kalhan, S.C. (2008). "Metabolism of methionine in the newborn infant: response to the parenteral and enteral administration of nutrients." Pediatr Res 64(4): 381-6.

Walkey, C.J., Donohue, L.R., Bronson, R., Agellon, L.B., Vance, D.E. (1997). "Disruption of the murine gene encoding phosphatidylethanolamine Nmethyltransferase.” Proc Natl Acad Sci U S A 94(24):12880-5.

Wang, T., Huo, Y.J., Shi, F., Xu, R.J. and Hutz, R.J. (2005). "Effects of intrauterine growth retardation on development of the gastrointestinal tract in neonatal pigs." Biol Neonate 88(1): 66-72.

Watkins, S.M., Zhu, X. and Zeisel, S.H. (2003). "Phosphatidylethanolamine-Nmethyltransferase activity and dietary choline regulate liver-plasma lipid flux and essential fatty acid metabolism in mice." J Nutr 133(11): 3386-91.

Yang, H., Fu, D., Shao, H., Kong, X., Wang, W., Yang, X., Nyachoti, C.M. and Yin, Y. (2012). "Impacts of birth weight on plasma, liver and skeletal muscle neutral amino acid profiles and intestinal amino acid transporters in suckling huanjiang mini-piglets." PLoS One 7(12): e50921.

Zeisel, S.H. (2006). "The fetal origins of memory: the role of dietary choline in optimal brain development." J Pediatr 149(5 Suppl): S131-6. 


\section{Appendix A: Methods}

\section{A.1. Determination of phosphatidylcholine concentration and DPM}

Phosphatidylcholine was isolated using the method of Folch et al. (1956) followed by separation by TLC and quantification via a modified Bartlet method (1958). Approximately $70 \mathrm{mg}$ of liver was homogenized in $300 \mathrm{ul}$ of $50 \mathrm{mM} \mathrm{NaCl}$ and transferred to a glass tube. $1.5 \mathrm{ml}$ of chloroform and methanol (2:1) was added and samples were vortexed and left at $4{ }^{\circ} \mathrm{C}$ overnight. The next day the samples were centrifuged at 3000 rpm for 10 min and the lower organic layer was removed and evaporated under nitrogen. The residue was re-dissolved in $100 \mathrm{ul}$ isopropanol and applied to a silica G-60 TLC plate. The plate was inserted in a saturated TLC chamber (chloroform/methanol/acetic acid/water, 25:15:4:2) and left until the mobile phase has migrated up $3 / 4$ of the plate. Iodine was used for visualization of the plate and the band corresponding to the PC standard was scraped into a glass tube containing $300 \mathrm{ul}$ perchloric acid. The tubes were heated at $180{ }^{\circ} \mathrm{C}$ for $2 \mathrm{~h}$ until no dark colour was visible. Samples were cooled and diluted with $1 \mathrm{ml}$ water followed by addition of $50 \mathrm{ul}$ of $5 \%$ ammonium molybdate and $50 \mathrm{ul}$ of a 1-amino-2-naphthol-4-sulfonic acid solution (1.0 $\mathrm{g}$ aminoapthalsulfonic acid in $390 \mathrm{ml}$ of $15 \%$ sodium metabisulfite plus $10 \mathrm{ml}$ of $20 \%$ sodium sulfite) with vortexing between additions. Tubes were then capped with marbles and samples were placed in a boiling water bath for $12 \mathrm{~min}$. Absorbance was read at $815 \mathrm{~nm}$ by a spectrophotometer and a standard curve was used for quantification of total phosphorus. A portion of the sample was used for scintillation counting to determine DPM. 


\section{A.2 Determination of creatine concentration and DPM}

Tissue creatine concentration was determined following a modified method of Lamarre (2012). Tissue was homogenized in $50 \mathrm{mM}$ (pH 7.4) Tris buffer (1:4.5) and left at room temperature for 20 minutes to allow for conversion of phosphocreatine to creatine. Trifluoroacetic acid was added to the samples which were set on ice for 10 min followed by centrifugation at $6000 \mathrm{rpm}$ at $4{ }^{\circ} \mathrm{C}$ for $10 \mathrm{~min}$. Samples were then filtered using a Bond-Elut C18 solid phase extraction cartridge and samples were separated via HPLC following injection of filtrate onto a Hypercarb column (100.03 x 4.6mm). An isocratic mobile phase of $0.1 \%$ TFA and 3\% methanol was used with a flow rate of $1 \mathrm{ml} / \mathrm{min}$ and run time of 18 minutes. A standard curve was used for quantification and peaks were determined using Empower 2 software (Waters, Milford, MA). Creatine was fraction collected for determination of DPM via liquid scintillation counting.

\section{A.3 Determination of DNA concentration and DPM}

DNA was extracted using phenol extraction. Samples were homogenized in a buffer with $50 \mathrm{mM}$ pH8 Tris, $1 \%$ sodium dodecyl sulfate, $100 \mathrm{mM}$ EDTA and $100 \mathrm{mM} \mathrm{NaCl}$. Proteinase $\mathrm{K}$ was then added and samples were incubated overnight in a $56{ }^{\circ} \mathrm{C}$ water bath. An equal volume of PCI (phenol:chloroform:isoamyl alcohol 25:24:1) was added to samples which were then mixed and centrifuged for $15 \mathrm{~min}$ at $7000 \mathrm{rpm}$. The top aqueous layer was removed and transferred to a fresh tube. This extraction process was repeated several times until no protein interface was visible. After transfer to a fresh tube, CIA (chloroform:isoamylalcohol: 24:1) was then added to the aqueous layer and 
centrifuged for 10 min after mixing. The top layer was removed for DNA precipitation using an equal volume of isopropanol and $1 / 5$ volume of $1 \mathrm{M}$ sodium acetate. DNA was washed twice in $70 \%$ ethanol and centrifuged in $95 \%$ ethanol for $10 \mathrm{~min}$ at 10,000 rpm. The ethanol was then removed and after drying, the remaining DNA pellet was resuspended in $\mathrm{TE}^{-4}$ buffer (10 $\mathrm{mM}$ Tris, $0.1 \mathrm{mM}$ EDTA, $\mathrm{pH}$ 8). DNA concentration was determined using a NanoDrop and DPM were determined with liquid scintillation counting.

\section{A.4 Determination of SAM/SAH concentration and SAM DPM}

Tissue SAM and SAH were determined using a method by Ratnam et al. (2006). Tissue was homogenized in cold $8 \%$ TCA (1:5) and centrifuged at 12,000 rpm for $5 \mathrm{~min}$. Samples were then filtered using a 45 um syringe filter and HPLC was used for separation following injection of filtrate onto a Vydac C18 reverse phase column and Empower 2 software (Waters, Milford, MA) was used for peak detection. A dual buffer mobile phase (Buffer A: $50 \mathrm{mM} \mathrm{NaH}{ }_{2} \mathrm{PO}_{4}$ and $10 \mathrm{mM}$ heptanesulfonic acid at pH 3.2; Buffer B: acetonitrile) was used with a flow rate of $1 \mathrm{ml} / \mathrm{min}$ and run time of 30 minutes. Fraction collection and liquid scintillation counting was used to determine DPM of SAM and a standard curve was used to quantify SAM and SAH.

\section{A.5 Determination of Tissue and Plasma amino acid concentrations and Methionine $D P M$}

Amino acid concentrations were determined by a modified method of Nyachoti et al. (2000). 


\section{A.5.1Tissue Preparation}

Tissue was homogenized in cold perchloric acid (1:3 wt/vol) and centrifuged at $3000 \mathrm{x} \mathrm{g}$ for 15 minutes followed by decanting of supernant into a scintillation vial. This step was repeated 3 times to total 1:9 wt/vol. Norelucine was added to the scintillation vial as an internal standard and the pellet remaining in the tube was used for tissue bound amino acid analysis.

\section{A.5.2 Tissue Free Preparation}

$\mathrm{K}_{2} \mathrm{CO}_{3}(2.0 \mathrm{M})$ was added to supernatant $(0.125: 1)$ in a plastic test tube which was mixed and centrifuged at $3000 \mathrm{rpm}$ for 3 minutes. Using a syringe filter, $1 \mathrm{ml}$ of supernant was added to another plastic test tube which was flash frozen in liquid nitrogen and placed on a freeze dryer overnight followed by derivatization.

\section{A.5.3 Tissue Bound Preparation}

The pellet was resuspended in $1.0 \mathrm{M} \mathrm{NaOH}(1: 8 \mathrm{wt} / \mathrm{vol})$ and the tube was covered with parafilm and mixed. Protein was solubilized by adding tubes to a $37{ }^{\circ} \mathrm{C}$ water bath for $\sim 1.5$ hours or until clear. Protein was recovered by adding $1 / 2$ volume of cold $20 \%$ perchloric acid and mixing tubes. Samples were then placed on ice for 20 minutes followed by centrifugation at $2000 \mathrm{~g}$ for 15 minutes. Supernant was discarded and norelucine was added as an internal standard. $\mathrm{HCl}(6.0 \mathrm{M})$ was added to the tube (10 $\mathrm{ml} / \mathrm{g}$ tissue wt) and a glass rod was used to disrupt the pellet followed by transferring all contents to a Pyrex tube which was capped and placed in a $110{ }^{\circ} \mathrm{C}$ oven for 24 hours. 
Tubes were then removed and left to cool overnight. Hydrolysates were mixed by inversion and transferred to pre-weighed Erlenmeyer flasks using size 4 or size 54 filter paper and a small funnel. Tubes were rinsed twice with HPLC water and flasks were brought to a final volume of 25:1 (vol/original tissue wt). $1.0 \mathrm{ml}$ was then transferred into a plastic tube via a 0.45 um syringe filter and tubes were placed in a vacuum oven overnight which was followed by derivatization.

\section{A.5.4 Plasma Analysis}

$100 \mathrm{uL}$ of plasma was mixed with $1 \mathrm{ml}$ TFA (0.5\% TFA in methanol) and norleucine was added as an internal standard. Samples were vortexed and centrifuged at $5000 \mathrm{rpm}$ for 5 minutes and then poured into $3 \mathrm{ml}$ test tubes. Samples were then flash frozen with liquid nitrogen to dry down overnight.

\section{A.5.5 Derivatization}

100 ul of 2:2:6 TEA:MeOH:water was added to tubes followed by freeze drying for 1 hour. 50 ul of 1:1:1:7 TEA:PITC:Water:Methanol was added and tubes were left at room temperature for 35 minutes followed by flash freezing with liquid nitrogen and freeze dryer overnight. Samples were resuspended in diluent $\left(710 \mathrm{mg} \mathrm{Na} 2 \mathrm{HPO}_{4}\right.$ into $1 \mathrm{~L}$ of water. $\mathrm{pH}$ to 7.3 with $\mathrm{H}_{3} \mathrm{PO}_{4}$. Replace $5 \%$ of the volume with acetonitrile) and following centrifugation, samples were transferred to vials for HPLC analysis. 


\section{A.5.6 Amino Acid HPLC}

$40 \mathrm{ul}$ of sample was injected onto a Waters C18 Pico-Tag column (Waters, Milford, MA) connected to an HPLC. Amino acids were eluted using a dual buffer system of buffer A (70 mM sodium acetate and $2.5 \%$ acetonitrile at $\mathrm{pH} 6.55)$ and buffer $\mathrm{B}$ (45\% acetonitrile and 15\% methanol). Peaks were determined using Empower 2 software (Waters, Milford, MA) and a fraction collector was used to isolate methionine, followed by liquid scintillation counting to determine DPM.

\section{A.6 Cystathionine}

Tissue cystathionine was analyzed according to the method of Seo et al. (2005). $70 \mathrm{mg}$ of tissue was homogenized in $0.5 \mathrm{ml}$ borate buffer $(0.025 \mathrm{mM} \mathrm{pH} 9.5 \mathrm{w} 2 \mathrm{mM}$ EDTA) followed by addition of $50 \mathrm{ul}$ of tris-(2-carboxyethyl)phosphine $(100 \mathrm{mg} / \mathrm{ml})$. Samples were mixed and left at room temperature for 30 minutes. Protein was precipitated with 2\% PCA and centrifuged for 5 minutes at 3000 RCF. Supernant was transferred to a new tube and $113 \mathrm{ul}$ of $2 \mathrm{M} \mathrm{K}_{2} \mathrm{CO}_{3}$ was added followed by centrifugation for 5 minutes at $3000 \mathrm{rpm}$. Samples were flash frozen in liquid nitrogen and dried down overnight followed by resuspension in $300 \mathrm{ul}$ of $0.1 \mathrm{M} \mathrm{HCl}$. Samples were then Derivatized according to Waters AccQ-Tag Derivatization kit (Waters, Milford, MA). HPLC was used for separation of cystathionine following injection of Derivatized sample onto a AccQ-Tag HPLC column. A dual buffer system (Buffer A: AccQ•Tag Eluent A Concentrate (Waters); Buffer B: Acetonitrile) was used with a flow rate of $1 \mathrm{ml} / \mathrm{minute}$ 
with a run time of 30 minutes. Empower 2 software (Waters, Milford, MA) was used for peak detection.

\section{A.7 Tissue and Plasma Creatine and Guanidinoacetate (GAA)}

Tissue and plasma creatine and GAA were determined according to the method of Buchberger and Ferdig (2004).

\section{A.7.1 Tissue Creatine and GAA}

A ceramic mortar and pestle were used to grind tissues under liquid nitrogen and $50 \mathrm{mg}$ tissue was placed in a centrifuge tube followed by $2 \mathrm{ml}$ of $1.0 \mathrm{M}$ perchloric acid. Samples were homogenized on ice and centrifuged at $4{ }^{\circ} \mathrm{C}$ for 20 minutes at 12,750 RPM. Supernatant was poured into a glass tube while recording weight of liquid. $50 \mathrm{ul}$ of $50 \%$ $\mathrm{K}_{2} \mathrm{CO}_{3}$ and $20 \mathrm{uL}$ of universal indicator were added to each tube followed by vortexing. $250 \mathrm{ul}$ of $20 \% \mathrm{KOH}$ was added to neutralize ( $\mathrm{pH} 6.5-7)$ and samples were again vortexed and left on ice for 10 minutes. Samples were poured into labeled centrifuge tubes and centrifuged again for 10 minutes at $10,000 \mathrm{rcf}$ at $4{ }^{\circ} \mathrm{C}$. Supernatant was poured into a new glass tube and liquid weight was recorded.

\section{A.7.2 Plasma Creatine and GAA}

$14 \mathrm{ul}$ of $30 \%$ perchloric acid was added to $200 \mathrm{ul}$ of plasma and samples were vortexed and placed on ice for 15 minutes followed by centrifugation at 15,000 g for 8 minutes. $150 \mathrm{ul}$ of supernant was transferred to a new tube and $7.5 \mathrm{ul}$ of $\mathrm{K}_{2} \mathrm{CO}_{3}$ and $22 \mathrm{ul}$ of $20 \%$ $\mathrm{KOH}$ were added followed by vortexing and centrifugation at 10,000 $\mathrm{g}$ for 5 minutes. 


\section{A.7.3 Derivatization with Ninhydrin}

Derivatization for tissue samples (ratio adjusted for plasma) was then carried out by adding $300 \mathrm{ul}$ of $1.3 \mathrm{M} \mathrm{KOH}$ and $150 \mathrm{ul}$ of $0.9 \%$ Ninhydrin to $400 \mathrm{ul}$ of sample in a glass tube which was then mixed and left at room temperature for 15 minutes. $100 \mathrm{ul} 5 \%$ ascorbic acid and $100 \mathrm{uL}$ phosphoric acid were then added to samples which were again mixed, capped with marbles and incubated in a $90{ }^{\circ} \mathrm{C}$ water bath for 30 minutes. Tubes were cooled and samples were filtered using a 0.45 um syringe filter. Metabolites were quantified via HPLC following injection onto a C18 Hypersil ODS 150x4.6 column and Empower 2 software was used for peak detection (Waters, Milford, MA). A dual buffer system was used (Buffer A: 50 mM Formic Acid and Buffer B: 100\% Methanol).

\section{A.8 Plasma Homocysteine and Cysteine}

Plasma homocysteine was determined using a modified method by Vester and Rasmussen (1991). $150 \mu \mathrm{L}$ of plasma was combined with $20 \mu \mathrm{L}$ of tris-(2-carboxyethyl)phosphine $(100 \mathrm{mg} / \mathrm{ml})$ which was vortexed and left at room temperature for 30 minutes. $50 \mathrm{ul}$ of 0.2 mM 8-amino-naphthalene-1,3,6-trisulfonic acid disodium salt (ANTS) (dissolved in 0.1 $\mathrm{mM}$ borate buffer with $2 \mathrm{mM}$ EDTA at $\mathrm{pH}=9.5$ ) and $125 \mathrm{uL}$ of $0.6 \mathrm{M}$ perchloric acid were added to samples which were left at room temperature for 10 minutes followed by centrifugation at $4^{\circ} \mathrm{C}$ at $6000 \mathrm{rpm}$ for 5 minutes. $100 \mu \mathrm{L}$ of supernatant was then transferred to dark Eppendorf tubes followed by addition of $200 \mu \mathrm{L}$ of borate buffer $(2 \mathrm{M}$ at $\mathrm{pH}=10.5)$ and $100 \mu \mathrm{L}$ of derivatizing agent 7-fluorobenzo-2,1,3-oxadiazole-sulfonic 
acid ammonium salt (SBD-F) solution $(1 \mathrm{mg} / \mathrm{mL}$ SBDF in $0.1 \mathrm{M}$ borate buffer with 2 mM EDTA at $\mathrm{pH}=9.5$ ). Samples were covered in aluminum foil and vortexed followed by incubation at $60^{\circ} \mathrm{C}$ in a waterbath for 60 minutes. Samples were then removed and placed on ice for 5 minutes followed by centrifugation at $7000 \mathrm{rpm}$ for 5 minutes. Samples were injected into a Waters YMC column (Milford, MA) and homocysteine and cysteine were separated via reverse phase HPLC using a dual buffer system (Buffer A: and Buffer B:) with a run time of 20 minutes at $1 \mathrm{~mL} /$ minute. Internal standard ANTS was used for quantification and Empower 2 software (Waters, Milford, MA) was used to determine area under the curve.

Buffer Solution Preparation:

Solution 1: Dissolve $6.8 \mathrm{~g}$ of sodium acetate trihydrate in $500 \mathrm{~mL}$ of HPLC water Solution 2: Add $11.5 \mathrm{~mL}$ glacial acetic acid $(99.9 \%, 17.4 \mathrm{M})$ to $2 \mathrm{~L}$ of HPLC water Solution 3:Add Solution 1 for Solution 2 until $\mathrm{pH}=4.0$ (approximately $400 \mathrm{~mL}$ ) HPLC Buffer A: Combine $980 \mathrm{~mL}$ of Solution 3 with $20 \mathrm{~mL}$ of methanol HPLC Buffer B: Combine 800 mL of Solution 3 with $200 \mathrm{~mL}$ of methanol 


\section{A.10 References}

Bartlett, G.R. (1959). "Phosphorus assay in column chromatography." J Biol Chem 234(3): 466-68.

Buchberger, W. and Ferdig, M. (2004). "Improved high-performance liquid chromatographic determination of guanidino compounds by precolumn derivatization with ninhydrin and fluorescence detection." J Sep Sci 27(15-16): 1309-12.

Folch, J., Lees, M. and Sloane Stanley, G.H. (1957). "A simple method for the isolation and purification of total lipides from animal tissues." J Biol Chem 226(1): 497-509.

Holm, P.I., Uel, P.M., Ueland, P.M., Kvalheim, G. and Lien, E.A. (2003). "Determination of choline, betaine, and dimethylglycine in plasma by a high-throughput method based on normal-phase chromatography-tandem mass spectrometry." Clin Chem 49(2): 286-94.

Kirsch, S.H., Herrmann, W., Rabagny, Y. and Obeid, R. (2010). "Quantification of acetylcholine, choline, betaine, and dimethylglycine in human plasma and urine using stable-isotope dilution ultra performance liquid chromatography-tandem mass spectrometry." J Chromatogr B 878(32): 3338-44.

Lamarre, S.G., Edison, E.E., Wijekoon, E.P., Brosnan, M.E. and Brosnan, J.T. (2012). "Suckling rat pups accumulate creatine primarily via de novo synthesis rather than from dam milk." J Nutr 140(9): 1570-3.

Lamarre, S.G., MacMillan, L., Morrow, G.P., Randell, E., Pongnopparat, T., Brosnan, M.E. and Brosnan, J.T. (2014). An isotope-dilution, GC-MS assay for formate and its application to human and animal metabolism." Amino Acids 46(8): 1885-91.

Nyachoti, C.M., de Lange, C.F., McBride, B.W., Leeson, S. and Gabert, V.M. (2000). "Endogenous gut nitrogen losses in growing pigs are not caused by increased protein synthesis rates in the small intestine." J Nutr 130(3): 566-72.

Ratnam, S., Wijekoon, E.P., Hall, B., Garrow, T.A., Brosnan, M.E. and Brosnan, J.T. (2006). "Effects of diabetes and insulin on betaine-homocysteine S-methyltransferase expression in rat liver." Am J Physiol Endocrinol Metab 290(5): E933-9.

Seo, S.S. (2005). "High performance liquid chromatographic determination of homocysteine and cystathionine in biological samples by derivatization with 6aminoquinolyl-N-hydroxylsuccinimidyl carbamate (AQC)." J Korean Chem Soc 49(3): 278-82. 
Vester, B. and Rasmussen, K. (1991). "High performance liquid chromatography method for rapid and accurate determination of homocysteine in plasma and serum." Eur J Clin Chem Clin Biochem 29: 549-54. 